$$
\begin{aligned}
& \text { UNIVERSIDADE DE SÃO PAULO } \\
& \text { INSTITUTO DE PSICOLOGIA } \\
& \text { PSICOLOGIA EXPERIMENTAL }
\end{aligned}
$$

PROGRAMA DE PÓS-GRADUAÇÃO EM PSICOLOGIA EXPERIMENTAL

RESPOSTA DE OBSERVAÇÃO E MOVIMENTO DOS OLHOS EM UMA SITUAÇÃO DE DISCRIMINAÇÃO SIMPLES SIMULTÂNEA

Peter Endemann

Prof. Dr. Gerson Yukio Tomanari

São Paulo

2008 
UNIVERSIDADE DE SÃO PAULO

INSTITUTO DE PSICOLOGIA

PSICOLOGIA EXPERIMENTAL

PROGRAMA DE PÓS-GRADUAÇÃO EM PSICOLOGIA EXPERIMENTAL

RESPOSTA DE OBSERVAÇÃO E MOVIMENTO DOS OLHOS EM UMA SITUAÇÃO DE DISCRIMINAÇ̃̃O SIMPLES SIMULTÂNEA

Peter Endemann

Dissertação de mestrado apresentada junto ao Programa de Pós-Graduação em Psicologia Experimental da Universidade de São Paulo (USP) como parte dos requisitos necessários à obtenção do Título de Mestre em Psicologia Experimental.

Área de concentração: Psicologia Experimental

Orientador: Prof. Dr. Gerson Yukio Tomanari.

São Paulo 

POR QUALQUER MEIO CONVENCIONAL OU ELETRÔNICO, PARA FINS DE ESTUDO E PESQUISA, DESDE QUE CITADA A FONTE.

Catalogação na publicação

Serviço de Biblioteca e Documentação

Instituto de Psicologia da Universidade de São Paulo

Endemann, Peter.

Resposta de observação e movimento dos olhos em uma situação de discriminação simples simultânea / Peter Endemann; orientador Gerson Yukio Tomanari. --São Paulo, 2008.

$107 \mathrm{p}$.

Dissertação (Mestrado - Programa de Pós-Graduação em Psicologia. Área de Concentração: Psicologia Experimental) Instituto de Psicologia da Universidade de São Paulo.

1. Resposta de observação 2. Movimentos oculares 3. Controle do estímulo I. Título.

BF319 
FOLHA DE APROVAÇÃO

\title{
RESPOSTA DE OBSERVAÇÃO E MOVIMENTO DOS OLHOS EM UMA SITUAÇÃO DE DISCRIMINAÇÃO SIMPLES SIMULTÂNEA
}

\author{
Peter Endemann
}

Dissertação defendida e aprovada em:

Banca Examinadora

Prof. Dr

Instituição Assinatura

Prof. Dr

Instituição Assinatura

Prof. Dr

Instituição Assinatura 
DEDICATÓRIA

À minha querida mãe, sua força, seus exemplos

À presença e memória de meu Pai

Ao Enzo, ao Deryck

iii 


\section{AGRADECIMENTOS}

Agradeço ao Professor Gerson pela construção deste trabalho, pelas possibilidades, pelo aprendizado, por uma nova linguagem, nascente do espírito científico. Ao Professor Emmanuel pela confiança, por ter me guiado por caminhos e labirintos da pesquisa em Análise do Comportamento. À Denise, pelo ensino, pela amizade, pelos primeiros passos rumo à pesquisa sobre linguagem.

Às Professoras, Paula e Marta e a todos os alunos da disciplina seminários pelos comentários que enriqueceram o projeto.

À Ramaiana, uma doce figura. Mesmo longe, dos mais diversos jeitos, estava sempre perto, durante todo o tempo de mestrado e de São Paulo.

Aos colegas de laboratório, Edson, pelo apoio, por ter acompanhado o projeto desde seus primeiros momentos, desde as brincadeiras do homem da luva. Candido, pelos momentos de muita produção, diversão e aprendizagem. Will, companheiro, amigo, pelo trabalho, pelos estudos, planos, cafezinho e chocolate. A todos Saulo, Alessandra, Vivi, Eliana, Marcelo, Nico, Rafael que estavam sempre presentes, com boas conversas, em bons momentos, outros difíceis. Todos são, de algum modo, autores deste trabalho.

Aos velhos amigos Gil, pelas longas conversas produtivas, pela viola na praça, garça e castelos poéticos invertidos. Heitor, pelo sempre incentivo, pela língua francesa, pelos puxões de orelha. Luciana, por ser tão poesia, seu riso, tão presente. Rubens, pela escrita, os saraus. Angela, pela amizade, cumplicidade, praça do horto, nossos tropeços, nossas vitórias. Carolina, por seu jeito querido de entregar aos olhos formas mais leves de ver o mundo. Trouxe todos comigo. Sozinho, aqui, não teria chegado lá.

A minha família, minha avó Rosa, minha irmã amiga Roseane, meu irmão Wolf, meus doces e guerreiros sobrinhos Deryck e Enzo, minha querida mãe pelo suporte, pela história, pela força, pelo apoio. Não precisei nem trazê-los comigo, já me (a)guardavam aqui.

Ao meu pai, meu avô e ao tio Renê, meu querido tio Renê. "Por muito tempo achei que a ausência é falta/ E lastimava, ignorante, a falta/ Hoje não a lastimo/ Não há falta na ausência/ A ausência é um estar em mim”. (Carlos Drummond de Andrade).

Ao Conselho Nacional de Desenvolvimento Científico e Tecnológico (CNPq), pelo financiamento deste trabalho. 


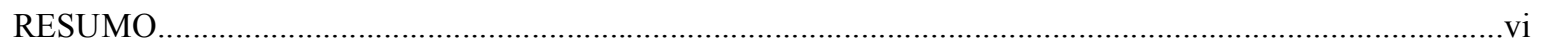

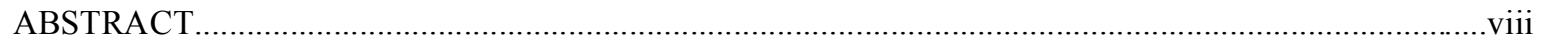

INTRODUÇÃ O

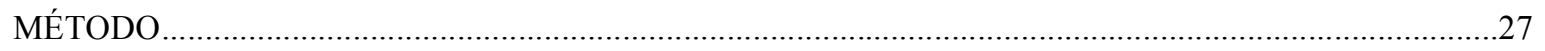

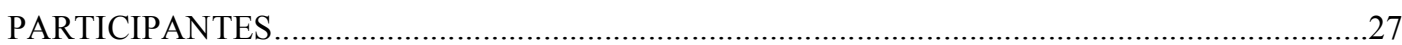

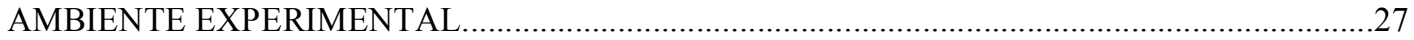

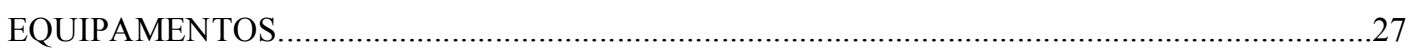

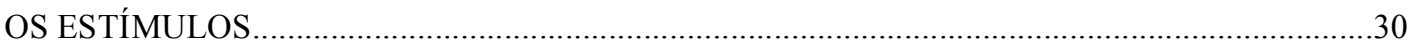

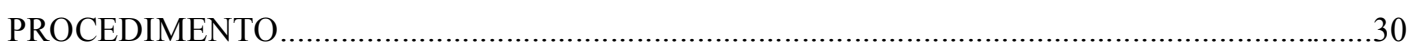

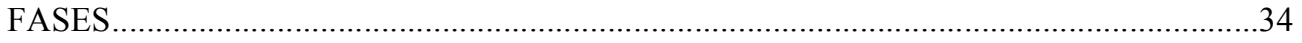

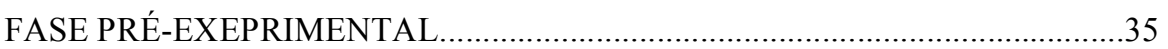

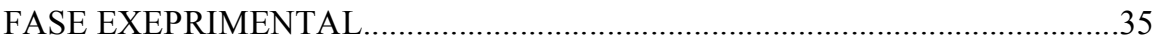

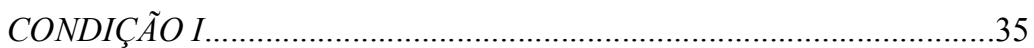

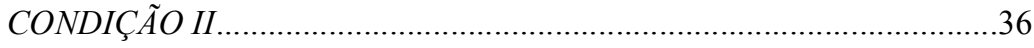

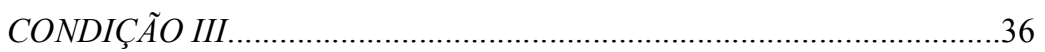

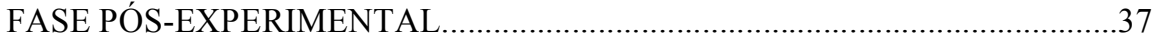

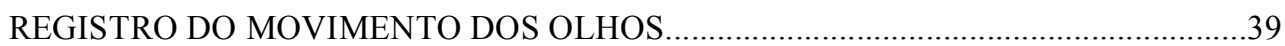

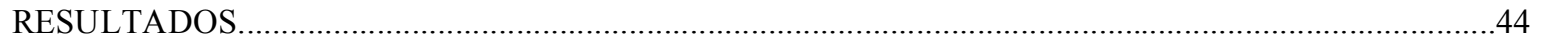

DISCUSSÃO

RESPOSTAS MANUAIS, APRENDIZADO E DISCRIMINAÇÃO..............................................66

DISTRIBUIÇÃO DO OLHAR: UMA INTRODUÇÃO PARA A DISCUSSÃO SOBRE

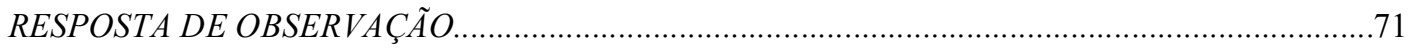

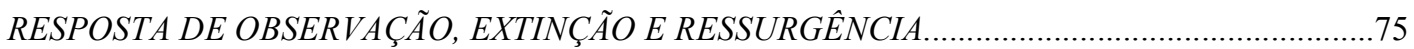

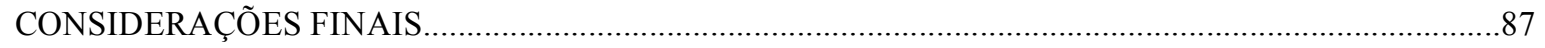

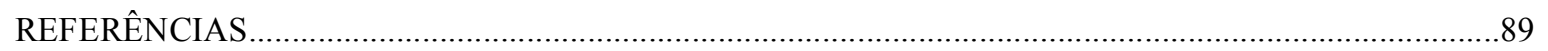

ANEXOS 


\section{RESUMO}

Endemann, P. (2008). Resposta de observação e movimento dos olhos em uma situação de discriminação simples simultânea. 107 pp. Dissertação de mestrado, Instituto de Psicologia, Universidade de São Paulo, São Paulo.

Estudos anteriores chamam a atenção para a importância da resposta de observação para o estabelecimento da discriminação em um treino de reforçamento diferencial. A presente pesquisa tem por objetivo analisar a resposta de observação e o movimento dos olhos em uma situação de discriminação simples simultânea. Participaram desta pesquisa seis adultos. Como estímulos, foram utilizadas imagens com alterações da tela Don Quixote, pintada por Pablo Picasso. Duas imagens foram apresentadas simultaneamente, ao longo de tentativas discretas. Em cada tentativa, houve uma imagem na presença do qual a resposta foi reforçada, bem como uma imagem na presença do qual a resposta não foi reforçada. O experimento foi dividido em três fases. Uma Fase Pré-experimental, uma Fase Experimental e uma Fase Pós-experimental. Na Fase Pré-experimental, foram apresentadas duas imagens idênticas. Na Fase Experimental, primeiramente, foram apresentadas as imagens com uma diferença localizada na parte superior esquerda de uma delas. Posteriormente, a diferença foi deslocada para a parte inferior esquerda e finalmente, a diferença foi apresentada na parte superior direita. O conjunto das condições da Fase Experimental previu o estabelecimento de novas discriminações ao modificar as propriedades diferenciais das imagens. Na Fase Pós-experimental, foram novamente apresentadas duas imagens inteiramente idênticas, as mesmas da Fase Pré-experimental. Para o registro do movimento dos olhos, durante todas as fases, foi utilizado um equipamento de rastreamento do olhar. Para efeito de análise, a imagem como um todo foi dividida, primeiramente, em três partes: parte 1 - a área que circunscreve a diferença 
apresentada na Condição 1 ; parte 2 - a área que circunscreve a diferença apresentada na Condição 2; e parte 3 - a área que circunscreve a diferença apresentada na Condição 3. Após esta divisão, foi analisada a distribuição da duração do olhar entre as partes ao longo de todas as fases. Todos os participantes apresentaram um responder discriminado que se replicou nas três condições sucessivas. Um primeiro padrão observado na distribuição da duração do olhar para os três participantes é que, na Fase Pré-experimental, todos olharam a) por mais tempo para o Dom Quixote, b) por um tempo intermediário para o Sancho Pança e c) por menos tempo para o Sol. Estes padrões se repetiram, com pequenas alterações, ao longo das condições experimentais e na última fase. Nas condições experimentais, durante a discriminação, o que pôde ser observado é que a duração de olhar para as partes das imagens que possuíam a propriedade relevante para a discriminação foi elevada enquanto a duração de olhar para outras partes diminuiu. Todos os participantes apresentaram uma duração de observação maior para o S+ do que para o $\mathrm{S}_{-}$, observação seletiva. Os dados sobre as respostas manuais na tarefa foram discutidos a partir do aprendizado cumulativo, learning set e do controle de estímulos. Os dados sobre a distribuição do olhar foram discutidos a partir de seu estabelecimento enquanto resposta de observação, sua extinção e ressurgência.

Palavras-chave: resposta de observação, movimento dos olhos, discriminação simples simultânea, humanos. 


\begin{abstract}
Endemann, P.(2008). Observing response and eye movement in a simultaneous simple discrimination situation. 107 pp. Dissertation for a Master's Degree, Institute of Psychology, University of São Paulo, São Paulo.
\end{abstract}

Previous studies draw attention to the importance of observing response to the discrimination establishment in differential reinforcement training. This research aims to analyze the observing response and eye movement in a simultaneous simple discrimination situation. Six adults participated. Images of Don Quixote screen painted by Pablo Picasso were used as stimuli. Two images were presented simultaneously along discrete trials. The experiment was divided in three phases: Pre-experimental Phase, Experimental Phase and Post-experimental Phase. In Pre-experimental phase, two identical images were presented. In the Experimental Phase, the images were displayed with a difference at the top left of it. Subsequently the difference was moved to its bottom left portion and finally the difference was displayed on its upper right. The set of conditions of the Experimental Phase predicted the establishment of new discriminations. In Post-experimental Phase, two identical images were presented again. The picture was divided in three parts: Part 1 - the area surrounding the difference displayed in Condition 1; Part 2 - the area surrounding the difference displayed in Condition 2; and Part 3 - the area surrounding the difference displayed in Condition 3. After this division, the duration of looking at these parts was analyzed throughout all phases. All participants showed discriminative performance in three successive conditions. During the Pre-experimental Phase, all participants: a) spent more time looking at Don Quixote, b) spent an intermediary time looking at Sancho Pança, and c) spent a shot time looking at Sol. These patterns were repeated with minor changes along the experimental conditions and the last phase. Under the experimental conditions the 
duration of looking at the parts of the images whose property was relevant to the discrimination increased while the duration of looking at other parts decreased. All participants showed an increased duration of looking at the $\mathrm{S}+$ than at the $\mathrm{S}$ - (selective observing). The manual responses were discussed in terms of learning set and stimulus control. The distribution of looking at was discussed in terms of its establishment as an observing response, its extinction and resurgence.

Key-words: observing response, eye movements, simultaneous simples discrimination, humans 
A Análise Experimental do Comportamento, enquanto parte de um sistema explicativo dos fenômenos psicológicos (Análise do Comportamento), estuda os princípios básicos da relação entre um organismo e seu ambiente e elabora uma análise científica de suas condições e conseqüências, com vista à previsão e controle de relações similares e futuras. (cf. Tourinho, 2003).

Segundo Skinner (1953), a unidade de análise de uma ciência preditiva (especificamente, a Análise Experimental do Comportamento) deve ser uma classe de respostas, pois "uma resposta que já ocorreu não pode, é claro, ser prevista ou controlada. Apenas podemos prever a ocorrência futura de respostas semelhantes" (p. 71, itálico do autor). A classe de resposta é identificada pelo termo comportamento operante. As propriedades que definem a semelhança e, por isso, uma classe de resposta, são tanto as condições em que respostas ocorrem como as conseqüências produzidas pelas respostas em contingências de reforço.

Skinner $(1938 ; 1953)$ definiu contingência como a relação entre a condição na qual a resposta ocorre, a própria resposta e a conseqüência produzida pela resposta. A contingência também é chamada de tríplice contingência ou contingência de três termos ( $\mathrm{Sd}-\mathrm{R}$ - Sc). Segundo Lattal (1995), a noção de contingência é a raison d'être da Análise do Comportamento. A definição do comportamento operante e de contingências de reforço parte do princípio de que, sob determinadas condições, o organismo age sobre o ambiente produzindo conseqüências, essas conseqüências atuam na modificação da probabilidade de o organismo, naquelas condições, comportar-se (Catania, 1973, 1998/1999; Fester, 1978; Keller \& Schoenfeld, 1950/1973; Skinner, 1938, 1953, 1957).

O processo pelo qual o efeito da conseqüência age sobre a condição antecedente, alterando a probabilidade de respostas futuras, foi definido por Skinner $(1938,1953)$ como discriminação, ou como se têm chamado, discriminação simples. Segundo Skinner (1953), 
a discriminação deve fazer referência a uma relação de controle entre um conjunto particular de propriedades do ambiente (o que compõe um estímulo) e uma classe de resposta.

Ao se reforçarem respostas (dispor conseqüências positivas específicas ou generalizadas, ou seja, conseqüências relacionadas ao reforço e ao aumento da probabilidade de respostas futuras) na presença de certos estímulos ou propriedades de estímulos em detrimento de outros, como por exemplo, na presença da cor verde em detrimento da cor vermelha (ou nuances de uma mesma cor em detrimento de outras), fortalecemos aquelas propriedades para o controle da resposta e enfraquecemos outras.

As propriedades que são fortalecidas, por terem a resposta reforçada em sua presença, recebem o nome de $\mathrm{S}+$ ou estímulo discriminativo $\left(\mathrm{S}^{\mathrm{d}}\right)$; as propriedades que são enfraquecidas para o controle da resposta, recebem o nome de S- ou $\mathrm{S}^{\Delta}$. O S+ é definido comumente como condição de reforço, ou seja, condição na qual a resposta, quando emitida, produzirá o reforço e o S- como extinção, em que a resposta não produzirá o reforço.

Em uma tarefa de discriminação simples em contexto de laboratório, os estímulos podem ser apresentados ao participante de duas maneiras diferentes. Podem ser apresentados juntos, simultaneamente, ou podem ser apresentados um após o outro, sucessivamente. Na situação de discriminação simultânea (Skinner, 1950), escolher o estímulo definido como correto $(\mathrm{S}+)$ é seguido de uma conseqüência positiva e, provavelmente, de alguma medida de intervalo entre tentativas (IET); escolher o estímulo definido como incorreto (S-) é seguido de uma conseqüência negativa (conseqüência não relacionada ao reforço) ou de nenhuma conseqüência programada e, provavelmente, de alguma medida de IET, podendo, ainda, ocorrer a reapresentação da mesma tentativa (procedimento de correção). Em Sério et al., (2005a), as autoras apontam que o aspecto 
crítico deste tipo de procedimento para o estabelecimento da discriminação é a localização em que os estímulos são apresentados. Esta localização deve ser randomizada para que não haja controle por posição. Na situação de discriminação sucessiva (Skinner, 1938), em que os estímulos nunca são apresentados ao mesmo tempo, mas sim, um após o outro, emitir uma resposta de escolha na presença do $\mathrm{S}+$ e não emitir esta resposta na presença do $\mathrm{S}$ - são seguidos de uma conseqüência positiva e, provavelmente, de alguma medida de IET; emitir a resposta de escolha na presença do S- e não emitir essa resposta na presença do $\mathrm{S}+$ são seguidos de uma conseqüência negativa ou de nenhuma conseqüência programada podendo, ainda, ocorrer a reapresentação da mesma tentativa após o IET. Os aspectos críticos deste tipo de procedimento são o tempo de apresentação dos estímulos (cf. Sério et al. 2005a) e a sucessão em que os estímulos são apresentados. Estes aspectos devem variar para que não haja controle pela passagem do tempo e nem pela ordem de apresentação.

A discriminação é definida pela produção de um responder diferenciado do organismo a estímulos antecedentes específicos. Esta produção se dá por meio de um procedimento de reforçamento diferencial, em que, ao se apresentar um par de estímulos, por exemplo, uma luz verde e outra vermelha reforçam-se respostas na presença da luz verde e não na presença da luz vermelha. O procedimento de reforçamento não-diferencial seria reforçar respostas tanto na presença da luz verde como da luz vermelha, ou não reforçar respostas na presença das luzes, ou mesmo, reforçar inconsistentemente na presença de ambas. Desta forma, as cores não são relacionadas ao reforço ou extinção e por isso não adquirem as funções de $\mathrm{S}+$ e $\mathrm{S}$-. Ao longo do procedimento de reforçamento diferencial e da aprendizagem, a luz verde assume a função de $\mathrm{S}+$, adquirindo parcialmente o controle da resposta; e a luz vermelha assume a função de S-, extinguindo parcialmente a resposta. 
De qualquer modo, o organismo precisa entrar em contato com os estímulos apresentados ao longo do procedimento para que esses adquiram suas funções discriminativas em relação com as conseqüências dispostas em sua presença. Segundo Dinsmoor (1985), em um artigo teórico que discute o estabelecimento da discriminação, a relação do comportamento com as conseqüências observadas na presença de um par alternativo de estímulos depende do contato estabelecido entre o organismo e estes estímulos, ou seja, depende de diferentes modos em que o organismo observa os estímulos, o que inclui, principalmente, o tempo de observação. A observação, ou a resposta de observação (observing response) foi definida por Wyckoff $(1952,1969)$ como a resposta que resulta na exposição do organismo a estímulos discriminativos, podendo ser de várias modalidades, como por exemplo, auditiva, olfativa, tátil, visual etc.

Tendo em vista a dificuldade em mensurar respostas de observação "naturais", como por exemplo, mover a cabeça em direção a, mover e fixar os olhos, tocar etc., Wyckoff (1969) propôs um procedimento, com pombos, em que uma resposta de observação, no caso pisar em um pedal, permitisse controlar ou delimitar uma diversidade de eventos. Nesse caso, a reposta seria facilmente registrada, permitiria a certeza para o experimentador de o sujeito apenas entrar em contato com os estímulos discriminativos por meio da resposta etc.

No estudo de Wyckoff (1969), foram sujeitos 20 pombos. Eles eram colocados em uma caixa experimental que continha um pedal no chão e um disco que podia ser iluminado com as cores branca, verde ou vermelha. O objetivo de Wyckoff foi obter medidas do que ocorreria com a duração de respostas de observação em condições de reforçamento diferencial e de reforçamento não-diferencial para as respostas efetivas, bicar em um disco. O autor tinha, ainda, como objetivo verificar o que ocorreria com as respostas de observação em uma condição de reversão de discriminação. 
Primeiramente, os sujeitos foram colocados na caixa experimental e expostos a uma sessão de quarenta e cinco minutos de condicionamento na qual eram apresentadas as luzes branca, verde e vermelha sob condições de reforçamento não-diferencial. O disco ficava branco por quinze minutos e, logo em seguida, as luzes verde e vermelha se alternavam de trinta em trinta segundos por trinta minutos. As respostas foram reforçadas em FI 30" em metade das tentativas (componente positivo) e permaneceram em extinção na outra metade (componente negativo). As luzes acesas não mantinham coerência com os componentes positivos e negativos. O pedal não atuava de nenhum modo específico sobre a apresentação das luzes ou na alternação dos componentes, servindo deste modo como uma linha de base.

Posteriormente, foram criados dois grupos de sujeitos (Grupos I e II). Para os sujeitos do Grupo I, as sessões, de setenta e cinco minutos, consistiam de reforçamento não-diferencial, em que as cores não estavam relacionadas aos componentes. O Grupo II passou por reforçamento diferencial por cinco sessões de setenta e cinco minutos, em que as cores estavam relacionadas aos componentes. Em uma fase seguinte, o Grupo II foi dividido em três subgrupos, II-a, II-b e II-c. O subgrupo II-a continuou em reforçamento diferencial por sete sessões; para o subgrupo II-b os estímulos foram revertidos, ou seja, aquele que assumiu a função de $\mathrm{S}+$ passou a assumir a função de $\mathrm{S}$ - e vice versa; e o II-c passou novamente para um reforçamento não-diferencial, como na sessão de condicionamento. Os Subgrupos II-b e II-c a fase foi encerrada nos primeiros quinze minutos da sexta sessão. Os sujeitos que passaram por reforçamento diferencial podiam, no momento da emissão da resposta de observação (pisar no pedal), passar de um esquema misto FI 30' EXT para um esquema múltiplo de mesmo valor.

Com as diferentes fases experimentais aplicadas aos diferentes grupos, Wyckoff (1969) pôde comparar a resposta de observação a) durante o início da discriminação e b) 
imediatamente depois de uma mudança nas condições experimentais (reversão de discriminação e reforçamento não-diferencial, no caso dos grupos II-b e II-c, respectivamente). Os resultados mostraram que a duração das respostas de pressionar o pedal para o Grupo I foi alta no início da sessão, mas rapidamente diminuiu, permanecendo baixa ao longo de todas as sessões subseqüentes. Para o Grupo II, a resposta de pressionar o pedal, estabelecida como resposta de observação, também começou alta para todos e assim permaneceu para o subgrupo II-a; para o subgrupo II-b, a duração da resposta diminuiu, mas aumentou assim que a discriminação foi novamente estabelecida; para o subgrupo II-c diminuiu, assim permanecendo. Estes resultados apontam, primeiramente, para uma relação funcional entre a resposta de observação e o estabelecimento da discriminação. Deste modo, o autor argumenta que a probabilidade da resposta de observação cresce ou permanece alta sob condições de reforçamento diferencial e decresce ou permanece baixa em condições de reforçamento não-diferencial. Ressalta-se, ainda, que a alternância (aumento e diminuição) na duração das respostas de observação pode ser analisada junto à alternância do grau de discriminação das respostas efetivas.

Holland (1958) elaborou uma série de experimentos para investigar a atenção e a vigilância em humanos, tendo como foco de análise a resposta de observação. Nestes experimentos, os participantes permaneciam em uma sala inteiramente escura. Os participantes deviam detectar movimentos de um ponteiro em um visor de um painel, para tanto, os participantes podiam produzir flashs de luz por $0,07^{\prime}$ ' diante de quatro visores posicionados nos quatro cantos do painel, cada um contendo um ponteiro. Para produzir esses flashs, os participantes deviam pressionar um botão. Pressionar este botão foi definido por Holland como a resposta de observação. Assim que os participantes detectavam algum movimento dos ponteiros, eles deviam pressionar outro botão “informando" a detecção dos movimentos nos ponteiros. 
Esta série de experimentos era composta por diferentes esquemas de reforçamento para a mesma tarefa, ou seja, detectar os movimentos nos ponteiros por meio da emissão da resposta de observação. Os esquemas foram programados em FI, FR, mult FR FI, DRL e VI com contenção limitada (limited hold), um para cada experimento. As contingências determinadas por esses esquemas atuavam na resposta de pressionar o botão que produzia um flash de luz, ou seja, os movimentos dos ponteiros foram produzidos em acordo com os esquemas de reforço programados.

Os padrões das respostas de observação (pressionar o botão que produzia a luz) encontrados para cada um dos esquemas de reforçamento foram similares àqueles descritos em estudos sobre condicionamento operante que utilizaram outras respostas instrumentais e outros organismos, tais como, pressão à barra em ratos (Fester \& Skinner, 1957). O principal objetivo desta série de experimento foi demonstrar que a resposta de observação, no caso, detectar sinais, seguia os mesmos princípios do comportamento operante e por isso, seria sensível a contingências de reforçamento, o que foi demonstrado no momento em que os diferentes esquemas determinaram a freqüência e a distribuição das respostas de observação emitidas pelos participantes.

Posteriormente, Schroeder e Holland (1968a, 1968b, 1969) trabalharam com a resposta de observação chamada por Wyckoff (1969) de "familiar" e por Schroeder e Holland de "natural", os movimentos dos olhos. Os pesquisadores (Schroeder \& Holland, 1968a) utilizaram um equipamento de rastreador de movimentos dos olhos chamado Mackworth Eye Movement Camera (Mackworth \& Thomas, 1962) para o registro destes movimentos e de suas fixações ${ }^{1}$. A resposta de olhar foi definida como a intrusão da

\footnotetext{
${ }^{1}$ Fixação pode ser entendida como o momento em que os olhos deixam de se mover e se fixam em um determinado ponto do campo visual e, a partir disso, como a formação de uma imagem na retina. A fixação somente acontece na ausência de movimentos (macro-sacádicos) dos olhos. Os movimentos macrosacádicos, ou movimento sacádico dos olhos faz referência ao simples movimento dos olhos de um ponto do campo visual para outro. O movimento sacádico dos olhos, por sua vez, permite que novas imagens sejam formadas na retina (Beckert, 1991; Schwartz, 2004)
} 
reflexão da córnea em um dos visores, independente do seu tempo de permanência. No experimento de Schroeder e Holland (1968), três participantes foram colocados em uma sala iluminada diante de um painel com quatro visores eqüidistantes contendo, cada um, um ponteiro que se mexia de acordo com contingências programadas. Em sessões de 40 minutos, os participantes foram instruídos a relatar os movimentos dos ponteiros através de quatro botões correspondentes espacialmente a cada um dos visores.

As contingências programadas previam a apresentação dos seguintes esquemas: DRL 10', FR 45', FI 120' e mult DRL FR FI. As contingências determinadas por esses esquemas atuavam sobre as respostas de olhar, ou seja, o movimento de um dos ponteiros foi produzido pelo movimento dos olhos de acordo com o esquema de reforçamento em vigor. Qual visor apresentava o movimento de um ponteiro era aleatório. Levando em consideração uma alta freqüência de movimentos dos olhos observada, foi programado um DRL 10 para todos os participantes. Dessa forma, o movimento de um dos quatro ponteiros só era produzido caso um período de tempo de 10 segundos passasse sem nenhuma ocorrência da resposta de olhar para os visores. Após encerrarem esta fase, os participantes foram submetidos a um esquema FR 45. Em seguida, os participantes foram informados sobre uma nova mudança, o movimento dos ponteiros, agora, estava sob um esquema de intervalo fixo de 2 min. A partir disso, um esquema mult DRL 10, FR 45 e FI 2 min foi apresentado. A apresentação de cada componente durava 4 minutos e foi sinalizada pela presença de diferentes luzes localizadas no centro do painel.

Neste experimento, foram medidos a freqüência da resposta de olhar, a duração das fixações do olhar em cada visor e o tempo entre o movimento dos ponteiros e a resposta de pressionar o botão que informava tal movimento. Cada um dos esquemas de reforçamento, mesmo quando utilizados em uma mesma sessão, produziu um padrão distinto de ocorrência de respostas de movimento dos olhos. As curvas de movimentos dos 
olhos encontrados para cada um dos esquemas de reforçamento foram similares àqueles descritos em estudos sobre condicionamento operante (Fester \& Skinner, 1957).

Os dados obtidos por Schroeder e Holland (1968) demonstraram que as respostas de movimento dos olhos podem ser controladas pelo esquema de reforçamento em vigor, confirmando a hipótese de que a detecção do movimento dos ponteiros poderia servir como estímulo reforçador para o estabelecimento e manutenção de padrões do movimento dos olhos, definido no contexto deste experimento de resposta de observação.

Outro estudo pioneiro sobre o movimento dos olhos que pode ser analisado sob a ótica do condicionamento operante é o de Kaplan e Schoenfeld (1966). Estes autores começam por citar um experimento realizado por Rees e Israel (1935). Sem registrar, ainda, os movimentos dos olhos dos participantes, Rees e Israel realizaram um experimento em que sucessivos anagramas de cinco de letras foram projetados para os participantes. As letras estavam sempre dispostas no formato de um xis, quatro letras nos quatro cantos do anagrama e um no centro. Durante todo o experimento, as letras dos anagramas formavam palavras sempre que ordenadas na mesma seqüência: partindo-se da letra do centro, em seguida a letra inferior esquerda e daí em diante no sentido anti-horário.

Os participantes do experimento foram divididos em um grupo experimental e um grupo de controle. O grupo experimental passou por duas fases. Na primeira fase, os participantes foram expostos a uma série de anagramas com apenas uma possibilidade de formar a palavra-solução, ou seja, as letras dispostas no anagrama podiam formar apenas uma palavra na língua inglesa. Esses anagramas foram chamados, pelos autores, de anagramas não-ambíguos. Imediatamente após a exposição a esta série de anagramas, começava a segunda fase dos participantes do grupo experimental. Nesta segunda fase, outros anagramas de cinco letras foram apresentados aos participantes. Esses novos anagramas eram ambíguos, assim chamados, pois além da palavra formada na seqüência da 
primeira fase, havia outras palavras possíveis de serem formadas por outras seqüências, ou seja, havia outras soluções. O grupo controle foi exposto somente aos anagramas ambíguos.

Enquanto os participantes do grupo experimental, diante dos anagramas ambíguos, vocalizaram a palavra-solução formada pela seqüência presente na primeira fase $94,6 \%$ das vezes, os participantes do grupo controle vocalizaram estas palavras apenas 47,3\% das vezes

Kaplan e Schoenfeld (1966) também utilizaram anagramas de cinco letras dispostas em formato de um xis em um novo experimento. Os anagramas foram apresentados por meio de um projetor chamado Kodak Carousel slide projector e os experimentadores registraram os movimentos dos olhos dos participantes por meio de um equipamento fotográfico chamado Bolex $16 \mathrm{~mm}$. Movie camera, cuja velocidade fotográfica era de 13,6 quadros por segundo.

Na Fase 1 do experimento, as letras dos anagramas novamente formavam uma só palavra, sempre quando lidas na mesma seqüência. Na Fase 2, as letras dos anagramas formavam também uma só palavra-solução, só que em uma seqüência diferente, e, na Fase 3, a seqüência da única solução foi novamente modificada.

Foi requerido dos participantes apertarem um botão quando encontrassem a palavra que era formada pelas cinco letras, ou seja, quando eles resolvessem o anagrama. Após apertar o botão, os participantes deveriam vocalizar a palavra-solução. Os experimentadores registraram o tempo entre a apresentação do anagrama e a resposta de apertar o botão e a palavra vocalizada.

Kaplan e Schoenfeld (1966) verificaram que, nas primeiras tentativas, os movimentos dos olhos dos participantes seguiram seqüências diversas e, em seguida, seguiam apenas a seqüência que formava a palavra-solução. Após a passagem da Fase 1 para a Fase 2, os 
participantes passaram a rastrear os anagramas de modo a formar várias seqüências, mas, em seguida, começaram a emitir a nova seqüência de movimentos requerida para a formação da palavra-solução. O mesmo ocorreu após a mudança para a Fase 3.

Kaplan e Schoenfeld (1966) interpretaram esses resultados como um condicionamento dos movimentos dos olhos. O condicionamento pode ser descrito como: diante do anagrama, a resposta de mover os olhos na seqüência que forma a palavrasolução produz a palavra-solução e diante da palavra solução, a resposta de vocalizar esta palavra produz um reforçador, como o elogio ou o sucesso em resolver o anagrama.

Segundo Schroeder (1969a), os movimentos dos olhos tornam disponíveis estímulos visuais e, por isso, tanto podem ser tratados como respostas de observação como seu estudo pode ser útil para identificação de relações funcionais no estabelecimento da discriminação. A partir disto, Schroeder (1969a, 1969b, 1970, 1997) elaborou uma série de experimentos para analisar o papel do movimento dos olhos (resposta de observação) em situações de discriminação simples simultânea e sucessiva e de transferência da discriminação.

Schroeder (1970) analisou a distribuição dos movimentos dos olhos em uma tarefa de discriminação simples simultânea com o intuito de verificar se a freqüência das fixações nos estímulos corresponderia às escolhas (àqueles estímulos) emitidas e reforçadas na tarefa.

Para o registro do movimento dos olhos, foi utilizado equipamento chamado Mackworth V-1164-2 Corneal Reflection e um digitalizador Polymetric Company. A freqüência do movimento dos olhos, as respostas manuais para cada estímulo apresentado foram registrados por Esterline Angus Event Recorder. Foram utilizarados quatro estímulos simultaneamente apresentados ao longo de tentativas discretas: quadrado, círculo, linha horizontal e linha vertical. Tais estímulos eram apresentados nos quatro 
cantos de uma tela (Pola-Coat Screen). Participaram da pesquisa 15 estudantes de graduação com visão normal divididos em três grupos. Todos os participantes passaram por apenas uma sessão de oitenta tentativas. A apresentação de cada estímulo variou semialeatoriamente de forma que cada um deles fosse apresentado um mesmo número de vezes em cada posição ao longo de blocos de vinte tentativas.

Uma vez iniciada a tentativa, o participante deveria responder em um de quatro botões correspondentes às posições espaciais em que eram apresentados os estímulos. Respostas de escolha na posição onde se encontrava os dois S+ eram consideradas corretas e eram seguidas da apresentação de uma luz verde no centro da tela e um IET de três segundos. Respostas de escolha nas posições onde se encontrava os dois S- eram consideradas incorretas e eram seguidas de uma luz vermelha e de um IET de 30 segundos e a reapresentação da mesma configuração de estímulos (procedimento de correção).

Para o Grupo I, respostas em um de quatro botões correspondentes às posições espaciais em que eram apresentados o quadrado ou a linha vertical eram consideradas corretas, respostas de escolha nas posições onde se encontrava o círculo ou a linha horizontal eram consideradas incorretas. Para o Grupo II, o procedimento que aplicado foi o mesmo para o Grupo I, com a diferença que os estímulos apresentados eram mais opacos. Os Grupos I e II foram diferenciados pela luminância dos estímulos. Para o Grupo III, foram apresentados um $\mathrm{S}+$, um quadrado com uma linha vertical sobreposta e um S-, um círculo com uma linha horizontal sobreposta e, ainda, dois estímulos redundantes (irrelevantes) em que respostas correspondentes a sua posição espacial não havia conseqüências programadas, um triângulo e uma linha oblíqua. A luminância para este Grupo III foi a mesma que para o Grupo I.

Uma análise das escolhas (respostas manuais) feitas pelos participantes mostra que uma vez reforçados por escolher o quadrado, a linha vertical (Grupo I e Grupo II) ou o 
quadrado com linha vertical sobreposta (Grupo III), estes realizavam suas escolhas subseqüentes em acordo com a primeira escolha reforçada. Todos os participantes do Grupo I escolheram o quadrado e todos os participantes do Grupo III escolheram o quadrado com linha sobreposta. No Grupo II, três participantes escolheram a linha vertical e dois participantes, o quadrado. No caso do Grupo I e Grupo II, embora existissem dois estímulos que poderiam ser seguidos de luz verde e menor IET (S+), apenas um dos estímulos controlou o responder. Outro dado interessante se remete ao fato de que nenhum participante cometeu mais de uma escolha seguida de luz vermelha e IET de 30 segundos (S-) o que, por sua vez, mostra que o aumento do IET reduziu a variabilidade das respostas de escolha dos participantes. No que se refere ao movimento dos olhos, um importante resultado é que, de fato, houve uma relação entre as escolhas realizadas e as respostas de movimento dos olhos emitidas pelos participantes. Em outras palavras, os estímulos para os quais os participantes direcionavam a maior freqüência de respostas de movimento dos olhos eram os estímulos mais escolhidos (no caso, um dos $\mathrm{S}+$ ) e deste modo, diminuiu, simultaneamente, a freqüência de respostas de movimento dos olhos nos estímulos não escolhidos (um S+ e os dois S-).

Schroeder (1970) analisou, ainda, o efeito da prática sobre o movimento e a fixação dos olhos. Observou-se que em muitos casos, os participantes realizavam suas escolhas sem fixar todos os estímulos, ou seja, posicionar os estímulos no centro da retina, chamada de imagem foveal (fóvea). Para parte dos participantes, nas primeiras tentativas, todos os estímulos eram fixados; nas tentativas subseqüentes, os participantes fixavam o quadrado e o círculo antes da escolha; depois só o quadrado; e, por fim, realizavam as escolhas sem fixar os estímulos. Deste modo, pôde-se concluir que mesmo os estímulos não sendo fixados, havia controle pelo estímulo, muito possivelmente, pelo fato de as imagens dos estímulos serem formada na região periférica. 
Tais resultados foram confirmados por Pessôa, Huziwara, Perez, Endemann \& Tomanari (2008) numa replicação recente de Schroeder (1970). Com base nesses resultados, sugeriu-se que a mensuração do comportamento de olhar pode fornecer medidas do controle exercido por estímulos quando apresentados em situações de discriminação simples (Dinsmoor, 1985; Schroeder, 1969a, 1970; Pessôa et al., 2008).

Schroeder (1969a) argumenta que o modo em que são apresentados os estímulos (simultâneo vs. sucessivo) pode afetar e determinar diferentes padrões de distribuição do movimento dos olhos. O autor lembra que em uma situação de discriminação simples simultânea, responder em um estímulo $(\mathrm{S}+)$ envolve necessariamente a não escolha do outro (S-), enquanto que em situações de discriminações simples sucessiva, a apresentação do $\mathrm{S}+$ e do S- ocorre em tentativas distintas e por isso suas escolhas são independentes. Deste modo, Schroeder (1969b) elabora um experimento com o objetivo de estender os resultados obtidos em Schroeder (1970), investigando o movimento dos olhos em treinos de discriminação simples simultânea e sucessiva com estímulos compostos.

O objetivo deste estudo era analisar padrões de fixação durante a transferência de uma discriminação simples com estímulos compostos para uma discriminação simples em que os componentes dos mesmos estímulos compostos apresentados anteriormente eram apresentados separadamente em uma fase de teste. Os equipamentos e estímulos utilizados foram os mesmos do estudo anterior (Schroeder 1970).

Participaram deste experimento 30 estudantes e estes foram divididos em seis grupos. Grupos I, II e III para discriminação simples simultânea e Grupos IV, V e VI para discriminação simples sucessiva. A todos os participantes foram apresentadas tentativas com quatro estímulos dispostos nos quatro cantos da tela. Nas tentativas simultâneas, os participantes deveriam responder em um de quatro botões correspondentes às posições espaciais ocupadas pelos estímulos na tela; nas tentativas sucessivas, os participantes 
deveriam pressionar o botão correspondente à posição do estímulo em um intervalo de até três segundos nas tentativas em que o $\mathrm{S}+$ estava presente e não responder por até três segundos nas tentativas em que o S- estava presente.

As contingências programadas (cores vermelha e verde e IET de 3 e 30 segundos) para a tarefa de discriminação simples simultânea e sucessiva foram as mesmas dos estudos anteriores (Schroeder 1970, 1969ª , respectivamente). Respostas de escolha aos estímulos redundantes não foram seguidas de conseqüências programadas.

Nas tentativas de treino do Grupo I, Grupo II e Grupo III, um quadrado com linha vertical sobreposta $(\mathrm{S}+)$ e um círculo com linha horizontal sobreposta (S-) eram apresentados simultaneamente com mais dois outros estímulos redundantes: triângulo e linha oblíqua. Nas tentativas de teste, para esses grupos, os estímulos redundantes deixavam de ser apresentados e os outros estímulos eram separados. Dessa forma, nas tentativas de teste, eram apresentados simultaneamente: quadrado, círculo, linha vertical e linha horizontal. Nas tentativas do Grupo IV, Grupo V e Grupo VI, o quadrado com linha vertical sobreposta $(\mathrm{S}+)$ ou o circulo com linha horizontal sobreposta (S-) eram apresentados, sucessivamente, junto de mais três outros estímulos redundantes: hexágono, triângulo e linha oblíqua. Nas tentativas de teste, para esses grupos, apenas dois dos três estímulos redundantes (triângulo e linha oblíqua) eram apresentados junto dos outros estímulos separados, ora com o quadrado e a linha vertical, ora com o círculo e a linha horizontal. Os Grupos I e IV não receberam tentativas de treino; os Grupos II e V receberam 20 tentativas de treino; os Grupos III e VI receberam 80 tentativas de treino. Todos os grupos receberam 80 tentativas de teste de transferência.

Os resultados das respostas manuais das tentativas de teste de transferência para todos os grupos mostraram que os participantes apenas escolheram ou o quadrado ou a linha vertical, mas nunca os dois. No que se refere ao movimento dos olhos, os resultados 
foram semelhante aos estudos anteriores (Schroeder 1970, 1969a). No começo da sessão, os participantes fixaram todos os estímulos, mas ao longo das tentativas, os estímulos mais fixados foram aqueles mais escolhidos, porém neste experimento houve uma preferência pelo quadrado tanto para as respostas manuais de escolha como para as fixações, ou seja, uma preferência por forma em detrimento da linha.

Mais recentemente, Schroeder (1997) discute sobre as técnicas de ensino a partir das teorias do aprendizado da discriminação, contrapondo as teorias que defendem o procedimento de tentativa e erro com as que defendem o uso da técnica da introdução gradual (fading), argumentando que há implícita, na primeira, a idéia de que errar é necessário para o aprendizado. Segundo o autor, errar pode atrapalhar o desenvolvimento da aprendizagem enquanto o fading produz menos erros e um aprendizado mais consistente. Segundo Schroeder, no procedimento de fading, o S+ é, primeiramente, apresentado sozinho. No momento seguinte há uma introdução gradual do S-. Uma vez estabelecida a discriminação, novos estímulos S+' e S-' são apresentados. No último momento há um fading out (retirada) dos estímulos originais (ou estímulos velhos, S+ e S). Uma questão levantada Schroeder (1997) é em que momento o participante modifica suas resposta para os outros estímulos, ou seja, em que momento ocorre a transferência da relação de controle. Outra questão é o que acontece durante o fading out (retirada) do velho estímulo e do fading in (introdução) do novo. O autor argumenta que analisar a resposta de observação, nesse caso, pode, entre outras coisas, dar dica ou mesmo revelar o momento em que ocorre essa transferência e seus determinantes.

Segundo Schroeder (1997) quatro conjuntos de variáveis parecem ser importantes para a análise da transferência do controle seletivo de estímulos: as características dos estímulos, a seqüência do fading, o efeito do treino e da prática e as contingências de 
reforço. Para discutir empiricamente estas questões, Schroeder realizou uma série de experimentos a partir de um procedimento geral.

Os movimentos dos olhos eram registrados por um aparato chamado Biometrics Eye-Trace Infra-red Eye Movement Monitor e os estímulos foram apresentados sucessivamente por meio de slides dispostos por uma Kodak Carousel Projector. Os estímulos usados eram brancos com fundo escuro e apresentados ao longo de tentativas discretas intermediadas por um intervalo entre tentativas de três segundos. Participou desta série de experimentos um total de 450 universitários com visão normal. No centro da tela, era apresentada uma luz que era acesa nos intervalos entre tentativas e que servia de conseqüência diferencial. As sessões duravam em média cinco minutos.

No primeiro experimento, todos os slides envolviam transferência de uma discriminação de tamanho (grande vs. pequeno) para uma discriminação envolvendo orientação (por exemplo, inclinação das linhas). Participaram deste experimento 90 estudantes universitários. Cada participante passou por uma sessão com cinco fases, contendo cada uma cinco slides. Schroeder (1997) usou três séries de seqüências de fading, diferindo basicamente no modo em que a relevância e a saliência das dicas (características dos estímulos) foram introduzidas, para demonstrar como a freqüência diferenciais de fixação pode ser usadas como dicas de controle seletivo de estímulos. Na série 1, as figuras foram fragmentadas; na série 2 figuras semelhantes foram apresentadas; na série 3, novas figuras foram apresentadas.

$\mathrm{O}$ experimento contava com cinco fases: uma inicial, em que o estímulo $\mathrm{S}+$ era apresentado. A fase de fading (Fase Experimental 1), em que o estímulo S- era apresentado. A Fase Experimental 2, em que novos estímulos eram gradualmente apresentados e a Fase Experimental 3, em que os estímulos originais eram gradualmente retirados. Nestas fases, uma luz verde era apresentada nos intervalos entre tentativas 
sinalizando uma resposta arbitrariamente definida como correta e uma luz vermelha sinalizando uma resposta arbitrariamente definida como incorreta e uma última fase, a Fase de Teste. Na Fase de Teste, os novos estímulos eram apresentados sozinhos e não havia conseqüência diferencial, ou seja, apresentação das luzes nos intervalos entre tentativas. Cada fase continha a apresentação de cinco slides.

A principal questão deste experimento era como as fixações para os primeiros estímulos apresentados se distribuíam e se transferiam para os novos estímulos apresentados gradualmente na Fase Experimental 2, exclusivamente apresentados na Fase Experimental 3 e no Teste.

No que se referem às respostas manuais, os participantes cometeram poucos erros nas sessões, geralmente um ou dois erros em uma sessão inteira. Ao utilizar uma análise fatorial, Schroeder (1997) não observou efeito significante das séries sobre a freqüência das fixações. Porém, ao observar a interação dos estímulos, fases e séries em termos relativos, o autor pôde constatar uma significante diferença entre freqüência relativa de fixações para diferentes dicas ao longo das fases e entre as séries.

O principal resultado de Schroeder (1997) foi que os participantes fixavam diferencialmente as novas dicas somente após a retirada das velhas (originais). Segundo o autor, ainda que uma nova dica seja introduzida é provável que não seja usada (enquanto dica), que seja, mesmo, tratada como irrelevante, até que, enfim, a dica original (propriedade relevante do estímulo original) já estabelecida na discriminação torne-se, de fato, irrelevante ou desapareça por completa. $\mathrm{O}$ autor argumenta, deste modo, que seu experimento expõe uma interação entre as características dos estímulos, a freqüência diferencial de fixação e a utilização da técnica de fading, no momento em que demonstra o modo como novas dicas são introduzidas e seus efeitos sobre a freqüência diferencial das fixações. 
Schroeder, em todos os experimentos, utilizou a freqüência, relativa ou não, como medida para a análise do movimento dos olhos e das fixações (resposta de observação). Sobre os resultados de Schroeder (1969a, 1969b, 1970, 1997), uma questão comum ainda pode ser apontada: o S- e os estímulos redundantes deixam de ser fixados ao longo dos diferentes procedimentos, enquanto o $\mathrm{S}+$ assume quase que o controle total das fixações.

A partir dos estudos de Schroeder (1969a, 1969b, 1970) sobre discriminação simples simultânea e sucessiva, Silva (2008) comparou padrões de movimentos dos olhos e diferentes relações de controle em procedimentos de discriminação simples sucessiva e simultânea utilizando a duração como medida de análise. Foi utilizado, para a execução da tarefa e registro de respostas, um micro-computador Apple Macintosh e o aplicativo MTS v. 11.3.4 (C) E. K. Shriver Center) desenvolvido por William Dube e Eric Hiris (Dube \& Hiris, 1999). Para o rastreamento dos movimentos dos olhos ao longo de todo o experimento, foi utilizado um sistema completo de $I S C A N^{\circledR}$, modelo RK-426PC, fabricado por $I S C A N^{\circledR}$. Os arquivos de vídeo gerados pelo $I S C A N^{\circledR}$ foram gravados e sua análise feita através do software Video Frame Coder (ver melhor descrição no método do presente projeto, secção Equipamentos). Os estímulos utilizados foram pinturas do pintor japonês do século XIX, Hiroshige, que eram apresentadas ora sucessivamente, ora simultaneamente ao longo das características sessões.

Participaram desta pesquisa seis adultos. Todos os participantes foram expostos a diferentes fases experimentais: quatro treinos de discriminação simples: uma de discriminação sucessiva, seguida de sua respectiva reversão, de uma discriminação simultânea, também seguida de sua respectiva reversão. Os participantes foram divididos em dois grupos, Grupo SiSu (simultâneo - sucessivo, nesta ordem de apresentação) e Grupo SuSi (sucessivo - simultâneo), cada um com 3 participantes. Para os participantes do Grupo $\mathrm{SiSu}$, os treinos de discriminação simultânea, na Fase 1a e reversão, na Fase 1 b 
antecederam os treinos de discriminação sucessiva da Fase 2a e reversão da Fase 2b. Para o Grupo SuSi, de maneira inversa, os treinos de discriminação sucessiva antecederam os treinos de discriminação simultânea.

Na discriminação sucessiva, os estímulos eram apresentados, na tela, um após o outro. Na discriminação simultânea, os estímulos eram apresentados ao mesmo tempo de dois em dois, ambos, ao longo de tentativas discretas intermediadas por um IET de 1 segundo. A apresentação dos estímulos era randomizada e variava entre quatro posições distintas da tela, nos quatro cantos. Os estímulos tinham dimensões aproximadas de 4 centímetros de largura por 5 centímetros de altura. O critério para ambas era de $91 \%$ de acerto. Ao atingir este critério, dava-se início à próxima fase, tanto para o treino como para a reversão. As conseqüências programadas para as respostas de escolha consideradas como "corretas" (sobre o $\mathrm{S}+$ ) eram o desaparecimento das imagens, o acréscimo de um ponto em um contador exibido durante o IET e um sinal sonoro, enquanto que para as respostas de escolhas "incorretas" (sobre o S-) era apenas o desaparecimento das imagens e o IET.

No que se refere à distribuição das respostas de escolha na tarefa de discriminação simples sucessiva ou simultânea, Silva (2008) relata que todos os participantes discriminaram, porém de diferentes modos. Os participantes, quando submetidos à discriminação sucessiva, levaram um número de tentativas superior para o alcance dos critérios e, por isso, para o estabelecimento de um responder discriminado, incluindo as reversões do que os participantes submetidos à discriminação simultânea. Estes dados são semelhantes aos obtidos por Schroeder (1969a, 1969b).

A duração das tentativas, exceto a tentativa em que era apresentado o S- na discriminação sucessiva, diminuiu com o decorrer das sessões, com pequeno aumento logo após as reversões. 
No que se refere à distribuição do movimento dos olhos, o autor argumenta, em termos práticos, porque foi utilizada a duração das fixações em detrimento da freqüência como medida de análise. Segundo o autor,

A duração das fixações do olhar foi adotada como critério de análise porque se mostrou um melhor indicador das características do olhar do que a freqüência de fixações, em situações em que o participante olhou bastante para os limites de cada estímulo. Em casos como este, eventualmente a imagem do cursor no quadro de vídeo podia estar ou não sobreposta ao estímulo. Embora se possa considerar que a fixação do olhar permaneça sobre o estímulo durante ocorrências como esta, de acordo com a codificação adotada, isso representa um acréscimo na freqüência de fixações para cada vez que a imagem do cursor sai e entra novamente sobre a imagem do estímulo. Já para a duração das fixações, o impacto de ocorrências como essa é de apenas um intervalo aproximado de $0,03 \mathrm{~s}$ para cada quadro em que o cursor eventualmente não esteja sobre o estímulo (Silva, 2008, p. 67).

Quando Silva (2008) fala em imagem do cursor no quadro de vídeo, ele está fazendo referência à análise dos vídeos através de programas que realizam a análise do rastreamento do olhar, em que o cursor indica exatamente para onde o participante fixa os olhos ou emite movimentos dentro de um campo visual. Como em Schroeder e Holland (1968), a resposta de olhar é definida como a intrusão da reflexão da córnea em uma determinada área, independente do seu tempo de permanência. Esta definição sustenta a freqüência como medida de análise. Transferindo a definição de Schroeder e Holland para o contexto dos argumentos de Silva, quando o cursor, que indica a fixação do participante, entra em uma área circunscrita, é registrada uma resposta. Este registro terá impacto nas medidas de freqüência, independentemente do tempo de permanência. Porém, isto pode 
trazer inconsistência na exposição dos dados, sobretudo, quando se trata da resposta de observação definida por Wyckoff $(1952,1969)$ e apoiada por Dinsmoor (1985) em termos de duração. Há situações em que o participante fixa um estímulo, por exemplo, por 1 segundo, o que é registrado como um resposta, e após isso passa os olhos, e por isso o cursor, sobre um outro estímulo no ínterim de um movimento sacádico (rever nota de rodapé, p. 7), deste modo, conta-se uma resposta, mesmo que ela tenha durado apenas 0,03 segundo e em seguida acomoda sua fixação em um terceiro estímulo por mais 3 segundos. Em termos de freqüência, temos uma resposta para cada estímulo, porém quando analisamos a partir da duração a diferença é significativa.

No que diz respeito, exclusivamente, à discriminação sucessiva, em que o participante, ao escolher o estímulo "correto", produzia seu desaparecimento e ao não escolher o "incorreto", este ficava exposto durante uma tentativa inteira, a análise da duração das fixações para o S+ e o S- ficou, de certa forma comprometida, porém, alguns participantes do Grupo SuSi apresentou uma queda na duração de fixação sobre os Sdurante alguns blocos das sessões, mesmo com um aumento concomitante do tempo de exibição destes estímulos. Mesmo com um maior tempo de exibição, o participante olhou cada vez menos para os S- exibidos. Silva (2008) argumenta que a resposta de olhar para este estímulo pode ter entrado em extinção em função de ele não ter estado em uma relação contingente com as conseqüências positivas programadas para a tarefa em questão. No que diz respeito à discriminação simultânea, os principais dados obtidos estão relacionados a uma queda na duração relativa das fixações sobre o S+ e o S- (efeito da prática), porém conservando uma duração relativa maior sobre S+ do que sobre o S-.

Silva (2008) analisou os dados obtidos na discriminação simultânea a partir do número acumulado de tentativas em que cada participante olhou para apenas um dos dois estímulos exibidos. Com estes dados, o autor pôde analisar diferentes topografias de 
controle de estímulos (seleção e rejeição). Os resultados mostraram que os participantes que aprenderam primeiro a discriminação simultânea apresentaram indícios de controle por seleção (olhar apenas para o estímulo definido como S+ e escolhê-lo), e dois dentre estes três também apresentaram indícios de posterior controle por rejeição (olhar apenas para o estímulo definido como S-, mas escolher o $\mathrm{S}+$ ). Os participantes que aprenderam a discriminação simultânea após a sucessiva apresentaram indícios de controle por rejeição desde o início, e dois deles mesmo antes do controle por seleção.

O autor discute o fato de que o participante, ao escolher olhando para apenas um dos estímulos, estaria escolhendo o estímulo correto $(\mathrm{S}+)$ por seleção ou rejeição, dependendo para qual estímulo ele olhou, argumentando que o estabelecimento de controle por seleção e rejeição seja um determinante importante para o processo de discriminação simultânea. No caso da discriminação sucessiva, o autor argumenta que o controle por rejeição, bem como por seleção, são requisitos para a aprendizagem.

De qualquer modo, como foi apresentado ao longo desta introdução, a discriminação é definida por uma relação de controle, seja por seleção, seja por rejeição, na produção de um responder diferenciado a pelo menos um par de estímulos por meio de um treino de reforçamento diferencial. Segundo Schroeder (1969a), o estudo do movimento dos olhos (da resposta de observação) pode ser importante para identificar relações funcionais, inclusive as diferentes topografias de controle (seleção e rejeição), como demonstrado por Silva (2008), no estabelecimento do controle de estímulos, da discriminação.

Os estudos apresentados de Holland (1958), Schroeder e Holland (1968a, 1968b) e os de Kaplan e Schoenfeld (1966) demonstraram, primeiramente, o papel do condicionamento operante no estabelecimento da resposta de observação e do movimento dos olhos (do comportamento de olhar). Os estudos apresentados de Schroeder (1969b, 
1970, 1997) e de Silva (2008) mostraram que a análise dos movimentos dos olhos pode ser útil na identificação de variáveis relevantes no estabelecimento da discriminação, assim como a identificação de medidas do controle exercido pelos estímulos quando apresentados em procedimentos de discriminação simples sucessiva ou simultânea ou, mesmo, quando apresentados gradualmente ao longo do procedimento.

Segundo Dinsmoor (1985), concomitante às relações de controle e ao modo como os estímulos são apresentados, a discriminação é o produto de dois processos complementares: primeiro, o efeito do esquema de reforçamento em vigor sobre a probabilidade da resposta na presença dos estímulos. E segundo, a transferência (indução, ver explicação abaixo) que é afetada, entre outras coisas, pelas características dos estímulos e, sobretudo, pelo tempo em que o sujeito observa os estímulos e suas características.

Dinsmoor (1985) aponta para alguns processos observados ao longo do aprendizado da discriminação, mais especificamente, no começo do procedimento de reforçamento diferencial, em que os estímulos não estão diferenciados, ou não assumiram, ainda, funções específicas para a determinação do responder. Este autor argumenta que, no início do estabelecimento da discriminação, há uma transferência, entre os estímulos, do controle da resposta. A conseqüência em responder na presença de um estímulo S1 (definido, a priori, como $\mathrm{S}+$ ) afeta o responder na presença de outro estímulo S2 (definido, a priori, como S-) e vice-versa, ou seja, reforçar a resposta na presença de S1 aumenta a probabilidade do responder na presença de S2; e não reforçá-la na presença de S2 diminui a probabilidade do responder no S1. Skinner (1938) chamou este processo de indução (Induction) e Wyckoff (1952), de efeito cruzado (“crossover" effect). Segundo Skinner (1953), do mesmo modo que a discriminação, a indução, também chamada, nesta obra, de generalização, não é uma atividade do organismo, mas uma relação de controle, que no 
caso, é compartilhada entre estímulos por meio de propriedades comuns. Em outras palavras, "o controle é compartilhado por todas as propriedades dos estímulos tomadas separadamente" (Skinner 1953, p. 147). Desta maneira, a discriminação deve envolver um contínuo processo de condicionamento e extinção (Skinner, 1938). Segundo Dinsmoor (1985), a diminuição da indução ao longo do procedimento de reforçamento diferencial é o que, de fato, define a discriminação.

Segundo Dinsmoor (1985), uma importante função da resposta de observação é aumentar o contato do organismo com os estímulos ou propriedades dos estímulos relevantes e diminuir o contato com aqueles que são irrelevantes, pois os estímulos programados para o controle da resposta é apenas uma parte do ambiente que afeta o organismo na sessão experimental. "Grande parte dos estímulos que estava presente quando a resposta foi reforçada também estava presente durante os períodos de nãoreforço" (Dinsmoor, 1985, p. 366) e a depender da resposta de observação, a indução, ou o efeito cruzado deve variar, de modo que "os efeitos de S+ e S- poderiam ser diluídos pelo controle exercido por estes estímulos “incidentais' ou 'estáticos"” (Dinsmoor, 1985, p. $366)$.

De modo que fosse apresentada, nos próprios estímulos, uma diversidade de características “estáticas" (Dinsmoor, 1985) e irrelevantes (semelhanças) para o estabelecimento da discriminação, a presente pesquisa tem por objetivo analisar a resposta de observação ao longo de toda uma situação de discriminação simples simultânea visual em que os estímulos apresentados, de dois em dois ao longo de tentativas discretas, são praticamente idênticos exceto por uma única e pequena propriedade diferencial.

No estudo de Wyckoff (1969), após os sujeitos do Grupo II-b passarem por um treino de reforçamento diferencial e apresentarem um responder discriminado e uma taxa alta de duração da resposta de observação, a contingência passou por reversão, ou seja, 
aquele estímulo que assumiu a função de $\mathrm{S}+$ na contingência anterior passou a assumir a função de S- na atual e vice versa. Deste modo, houve uma transferência ${ }^{2}$, entre os estímulos, do controle da resposta. Foi observado que a duração da resposta de observação emitida pelos sujeitos foi alterada, no caso, diminuiu, mas aumentou assim que a discriminação foi novamente estabelecida.

No estudo de Kaplan e Schoenfeld (1966), a resposta de observação, que pode ser definida pelo movimento dos olhos na seqüência em que produzia a palavra-solução, foi primeiramente estabelecida na Fase 1. Na mudança para a Fase 2, ou seja, no momento em que houve uma mudança na disposição das letras, os participantes deviam encontrar outra seqüência para formar a nova palavra-solução. No momento da mudança, os participantes passaram a rastrear os anagramas de modo a formar várias seqüências, mas em seguida começaram a emitir apenas a nova seqüência requerida, ocorrendo, deste modo, uma transferência de controle e, por isso, uma nova discriminação. O mesmo ocorreu após a mudança para a Fase 3 .

Assim como em Kaplan e Schoenfeld (1966), o presente projeto prevê o estabelecimento de novas discriminações ao deslocar a propriedade diferencial dos estímulos ao longo de três fases experimentais com o objetivo de observar e analisar como diferentes padrões do comportamento de olhar, em termos de duração (cf. Dinsmoor, 1985; Silva, 2008; Wyckoff, 1952, 1969), vão sendo estabelecidos e extintos à medida que as propriedades diferenciais vão assumindo funções diferenciadas para o responder do participante ao longo das fases. Diferentemente de Schroeder (1997), as modificações dos estímulos serão imediatas e concomitantes às mudanças de fase.

\footnotetext{
${ }^{2}$ Segundo Catania (1998/1999), a reversão da discriminação é um tipo de transferência de controle de estímulos. Segundo o autor, transferência de controle de estímulos diz respeito à substituição de "um conjunto de estímulos por outro (ou, como um processo, o controle de estímulos mantido depois de tal substituição). A transferência pode basear-se em propriedades comuns de dois conjuntos de estímulos ou em correlações similares de dois conjuntos de estímulos em contingências diferenciais." (Catania, 1998/1999, p. 424)
} 


\section{MÉTODO}

\section{Participantes}

Três adultos entre 18 e 26 anos participaram desta pesquisa como voluntários. Antes de participarem da pesquisa, os participantes leram e assinaram um Termo de Consentimento Livre e Esclarecido (ver Anexo 1).

\section{Ambiente experimental}

A pesquisa foi realizada em uma sala de 2,0 m X 3,5 m localizada no Laboratório F. S. Keller de Estudos do Comportamento Operante, do Instituto de Psicologia da Universidade de São Paulo (USP). Esta sala é dividida por um biombo. De um lado do biombo há uma cadeira, uma mesa com uma tela de computador e um teclado que foram utilizados pelos participantes. Do outro lado, os equipamentos utilizados pelo experimentador (descritos adiante).

\section{Equipamentos}

Para a tarefa em discriminação simples simultânea, foi utilizado um microcomputador Apple Macintosh modelo Performa 5215CD equipado com teclado e monitor LG de 17 polegadas. Para o controle da apresentação das contingências experimentais e o registro das respostas dos participantes foi utilizado o aplicativo MTS v. 11.3.4 (C) E. K. Shriver Center) desenvolvido por William Dube e Eric Hiris (Dube \& Hiris, 1999). Apesar de se tratar de um aplicativo para realização de tarefas em procedimentos de pareamento ao modelo, este foi adaptado de modo a permitir a realização de discriminações simples simultâneas.

Para o registro do movimento ocular foi utilizado o $I S C A N^{\circledR}$ (Figura 1). O ISCAN ${ }^{\circledR}$ é um equipamento de rastreamento do olhar. Este equipamento é composto por uma microcâmera de vídeo padrão, uma micro-câmera de vídeo sensível a luz infravermelha e por 
uma fonte de luz infravermelha. Estes três componentes são fixados em um suporte que se assemelha a uma viseira e estão conectados a duas placas de hardware, a RK-826PCI Pupil/Corneal Refletion Tracking System e a RK-630 Autocalibration System, instaladas em um computador PC com processador Pentium ${ }^{\circledR} 2 \mathrm{GHz}$ e $256 \mathrm{MB}$ de memória. O sistema também é composto pelo software ISCAN ${ }^{\circledR}$ Raw Movement Data Acquisition. O $I S C A N^{\circledR}$ contém uma saída de vídeo analógica, que foi conectada a uma placa de captura de vídeo, instalada em outro computador PC com processador Pentium ${ }^{\circledR} 2 \mathrm{GHz}$ e $1 \mathrm{~GB}$ de memória RAM. Neste segundo computador, foram instalados dois programas, o Pinnacle Studio Plus $9^{\circledR}$ e o Video Frame Coder, este segundo desenvolvido pela equipe do Shriver Center e descritos abaixo.

O sinal de vídeo com o campo de visão do participante e com o cursor indicando o ponto central da fixação do olho em relação a este campo é capturado no segundo computador através da placa de captura de vídeo e do software Pinnacle Studio Plus $9^{\circledR}$ e gravado em arquivos com formato AVI. A análise dos arquivos gravados é feita com o software Vídeo Frame Coder. Por meio deste software é possível avançar o vídeo quadro a quadro e realizar marcações de letras ou números em cada um destes quadros. A partir destas marcações, o programa gera automaticamente uma planilha eletrônica com o número do quadro, seu instante e a marcação atribuída.

A partir das imagens geradas pela câmera de vídeo sensível à luz infravermelha, a placa de hardware RK-826PCI monitora a posição da pupila e marca da reflexão corneal em uma imagem de olho em tempo real. Usando a diferença de reflexão entre a pupila e a córnea, a posição do olhar pode ser determinada com uma precisão tipicamente melhor que $0,3^{\circ}$ em um campo de visão de aproximadamente 20 graus verticais por $20^{\circ}$ horizontais. 


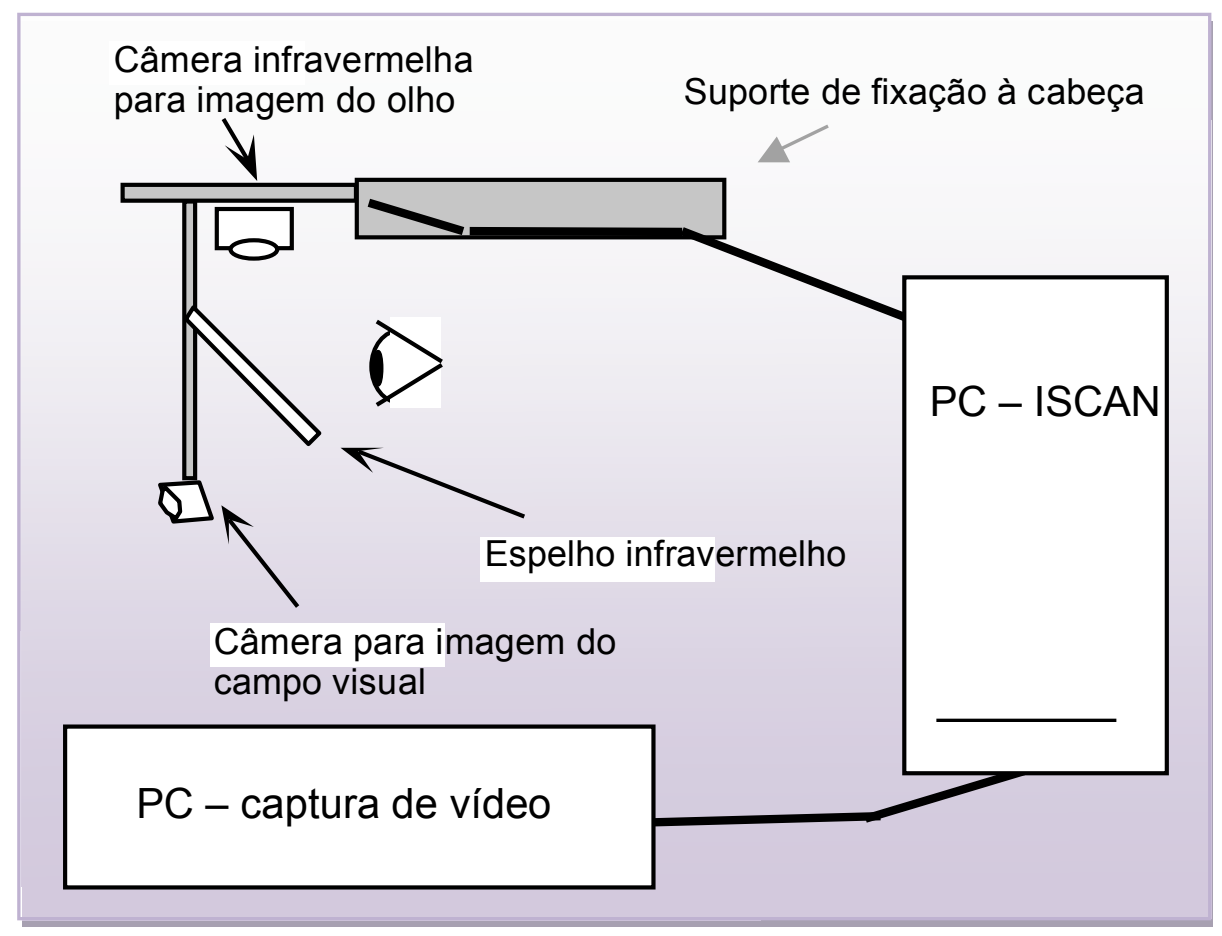

Figura 1. Representação esquemática dos principais componentes do equipamento de rastreamento do olhar utilizados na presente pesquisa. 


\section{As imagens}

As imagens utilizadas foram alterações da imagem representada na tela Don Quixote pintada por Pablo Picassso em 1955 (Figura 2). As imagens foram digitalizadas, em um editor de imagens GIMP 2.4.4 Final, no formato compatível com o aplicativo MTS. Foram retiradas as impurezas das imagens, de modo a deixá-las exclusivamente nas cores preta e branca, conforme pode-se verificar no Quadro 1. Foram produzidas seis variações da pintura. As diferenças entre elas podem ser verificadas na Tabela 1. As imagens foram apresentadas em dimensões aproximadas de $9 \mathrm{~cm}$ de comprimento por $12 \mathrm{~cm}$ de altura, referentes respectivamente a $8,6^{\circ}$ e a $11,5^{\circ}$ a partir dos olhos do participante. A distância entre as imagens no monitor de vídeo foi de $14 \mathrm{~cm}$ e a distância entre o olho do participante e a tela foi de aproximadamente $60 \mathrm{~cm}$. Com isso, a distância angular entre as imagens foi de aproximadamente $11,4^{\circ}$.

\section{Procedimento}

Antes de cada sessão experimental, o equipamento ISCAN $^{\circledR}$ foi ajustado à cabeça do participante, e foi realizada uma breve rotina de calibragem do equipamento. A iluminação da pupila e a reflexão corneal foram ajustadas utilizando comandos do próprio software ISCAN Raw Movement Data Acquisition. Com a cabeça parada e mantendo-se o foco de visão em pontos previamente estipulados na tela do computador, o programa de rastreamento do olhar estabeleceu parâmetros para garantir uma perfeita calibragem. Ao final, a precisão do rastreamento do olhar foi verificada pedindo ao participante que olhasse para cinco pontos distintos e definidos na tela do computador. $\mathrm{O}$ ajuste do equipamento e a calibragem levaram em média entre 10 e 15 minutos. 


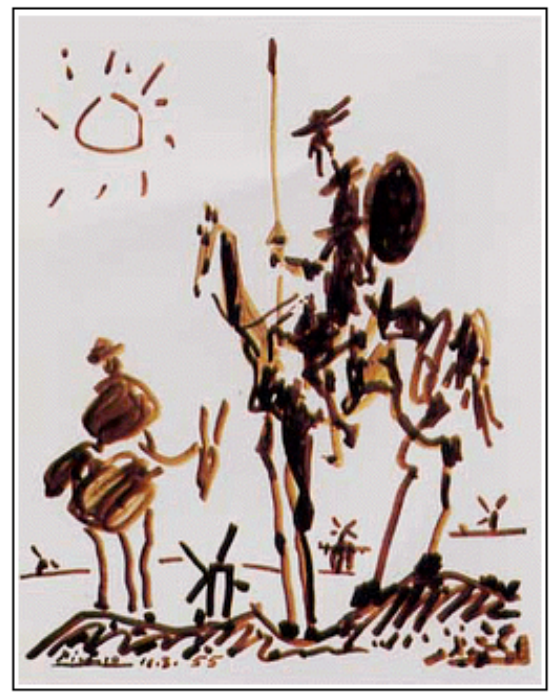

Figura 2. Reprodução da tela original de Pablo Picasso, Don Quixote (1955). 
A

B

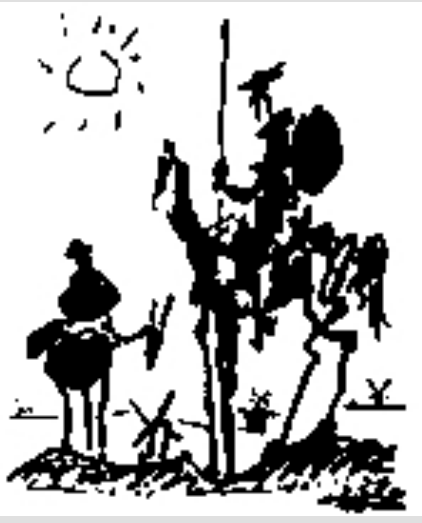

D

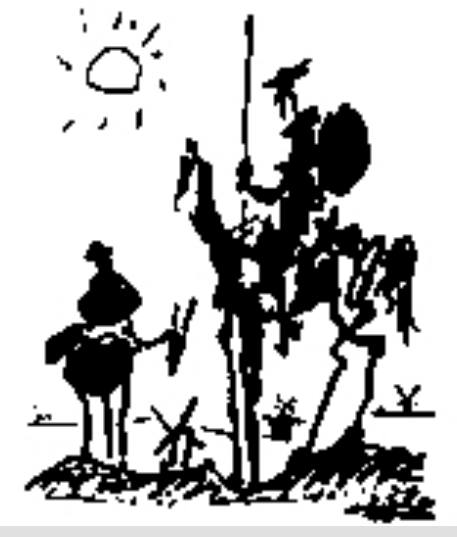

$\mathbf{E}$
C

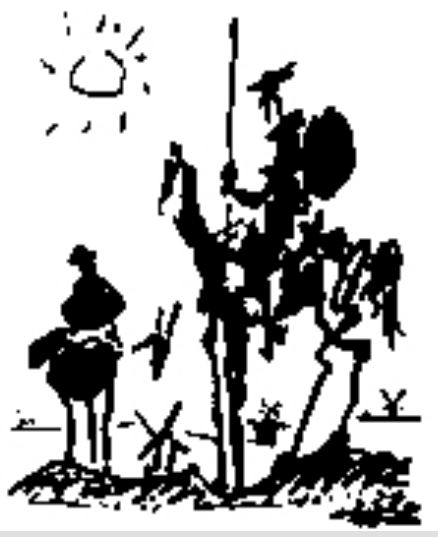

$\mathbf{F}$
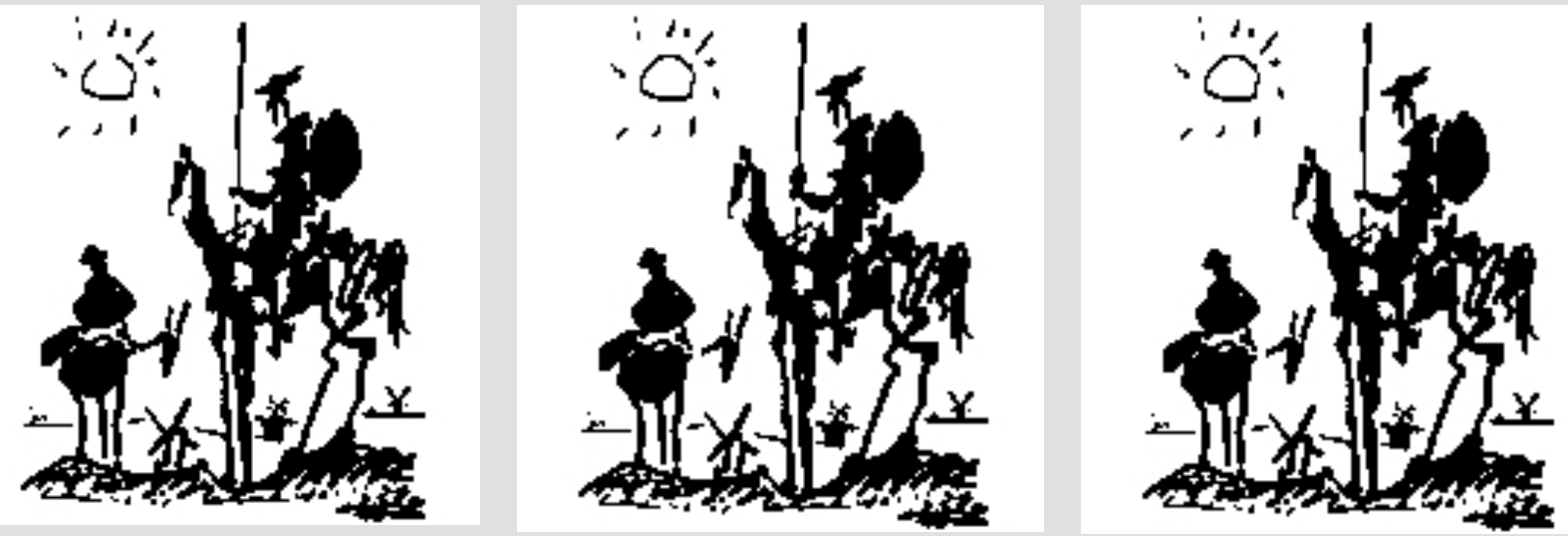

Quadro1. Representação das imagens apresentadas em todas as fases do experimento. 
Tabela 1. Apresentação das características diferenciais entre as imagens

\begin{tabular}{|c|c|c|c|c|c|}
\hline A & B & $\mathrm{C}$ & $\mathrm{D}$ & $\mathrm{E}$ & $F$ \\
\hline Sol aberto & Sol fechado & $\begin{array}{l}\text { Sol aberto - } \\
\text { Pescoço do } \\
\text { burrico do } \\
\text { Sancho pança } \\
\text { aberto }\end{array}$ & $\begin{array}{l}\text { Sol aberto - } \\
\text { Faltando a } \\
\text { mão do Dom } \\
\text { Quixote }\end{array}$ & $\begin{array}{l}\text { Sol fechado - } \\
\text { Pescoço do } \\
\text { burrico do } \\
\text { Sancho Pança } \\
\text { aberto }\end{array}$ & $\begin{array}{l}\text { Sol fechado - } \\
\text { Pescoço do } \\
\text { burrico do } \\
\text { Sancho Pança } \\
\text { aberto } \\
\text { Faltando a } \\
\text { mão do Dom } \\
\text { Quixote }\end{array}$ \\
\hline
\end{tabular}


Uma vez calibrado o rastreamento do olhar e com todo equipamento pronto para a execução da tarefa experimental, foram apresentadas, na tela do computador, as seguintes instruções.

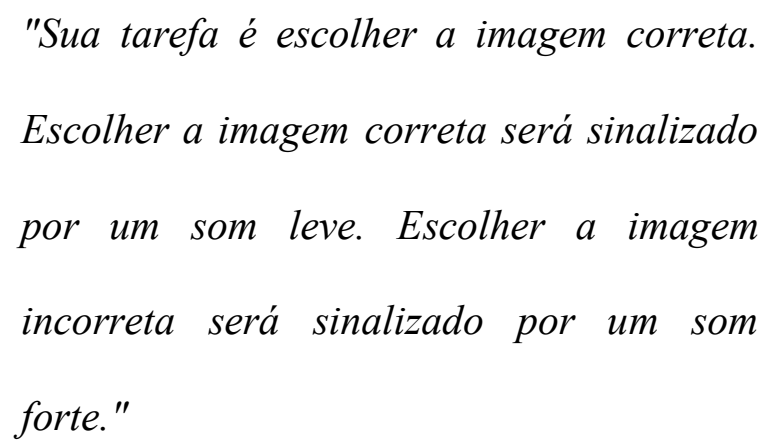

O procedimento consistiu na apresentação simultânea de duas imagens alinhadas horizontalmente nos dois cantos superiores da tela. As imagens foram apresentadas em blocos de 20 tentativas discretas. A tentativa encerrou no momento em que o participante clicou com o cursor do mouse sobre uma das imagens. A localização, em que as imagens foram apresentadas, foi randomizada para que não houvesse controle por posição. Clicar com cursor do mouse sobre a imagem definida arbitrariamente como correta (resposta correta) teve como conseqüência a apresentação de um som leve seguido pelo desaparecimento das imagens e um intervalo até a próxima tentativa (Intervalo entre Tentativas, IET) de $1 \mathrm{~s}$. Clicar com o cursor do mouse sobre a imagem definida como incorreta (resposta incorreta) teve como conseqüência a apresentação de um som forte seguido pelo desaparecimento dos estímulos e um IET, também, de $1 \mathrm{~s}$.

Fases

O experimento foi dividido em três fases: Fase Pré-experimental (linha de base), Fase Experimental (estabelecimento de discriminações simples simultâneas) e Fase Pósexperimental (retorno às condições de linha de base), descritas a seguir. 


\section{Fase Pré-experimental (PRE)}

O objetivo desta fase foi obter uma medida da distribuição do movimento dos olhos antes que alguma propriedade da imagem assumisse função discriminativa para as respostas de escolha.

Nessa fase, as duas imagens "B" e "B" (Quadro 1) apresentadas simultaneamente foram idênticas para todos os participantes. Em todas as tentativas dessa fase, a escolha por uma das imagens era seguida pela apresentação não diferencial do som leve ou do som forte. Do ponto de vista metodológico, a variável relevante no estudo diz respeito à ausência de características discriminativas na linha de base versus a sua presença na fase experimental. Portanto, para especificar as variáveis críticas no estudo e evitar ao menos uma dupla manipulação de variáveis ao se iniciar a fase experimental (i.e., a presença de características discriminativas nas imagens e a possibilidade de obtenção de pontos), optou-se por empregar reforçamento não diferencial na linha de base. Dito de outra forma, a fase experimental distingue-se da linha de base não pela possibilidade de reforçamento, mas sim pelo aspecto diferencial do mesmo. Sendo assim, a imagem sob a qual uma resposta produziu um som leve ou um som forte foi definida aleatoriamente. Como foram apenas 10 tentativas, houve cinco imagens corretas do lado direito e cinco do lado esquerdo, distribuídas aleatoriamente. Esta fase se encerrou após o participante ter sido exposto a 10 tentativas.

\section{Fase Experimental}

O objetivo desta fase foi estabelecer uma seqüência de três discriminações visuais simples simultâneas com base em três pares de características distintivas da imagem de Don Quixote.

Condição I. Esta condição consistiu na apresentação simultânea das imagens "A" 
e "B" (Quadro 1). Entre as duas imagens, havia uma diferença. Uma delas apresentava uma pequena abertura na parte superior do Sol (falha). Clicar sobre a imagem com o Sol aberto (estímulo "A") foi considerada a resposta correta. Clicar sobre a imagem com Sol fechado (estímulo “B”), a resposta incorreta.

O critério de encerramento desta condição, para todos os participantes, foi a emissão da resposta correta, em 20 tentativas consecutivas.

Condição II. Nesta condição, a diferença, entre as imagens foi deslocada para o Pescoço do burrico do Sancho Pança. Clicar sobre a imagem com parte do pescoço do burrico do Sancho Pança aberta foi a resposta correta. Clicar sobre a imagem com o pescoço do burrico do Sancho pança completo (fechado) foi a resposta incorreta.

Nessa condição, possíveis efeitos oriundos das funções discriminativas previamente estabelecidas na Condição I foram controlados por balanceamento dos estímulos. Assim, para os Participantes 1 e 2, foram apresentadas as imagens "A" e "C" (Quadro 1). Para o Participante 3, foram apresentadas as imagens "B" e "E" (Quadro 1). A diferença entre as imagens consistia na apresentação de dois sóis abertos ou fechados.

O critério de encerramento desta condição, para todos os participantes, foi a emissão da resposta correta em 20 tentativas consecutivas.

Condição III. Nesta condição, a diferença foi deslocada para a Mão do Dom Quixote. Clicar sobre a imagem com uma falha na mão do Dom Quixote foi a resposta correta. Clicar sobre a imagem a mão do Dom Quixote completa foi a resposta incorreta.

Pelas mesmas razões anteriormente descritas, os estímulos foram balanceados entre os sujeitos. Para os Participante 1 e 2, foram apresentadas as imagens "A" e "D" (Quadro 1). Para o Participante 3, foram apresentadas as imagens "E" e "F" (Quadro 1). A diferença entre as imagens consistia apenas na apresentação de dois pescoços do burrico do Sancho Pança abertos ou fechados. 
O critério de encerramento desta condição --e, portanto, desta fase-- foi, para todos os participantes, a emissão da resposta correta em 20 tentativas consecutivas.

Fase Pós-experimental (POS)

O objetivo desta fase foi avaliar os efeitos do responder sob controle discriminativo sobre o restabelecimento das condições em que vigorava a ausência de reforçamento diferencial, à semelhança da linha de base.

Nesta fase, para os todos os participantes, foram apresentadas simultaneamente as imagens "B" e "B" (Quadro 1) em que todas as partes das imagens estão fechadas e idênticas.

A imagem sob a qual uma resposta produziu um som leve ou um som forte foi definida aleatoriamente. Não houve critério de acerto. Esta fase foi encerrada após 10 tentativas ou três minutos desde seu início. Esta fase encerrou o experimento. Para uma revisão simplificada do procedimento, ver resumo esquemático a seguir (Figura 2). 
todos os Participantes

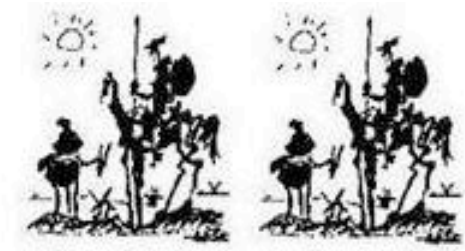

todos os Participantes
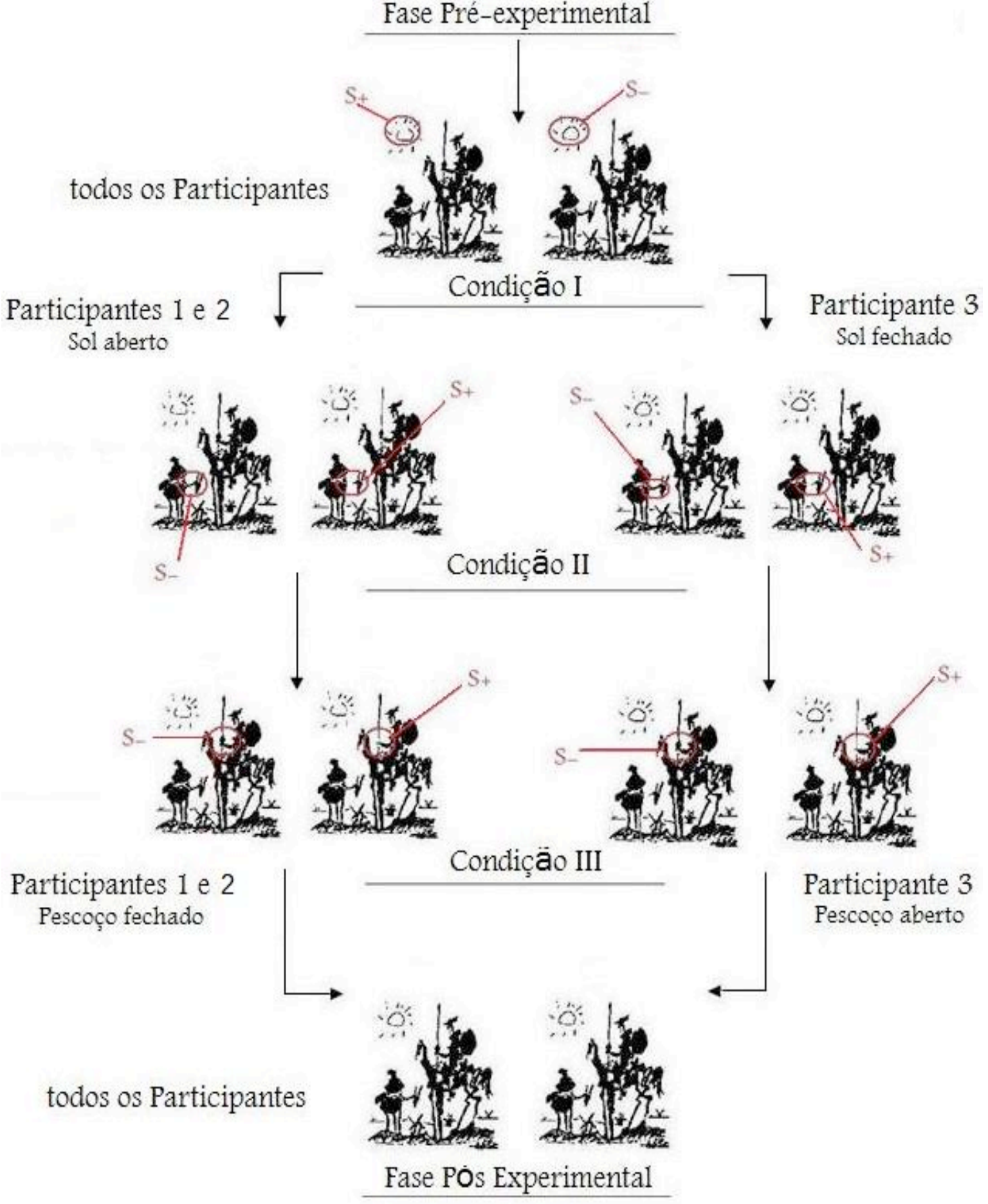

Figura 2. Resumo esquemático da apresentação das imagens ao longo das Fases e entre os Participantes. 
Para o registro e análise do movimento dos olhos, a imagem foi dividida, primeiramente, em três partes: Parte 1 - a área que circunscreve o Sol; Parte 2 - a área que circunscreve o Sancho Pança; Parte 3 - a área que circunscreve o Dom Quixote, conforme se pode observar na Figura 3.

No que se refere, ainda, aos movimentos e fixação dos olhos, o rastreamento destes movimentos foi registrado por meio da placa digitalizadora de vídeo Pinnacle, que tem sua entrada conectada à saída de vídeo do equipamento de ISCAN ${ }^{\circledR}$.

O vídeo gerado das sessões pelo $\operatorname{ISCAN}^{\circledR}$ foi analisado quadro a quadro (30 quadros por segundo) por meio do aplicativo Video Frame Coder que, por sua vez, permitiu obter medidas de interesse.

Por meio deste aplicativo é possível, ao experimentador, avançar o vídeo quadro a quadro e realizar marcações de letras ou números, indicativas de elementos para a análise, em cada um destes quadros (Figura 4). A partir destas marcações, ou códigos, o programa gera automaticamente uma planilha eletrônica com o número do quadro, seu instante e a marcação atribuída.

A Figura 4 apresenta o campo de visão do participante por meio de um quadro gerado pelo Vídeo Frame Coder. No campo de visão, é possível observar o monitor e a disposição das imagens em uma tentativa. O cursor indica para onde o participante está fixando o olhar naquele momento. Os números à direita indicam os códigos utilizados para a tabulação dos quadros.

A ordem dos quatro primeiros números faz referência aos seguintes dados: tentativa; posição da imagem; a imagem; e as partes da imagem. A tentativa seguia uma ordem crescente a depender das respostas dos participantes. A posição da imagem variava entre 1 e 2, esquerda ou direita, respectivamente. A imagem, também, variava apenas entre 


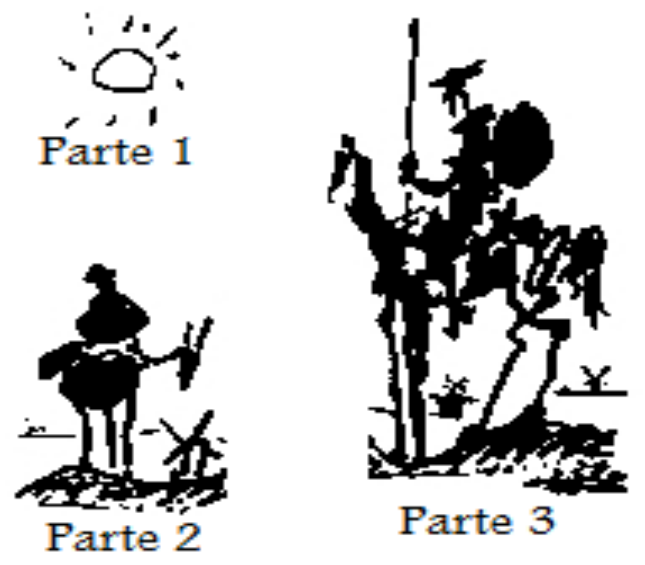

Figura 3. Representação das partes da imagem, divididas para posterior análise. 


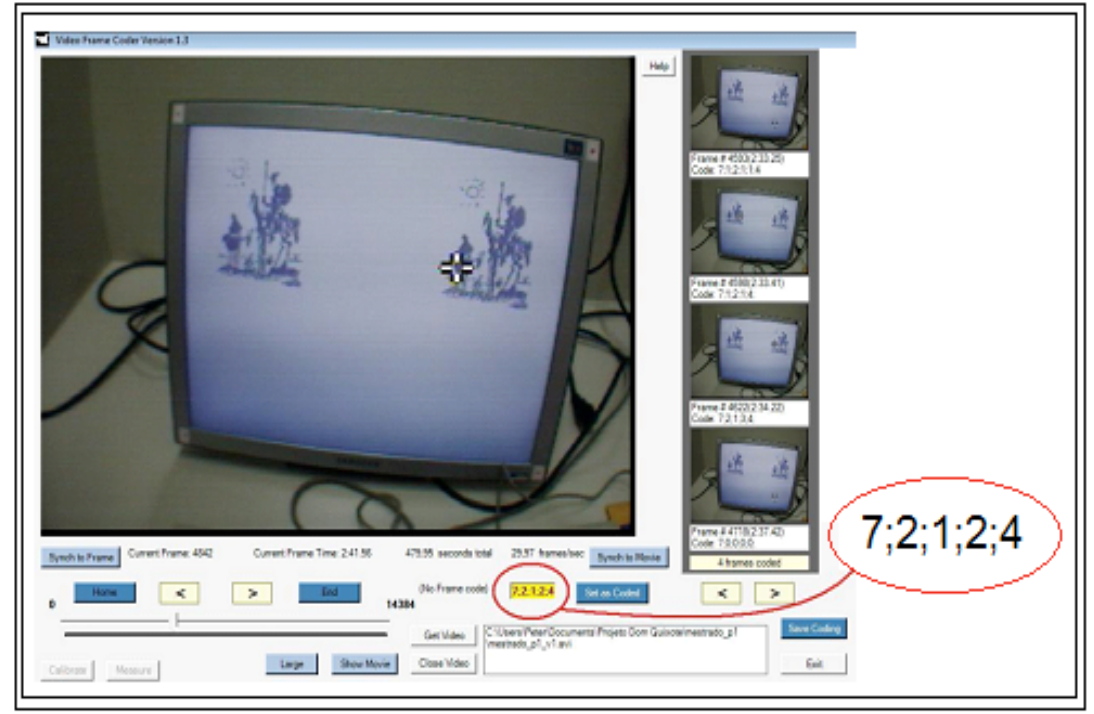

Figura 4. Representação de um quadro gerado pelo programa Vídeo Frame Coder. 
1 e 2 . A Imagem 1 era aquela que ao ser escolhida produzia um som leve e a Imagem 2 produzia um som forte. As Imagens 1 e 2 eram apresentadas em diferentes posições (direita e esquerda) aleatoriamente. As partes da imagem variavam entre 1 e 3 (Figura 3). O último código (que na Figura 4 aparece como “4”) será explicado posteriormente. Havia, ainda, outros códigos, como IET igual a 0 (zero) em toda a seqüência de códigos, por exemplo, "0;0;0;0;0"; piscada e ausente igual a 7 na segunda posição, por exemplo, "tentativa;7;0;0;0"; e fixação em qualquer outro lugar que não nas imagens igual a 0 nas quatro últimas posições, por exemplo, “tentativa;0;0;0;0".

Para uma análise mais refinada de possíveis diferenças no padrão do olhar ao longo das fases e na medida em que as propriedades das partes da imagem foram adquirindo funções discriminativas, estas partes foram divididas em partes ainda menores: Parte 5 - a área que circunscreve a diferença apresentada na Condição 1; Parte 6 - a área que circunscreve a diferença apresentada na Condição 2; e Parte 7 - a área que circunscreve a diferença apresentada na Condição 3 (Figura 5). Estas partes ainda menores serão chamadas, nesse trabalho, de estímulos, pois são as características e diferenças físicas destas partes ainda menores que concentram as propriedades discriminativas para o responder discriminado nas condições experimentais. Deste modo, a nomenclatura utilizada para se referir a estas partes ainda menores será:

$$
\begin{aligned}
& \text { Parte } 5=\mathrm{S} 1=\text { lugar da falha no Sol } \\
& \text { Parte } 6=\mathrm{S} 2=\text { pescoço } \\
& \text { Parte } 7=\mathrm{S} 3=\text { mão }
\end{aligned}
$$

O Código 4 que aparece na Figura 4 faz referência a qualquer parte das imagens que não contemplam as indicadas pelos códigos 5, 6 e 7. Assim, a marcação apresentava o código 4 quando o participante estivesse olhando para o Dom Quixote, Sol, ou Sancho, mas não nas áreas demarcadas por aqueles três códigos. 


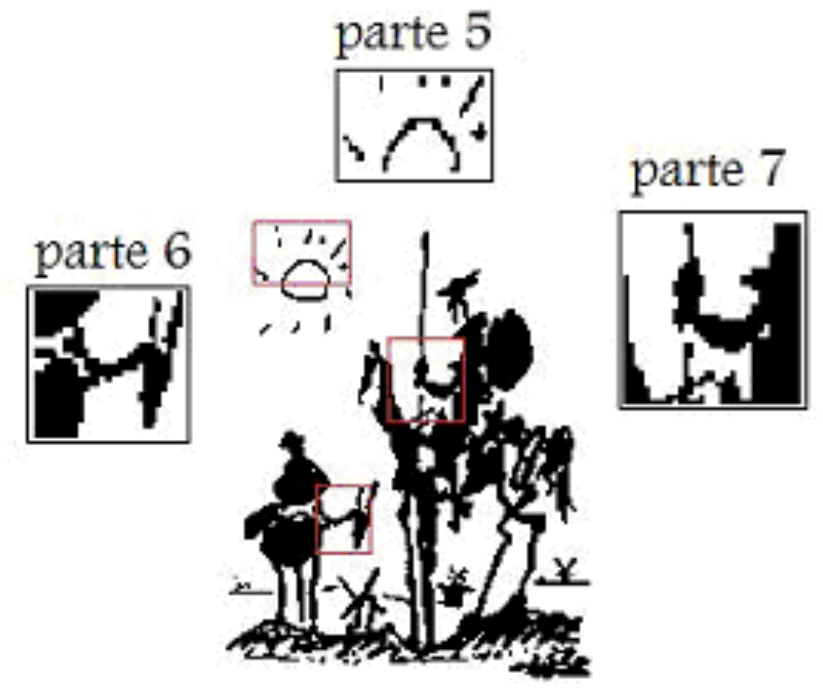

Figura 5. Representação de partes ainda menores da imagem, divididas para efeito de análise. 


\section{RESULTADOS}

Tendo em vista que o principal objetivo deste trabalho foi analisar o papel da resposta de observação visual no estabelecimento da discriminação simples simultânea, o presente estudo destaca os seguintes registros para a apresentação dos resultados e posterior discussão.

O desempenho dos participantes, ou seja, as respostas de clicar em cada uma das imagens ao longo das fases, foi registrado pelo programa MTS e será apresentado por um gráfico de respostas acumuladas (Figura 6). Estes dados atestam o estabelecimento da discriminação a partir de um treino de reforçamento diferencial ao longo das condições experimentais.

Sobre as respostas manuais, é importante esclarecer alguns pontos antes de apresentar os dados. A programação no MTS foi feita em blocos de 20 tentativas. Como critério para mudança de condição na Fase Experimental, os participantes deviam atingir um bloco completo de 20 respostas reforçadas consecutivamente. Caso houvesse ao menos um erro em um bloco, este era conduzido até a $20^{\text {a }}$ tentativa, após o qual um novo tinha início. Dessa forma, os participantes apenas passavam para a condição experimental seguinte após terem emitido respostas corretas em, no mínimo, 20 tentativas e, no máximo, 39 tentativas. Como medida uniforme a todos participantes, a seqüência variável a cada sujeito de tentativas consecutivas que encerrou cada condição experimental, bem como o tempo despendido para completá-la, foram tomados como indicativos do responder discriminado para fins de análise dos resultados.

A Figura 6 apresenta os dados do desempenho na tarefa manual ao longo das fases e o tempo de cada uma para os três participantes. Primeiramente, ela mostra que todos os participantes emitiram 10 respostas (clicaram com o mouse em uma das imagens) na Fase 
PRE, que era o único requisito para o participante passar para a fase seguinte. Nesta fase, as imagens foram apresentadas idênticas, o que impossibilitou o estabelecimento de um treino de reforçamento diferencial e, portanto, de um responder discriminado. No total das dez tentativas (ou dez respostas, uma vez que uma resposta era emitida a cada tentativa), o Participante 1, que levou 50,59 s para completar essa fase, emitiu respostas que produziam som leve em apenas 2 tentativas. O Participante 2 levou 110,51 s e as emitiu em seis tentativas. O Participante 3, que levou $120 \mathrm{~s}$, as emitiu em 5 tentativas. Deste modo, o Participante 1 emitiu um número maior de respostas que produziam um som forte e o Participante 2, um número menor.

A Condição 1 mostrou resultados diversos para os três participantes. Nesta condição, havia uma pequena diferença no Sol e a possibilidade de um treino de reforçamento diferencial (assim como nas duas condições seguintes). O Participante 1 completou essa condição em 200 tentativas e 418,68 s. O Participante 2 emitiu 32 respostas corretamente e encerrou a condição em 222,7 s, tendo acertado 28 tentativas consecutivas. O Participantes 3 emitiu 40 respostas em 227,08 s.

$\mathrm{Na}$ Condição 2, em que a diferença foi transferida para o Pescoço do burrico do Sancho Pança, o Participante 1 levou 110,36 s para completar a condição, 33 respostas corretas. O Participante 2 levou 69,9 s e emitiu 38 respostas corretas e consecutivas. O Participante 3 levou 125,18 s e emitiu as 20 respostas corretas, concluindo, deste modo, esta fase em 20 tentativas. 

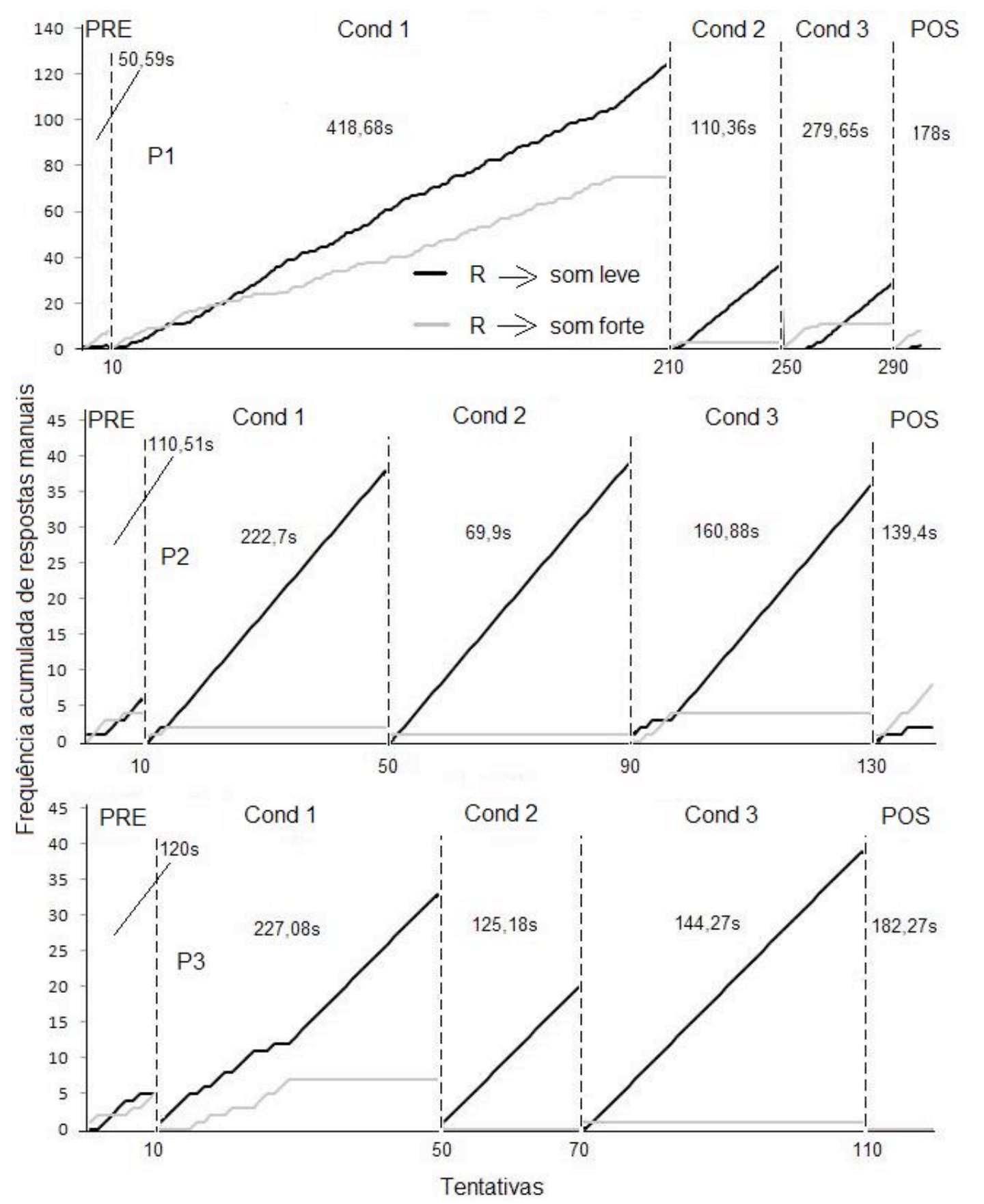

Figura 6. Freqüência acumulada de respostas manuais na tarefa de discriminação simples simultânea ao longo das tentativas da Fase PRE, das Condições Experimentais 1, 2 e 3 e da Fase POS. Os tempos dados em segundos se referem a duração da Fase ou Condição. 
Na condição 3, a mão do Dom Quixote continha o elemento distintivo das duas imagens. O Participante 1 emitiu 26 respostas corretas e consecutivas e levou 279,65 s para finalizar a condição. O Participante 2 levou 160,88 s e emitiu 33 respostas corretas e consecutivas. O Participante 3 levou 144,27 s e emitiu 39 respostas corretas.

$\mathrm{Na}$ última fase, em que as imagens foram novamente apresentadas idênticas, o critério de encerramento era emitir 10 respostas ou a passagem de três minutos. Os Participantes 1 e 2 emitiram as 10 respostas em um total de 178 s e 139,4 s respectivamente. O Participante 3 não emitiu respostas durante todo o tempo de 182,27 s. Os Participantes 1 e 2 emitiram 2 respostas que produziram som leve e 8 que produziram som forte.

Os dados da Figura 6 mostram o responder discriminado que se replica em três condições sucessivas. A partir da linha de base, como a distribuição do olhar se conformaria nessa situação de discriminação simples simultânea, em que duas imagens apresentadas são ora idênticas ora diferentes por conservarem apenas uma pequena diferença entre elas? Toda medida de análise utilizada por esse estudo na apresentação e discussão dos dados será em termos de duração (Dinsmoor, 1985; Silva, 2008; Wyckoff, 1952, 1969). Deste modo, as questões acima colocadas se acomodam, primeiramente e de modo geral, na distribuição da duração do olhar para cada parte $(1,2$ e 3$)$ da imagem ao longo de todas as fases (Figura 7).

$\mathrm{Na}$ Figura 7, as condições experimentais foram dividas em dois momentos: antes e durante o responder discriminado [i.e., antes e durante a seqüência de $n$ respostas corretas consecutivas (sendo $n$ entre 20 e 39)]. Optou-se por esta divisão na apresentação dos resultados para melhor identificar alterações no estabelecimento de diferentes padrões de olhar na medida em que propriedades do Sol, do Sancho Pança e do Dom Quixote foram adquirindo funções diferenciadas. Porém, esta divisão foi baseada nos seguintes 
parâmetros: a partir da programação do MTS para a disposição das tentativas e dos dados informados na Figura 6, a divisão foi realizada com base no número consecutivo de respostas corretas, desde o momento em que o participante responde efetivamente até o fim da condição. Deste modo, o que está sendo chamado de "durante a discriminação" diz respeito a uma seqüência ininterrupta de respostas corretas até o fim da condição. Na Tabela 2 a seguir, é possível conferir os tempos de cada momento, bem como o número de tentativas (respostas) e a duração média das tentativas (latência média)

Deste modo, a Figura 7 apresenta a distribuição da duração do olhar dos três participantes ao longo de oito momentos. As barras inteiras representam a porcentagem da duração do olhar para cada uma das três partes da imagem ao longo destes oito momentos. No tempo em que estão divididos os momentos, deve-se incluir um conjunto de outras relações comportamentais como, por exemplo, piscar, olhar para outras regiões que não as imagens etc. Assim, a distribuição apresentada apesar de não apontar esse conjunto, reserva a proporção de seu tempo gasto.

As barras estão divididas em duas cores, preta e cinza. Elas poderiam ser divididas de dois modos: por imagem ou por posição, pois ambas completariam as barras do mesmo modo, ou seja, as barras inteiras indicariam a mesma porcentagem de duração. Como as imagens são apresentadas nas diferentes posições aleatoriamente, a divisão por imagem possibilitaria obter um registro da distribuição para cada imagem independentemente da posição em que fossem apresentadas. Porém, isto seria relevante apenas durante a discriminação nas condições experimentais, pois apenas neste momento as imagens estão diferenciadas. Optou-se, então, realizar a divisão por posição. 
Tabela 2. Número de respostas (tentativas), duração das fases e condições experimentais, antes e durante a discriminação, e a duração média de cada tentativa (latência média) dos três participantes.

\begin{tabular}{|c|c|c|c|c|c|c|c|c|c|c|}
\hline \multirow[b]{2}{*}{ Fase/Cond } & \multirow[b]{2}{*}{ Discriminação } & \multicolumn{3}{|c|}{ P1 } & \multicolumn{3}{|c|}{ P2 } & \multicolumn{3}{|c|}{ P3 } \\
\hline & & רo de resp. & Duração & média & no de resp & Duração & média & no de resp & Duração & média \\
\hline PRE & & 10 & $50,59 \mathrm{~s}$ & $5,059 \mathrm{~s}$ & 10 & $110,5 \mathrm{~s}$ & $11,05 \mathrm{~s}$ & 10 & $120 \mathrm{~s}$ & $12 \mathrm{~s}$ \\
\hline \multirow{2}{*}{ COND 1} & antes & 180 & $387,35 \mathrm{~s}$ & $2,15 \mathrm{~s}$ & 8 & $88,59 \mathrm{~s}$ & $11,07 \mathrm{~s}$ & 20 & $185 \mathrm{~s}$ & $9,25 \mathrm{~s}$ \\
\hline & durante & 20 & $31,33 \mathrm{~s}$ & $1,56 \mathrm{~s}$ & 32 & $134,11 \mathrm{~s}$ & $4,19 \mathrm{~s}$ & 20 & $42,08 \mathrm{~s}$ & $2,10 \mathrm{~s}$ \\
\hline \multirow{2}{*}{ COND2 } & antes & 7 & $56,36 \mathrm{~s}$ & $8,05 \mathrm{~s}$ & 2 & $7,14 \mathrm{~s}$ & $3,57 \mathrm{~s}$ & 0 & $84 \mathrm{~s}$ & $84 \mathrm{~s}$ \\
\hline & durante & 33 & $54 \mathrm{~s}$ & $1,63 \mathrm{~s}$ & 38 & $62,76 \mathrm{~s}$ & $1,65 \mathrm{~s}$ & 20 & $41,18 \mathrm{~s}$ & $2,05 \mathrm{~s}$ \\
\hline \multirow{2}{*}{ COND3 } & antes & 14 & $229 \mathrm{~s}$ & $16,35 \mathrm{~s}$ & 7 & $108,8 \mathrm{~s}$ & $15,54 \mathrm{~s}$ & 1 & $57 \mathrm{~s}$ & $57 \mathrm{~s}$ \\
\hline & durante & 26 & $50,65 \mathrm{~s}$ & $1,94 \mathrm{~s}$ & 33 & $52,08 \mathrm{~s}$ & $1,57 \mathrm{~s}$ & 39 & $87,27 \mathrm{~s}$ & $2,23 \mathrm{~s}$ \\
\hline POS & & 10 & $178 \mathrm{~s}$ & $17,8 \mathrm{~s}$ & 10 & $139,4 \mathrm{~s}$ & $13,94 \mathrm{~s}$ & 0 & $182,27 \mathrm{~s}$ & $82,27 \mathrm{~s}$ \\
\hline
\end{tabular}


Um primeiro padrão observado na duração do olhar para os três participantes (Figura 7) foi que, na Fase PRE, todos olham a) por mais tempo para o Dom Quixote, b) por um tempo intermediário para o Sancho Pança e c) por menos tempo para o Sol. Além disso, os participantes olham por mais tempo o Dom Quixote da Posição 1 (esquerda) do que da Posição 2 (direita) e olham por mais tempo para o Sancho Pança da Posição 2 do que da Posição 1. O olhar para o Sol é distribuído proporcionalmente entre os Participantes 1 e 3, mas o Participante 4 olha por mais tempo para o Sol da Posição 2 do que da Posição 1. Estes padrões se repetem, com pequenas alterações nas porcentagens, para os Participantes 1 e 3 ao longo das condições experimentais antes da discriminação. O Participante 2 não apresenta esse padrão na Condição 2 antes da discriminação. Todos os participantes (re)apresentam aquele padrão na última fase.

Sobre as condições experimentais, durante a discriminação, o que pode ser observado, de modo geral, é que a duração de olhar para as partes das imagens que possuem a propriedade relevante para a discriminação é elevada enquanto a duração de olhar para outras partes diminui. Os Participantes 1 e 3 mantêm, sistematicamente, esse padrão. O Participante 2 o estabelece apenas a partir da Condição 2.

Os seguintes dados valem ser destacados: os Participantes 1 e 3, nas Condições 1 e 2, além de diminuírem a duração do olhar para o Dom Quixote, olham apenas o Dom Quixote da esquerda. Estes participantes, na Condição 1, durante a discriminação, além de diminuírem a duração do olhar para o Sancho, também olham apenas para o Sancho da direita. Para o Participante 2, nesta mesma Condição, a duração de olhar para o Sol se concentra praticamente apenas no Sol da direita. 


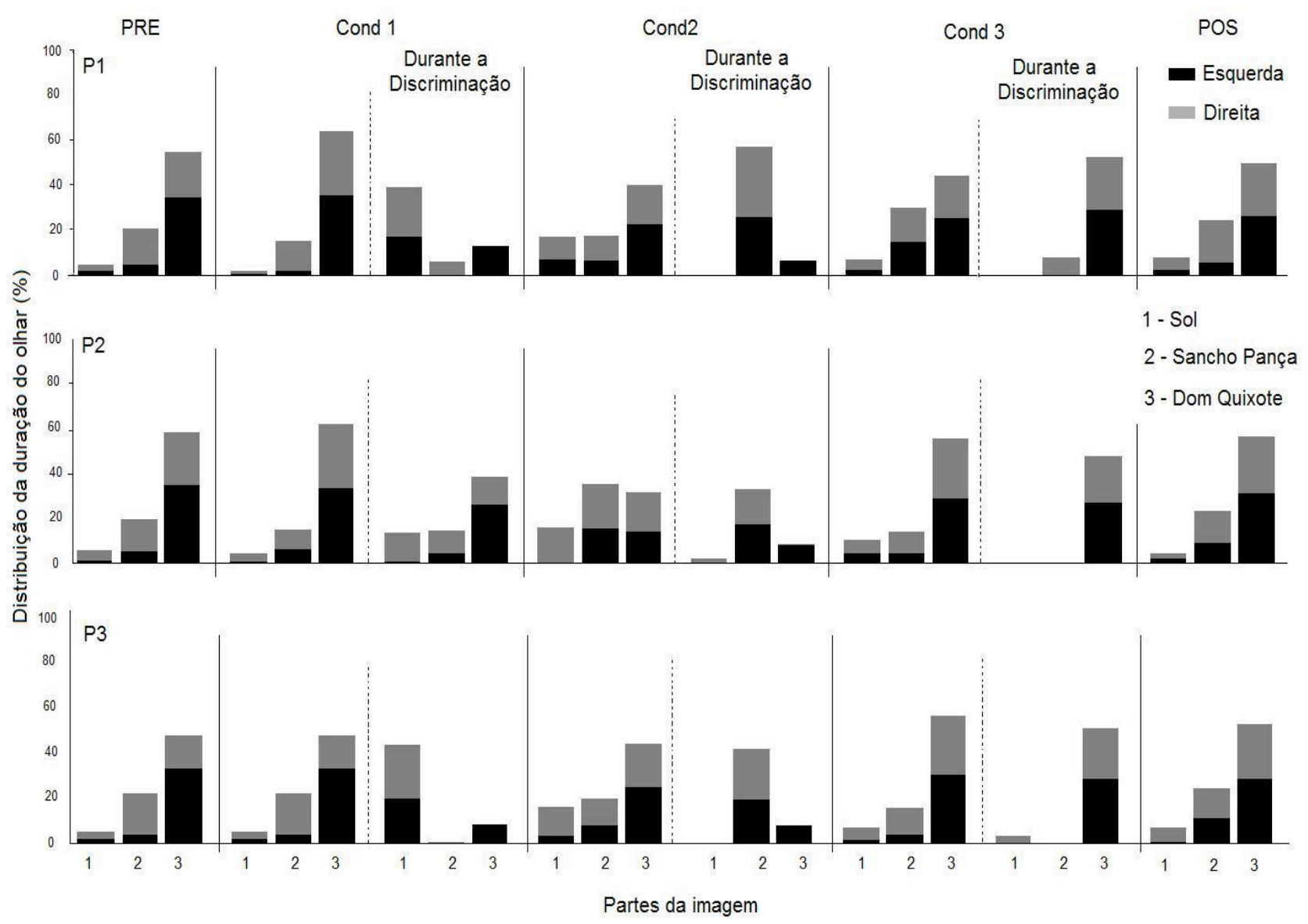

Figura 7. Distribuição do olhar dos Participantes 1, 2 e 3 para as partes da imagem: Sol, Sancho Pança e Dom Quixote ao longo da Fase PRE, das Condições Experimentais, antes e durante a discriminação e da Fase POS. As barras inteiras indicam o total da distribuição da duração do olhar para as partes, independentemente de qual imagem ou posição; e a divisão em cores, cinza e preta, indica qual parte, se da esquerda ou da direita. 
O Participante 2 apresenta dados dissonantes com os outros participantes nas Condições 1 (durante a discriminação) e 2 (antes da discriminação), porém, na Condição 3, estabelece padrão semelhante. Ainda na Condição 3, durante a discriminação, este participante apresenta um desempenho único, pois ele simplesmente não olha para nenhuma outra parte da imagem durante toda discriminação. Para os detalhes das porcentagens dos três participantes, ver Anexo 2.

Para evidenciar os efeitos das contingências sobre o estabelecimento de cada uma das três discriminações sucessivas na Fase Experimental, os dados da Figura 7 foram transformados. Na Figura 8, observa-se a razão entre a duração do olhar em cada fase e condição pela duração correspondente na linha de base. Em outras palavras, os pontos mostrados na Figura 8 foram obtidos dividindo os valores proporcionais da duração do olhar para as partes da imagem nas Condições 1, 2 e 3 e Fase POS pelos valores da Fase PRE. Sendo assim, a Fase PRE apresenta todos os seus valores fixados em 1 e, nas demais fases, o resultado dessa razão revela o índice multiplicador da duração a cada elemento discriminativo da imagem. Deste modo, resultados entre 0 e 1 atestam queda na duração. Resultados iguais a 1 mostram a manutenção na duração. Finalmente, resultados acima de 1 indicam aumento na duração em relação à Fase PRE. Por meio desta figura, é possível observar em quantas vezes a duração do olhar para o Sol, para o Sancho ou para o Dom Quixote, aumentou ou diminuiu ao longo das Fases. 


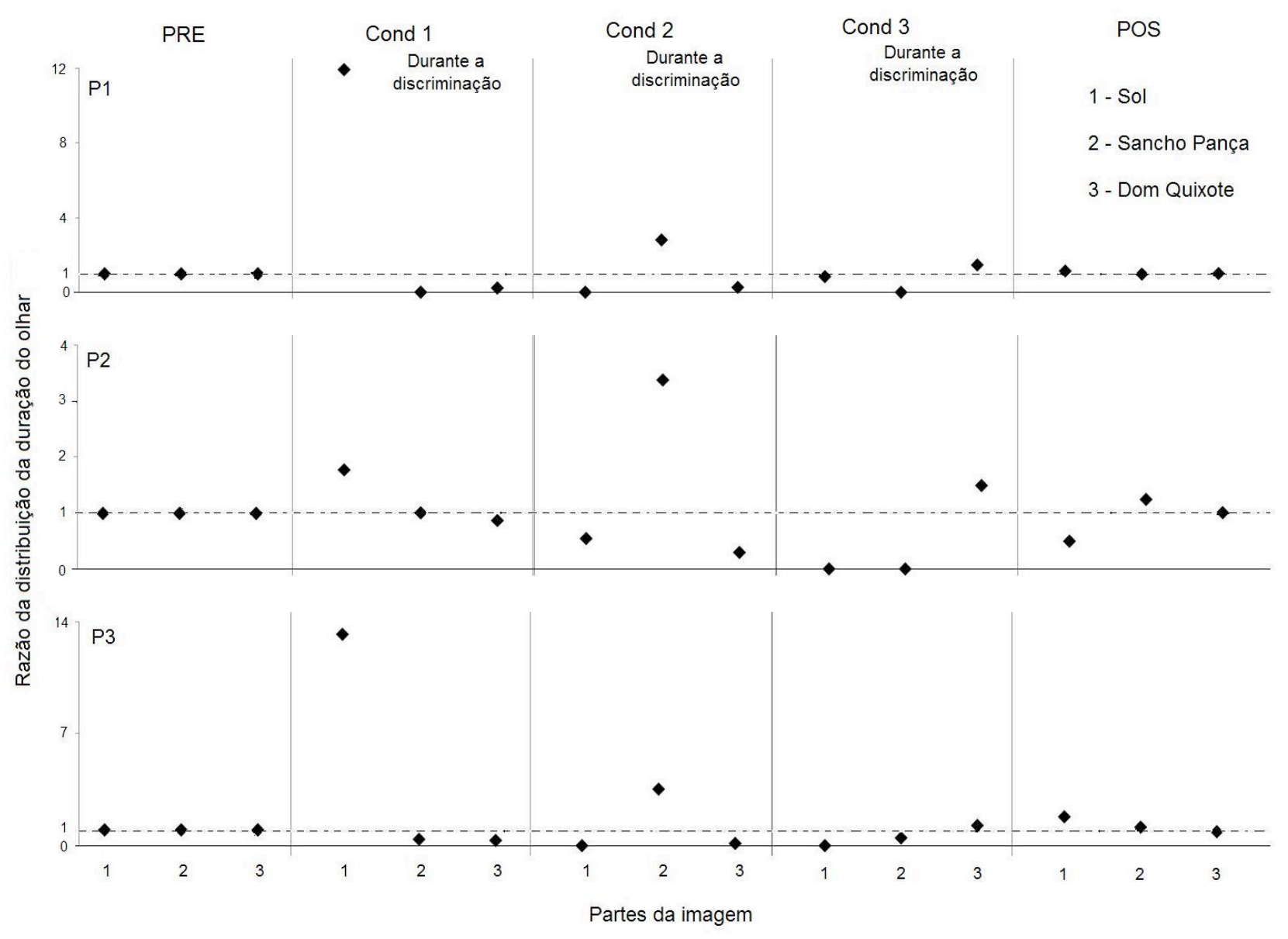

Figura 8. Razão da distribuição proporcional da duração do olhar entre as Condições 1, 2 e 3, durante a discriminação, a Fase POS e a Fase PRE. Os pontos pretos indicam o resultado da divisão entre as Condições e Fase POS e a Fase PRE. A linha horizontal tracejada indica o valor 1, onde são apresentados os pontos da Fase PRE e auxiliam na visualização do resultado da razão nas condições e Fase POS. 
Na Figura 8, os dados sobre as partes da imagem desconsideram diferenças entre posição ou imagem. Como a duração absoluta de cada fase foi bem distinta e, conseqüentemente, a duração absoluta de olhar para as partes, os dados apresentados têm como base a porcentagem da duração do olhar nas Fases PRE e POS e nas Condições Experimentais, durante a discriminação. Porém, para estes dados, foi excluída a duração de outras relações comportamentais. Nesse caso, foi analisada apenas a duração de olhar para as partes, o que totalizava, então, $100 \%$.

Nas Condições 1, 2 e 3, todos os participantes apresentam uma razão superior a 1 apenas para as partes correspondente a cada condição.

Para os Participantes 1 e 3, as razões são mais elevadas para o Sol, na Condição 1; uma razão intermediária para o Sancho, na Condição 2; e uma razão menor para o Dom Quixote, na Condição 3, sistematicamente. Para o Participante 2, a razão para o Sancho é a mais elevada; intermediária para o Sol; e menor para o Dom Quixote.

Para o Participante 1, o resultado da razão entre a duração proporcional de olhar para o Sol, na Condição 1, e sua duração na Fase PRE foi de 11,9. O resultado na Condição 2 (olhar para o Sancho nesta Condição em relação à Fase PRE) foi de 2,8 e, na Condição 3 (Dom Quixote), foi de 1,4. Para o Participante 2, estas mesmas razões, na Condição 1, foi de 1,8; na Condição 2, de 3,5; e, na Condição 3, de 1,3. Para o Participante 3, na Condição 1, foi de13,23; na Condição 2, de 3,5; e, na Condição 3, de 1,2.

Observa-se que isto não indica uma queda ou aumento na duração de olhar para estas partes ao longo das fases, em uma comparação entre elas. Os Participantes 1 e 3, por exemplo, não foram deixando de olhar as partes ao longo das Fases por apresentar, segundo verifica-se na Figura 8, uma linha decrescente entre elas. Neste sentido, a Figura 8 apenas indica queda ou aumento na duração de olhar para cada parte em relação à Fase PRE. 
$\mathrm{Na}$ Condição 1, é possível observar que, para todos os participantes, apenas o ponto que indica a razão da duração do olhar para o Sol está acima de 1 (um), indicando aumento proporcional (em relação a Fase PRE) em sua duração. Para os Participantes 1 e 3, as demais razões estão abaixo de 1 (um) indicando queda na duração do olhar para as outras partes. Para o Participante 2, apenas a razão que indica a duração do olhar para o Sancho Pança está fixado em 1 (um), indicando manutenção da duração do olhar para esta parte e queda para o Dom Quixote.

Nas Condições 2 e 3, para todos os participantes, todas as razões exceto para o Sancho Pança e Dom Quixote, respectivamente, estão abaixo de 1 (um), indicando queda na duração de olhar para outras partes..

Na última Fase, os Participantes 1 e 3 têm seus dados fixados muito próximos de 1(um), com um pequeno acréscimo na duração do olhar para o Sol. Isto indica um retorno à duração proporcional apresentada na Fase PRE. O Participante 2 apresenta uma queda na duração do olhar para o Sol, um aumento para o Sancho Pança, e um retorno exato à duração do olhar para o Dom Quixote apresentado na Fase PRE.

A Figura 9 busca analisar os movimentos dos olhos com relação às funções discriminativas positivas (S+) e negativas (S-) dos estímulos S1, S2 e S3. No decorrer das condições experimentais, como se distribuiriam os movimentos dos olhos a cada um dos estímulos discriminativos? Para essa figura, levam-se em consideração as Imagens 1 e 2, não importando a posição em que foram apresentadas. O S1 foi definido como o lugar da falha no Sol e correspondente à Condição 1 . Neste caso, o $\mathrm{S}+$ seria este lugar com a falha (da Imagem 1) e o S- este lugar, mas sem a falha (da Imagem 2). Do mesmo modo, S2 pescoço, na Condição 2; e S3 - mão, na Condição 3. 


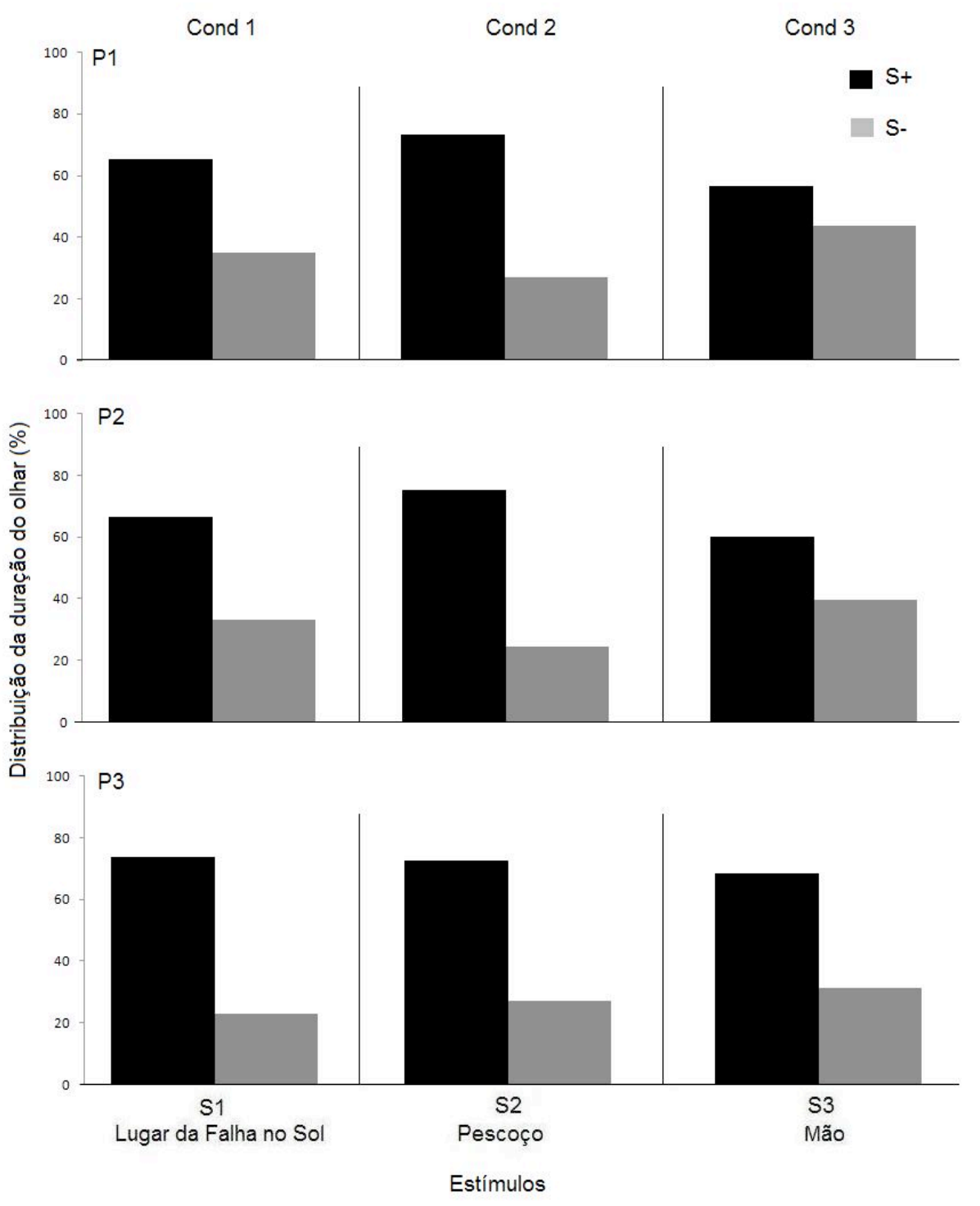

Figura 9. Distribuição da duração da observação para o $\mathrm{S}+$ e o $\mathrm{S}-$. Os pares das três colunas indicam o S1 - lugar da falha no Sol, S2 - pescoço e S3 - mão, respectivamente. A barra preta indica a função $\mathrm{S}+\mathrm{e}$ a barra cinza indica a função $\mathrm{S}-$. 
Na organização dos dados apresentados na Figura 9, também se teve o cuidado de excluir a duração dos outros eventos comportamentais e de obter apenas a duração do olhar para os estímulos, totalizando, assim, 100\%. Com isso, foi possível observar uma diferença específica entre a duração da observação do S+ e o S-.

A questão central observada na Figura 9 é a apresentação de um dado sistemático em todas as condições e para todos os participantes. Todos apresentam uma duração de observação maior para o $\mathrm{S}+$ do que para o $\mathrm{S}-$. Dados sobre as porcentagens, ver Anexo 3.

Considerando o fato de que o tempo de observação dos estímulos discriminativos foi claramente seletivo, é possível que a discriminação estabelecida em uma condição experimental tenha afetado o estabelecimento da discriminação seguinte. De que modo uma discriminação pode ter afetado as subseqüentes?

A Figura 10 apresenta os dados da duração das respostas de observação, por blocos de tempo, dos três participantes no momento de mudança da Condição 1 para a Condição 2 e no momento de mudança da Condição 2 para a Condição 3.

A primeira coluna da Figura 10 apresenta a duração da $\mathrm{Ro}^{1}$ - olhar para o lugar da falha no Sol, nos últimos cinco segundos da Condição 1 (demarcada pela linha tracejada comum a todos os participantes) e sua continuidade em oito blocos de cinco segundos da Condição 2. Na segunda coluna, é apresentada a duração da $\mathrm{Ro}^{2}$ - olhar para o pescoço, nos últimos cinco segundos da Condição 2 e sua continuidade em oito blocos de cinco segundos da Condição 3.

Por esta configuração, ou seja, pela análise da duração absoluta das respostas de observação em blocos de cinco segundos, não foi possível demonstrar efeito da apresentação dos estímulos (dois sóis abertos ou fechados ou dois pescoços abertos ou fechados) na condição posterior à sua discriminação. 


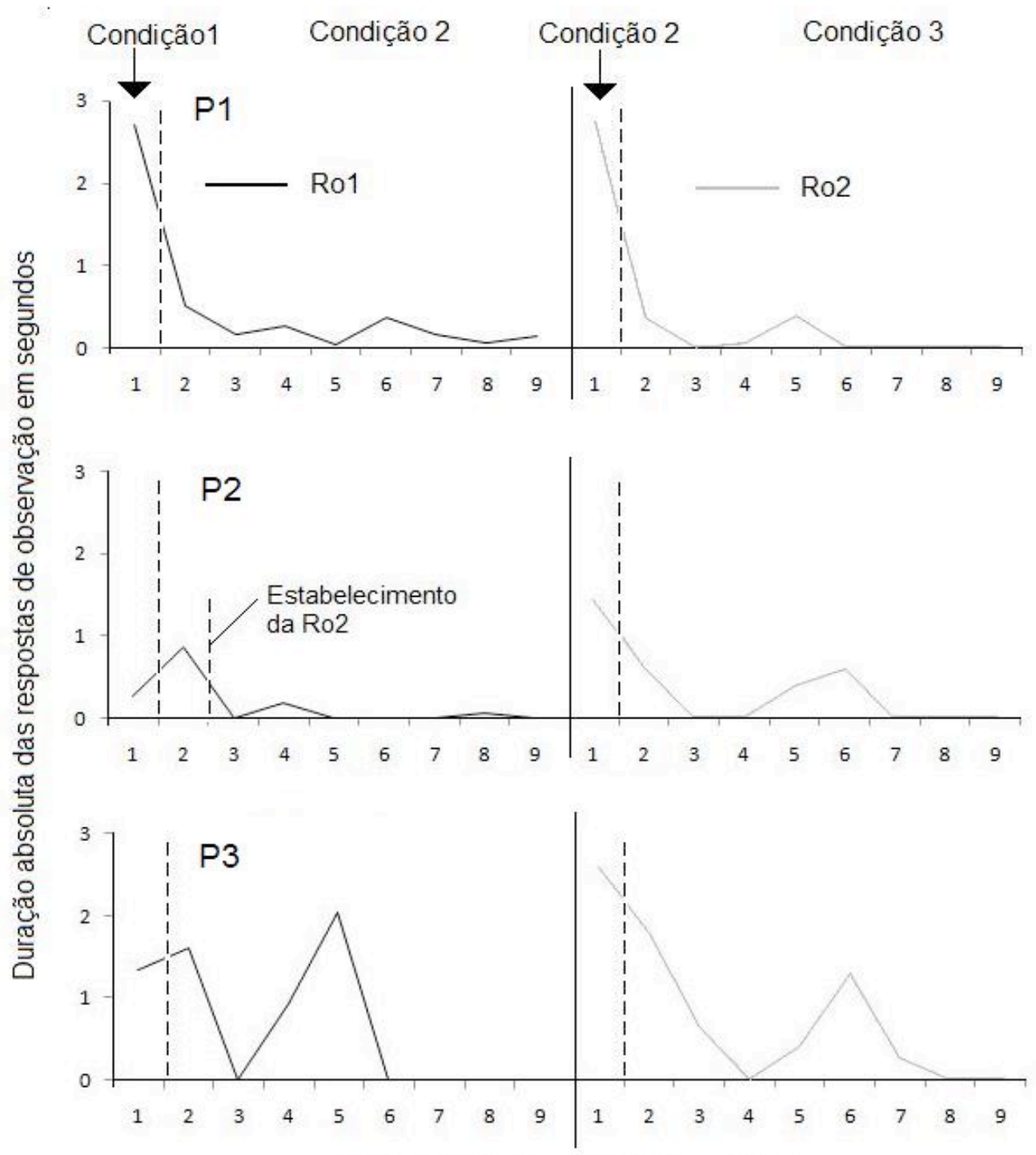

Blocos de cinco segundos em média

Figura 10. Duração absoluta das respostas de observação por blocos de cinco segundos em média para os três participantes na mudança da Condição 1 para a Condição 2 e na mudança da Condição 2 para a Condição 3. A linha preta indica a $\operatorname{Ro}^{1}$ e a linha cinza indica $\mathrm{Ro}^{2}$. 
Sobre a primeira coluna, da duração de $\mathrm{Ro}^{1}$, os Participantes 2 e 3 apresentaram ainda um acréscimo em sua duração no primeiro bloco da Condição 2. Após esse acréscimo, ambos apresentam uma queda em sua duração. Para Participante 3, após a queda, a duração ainda apresenta uma elevação que supera os últimos segundos da condição anterior. Para o Participante 2, a $\mathrm{Ro}^{1}$ se mantém com uma duração baixa, oscilando bem pouco até alcançar um número próximo de zero. Porém, este participante levou 7,14 s para encontrar a falha no pescoço (Nota-se que o Participante 2 tem duas linhas tracejadas). Sendo assim, outra resposta estava sendo selecionada, a $\mathrm{Ro}^{2}$. O Participante 1 apresenta uma queda na duração da $\mathrm{Ro}^{1}$ com poucas oscilações até chegar em números perto de zero.

Sobre a segunda coluna, da duração de $\mathrm{Ro}^{2}$, todos os participantes apresentam uma queda imediata à mudança de Fase com uma oscilação e queda absoluta (zero) até o fim dos blocos.

A partir da Figura 10, em que não foi possível, a partir de blocos de tempo, observar diferenças na duração das respostas de observação $\left(\operatorname{Ro}^{1}, \mathrm{Ro}^{2}\right.$ e $\left.\mathrm{Ro}^{3}\right)$ em efeito às diferenças apresentadas, pensou-se em analisar toda a história dessas respostas em blocos de tempo. A Figura 11 apresenta a distribuição da duração absoluta das repostas de observação ao longo de todas as fases e condições. O Eixo X indica blocos de tempos e foi diferente para cada participante, pois foi preciso encontrar um divisor comum entre as fases e condições. Nesse caso, para o Participante 1, foi encontrado o valor 28 e possibilitou a divisão de toda a sessão em 37 blocos. Para o Participante 2, foi encontrado o valor 25 e possibilitou 28 blocos. Para o Participante 3, foi encontrado o valor 20 e possibilitou 39 blocos. O critério utilizado para as linhas verticais que aparecem ao longo da figura foi o fim de uma fase ou condição e o início da outra. As linhas coloridas na figura indicam a duração das respostas de observação. A cor verde indica a duração de Ro ${ }^{1}$ 


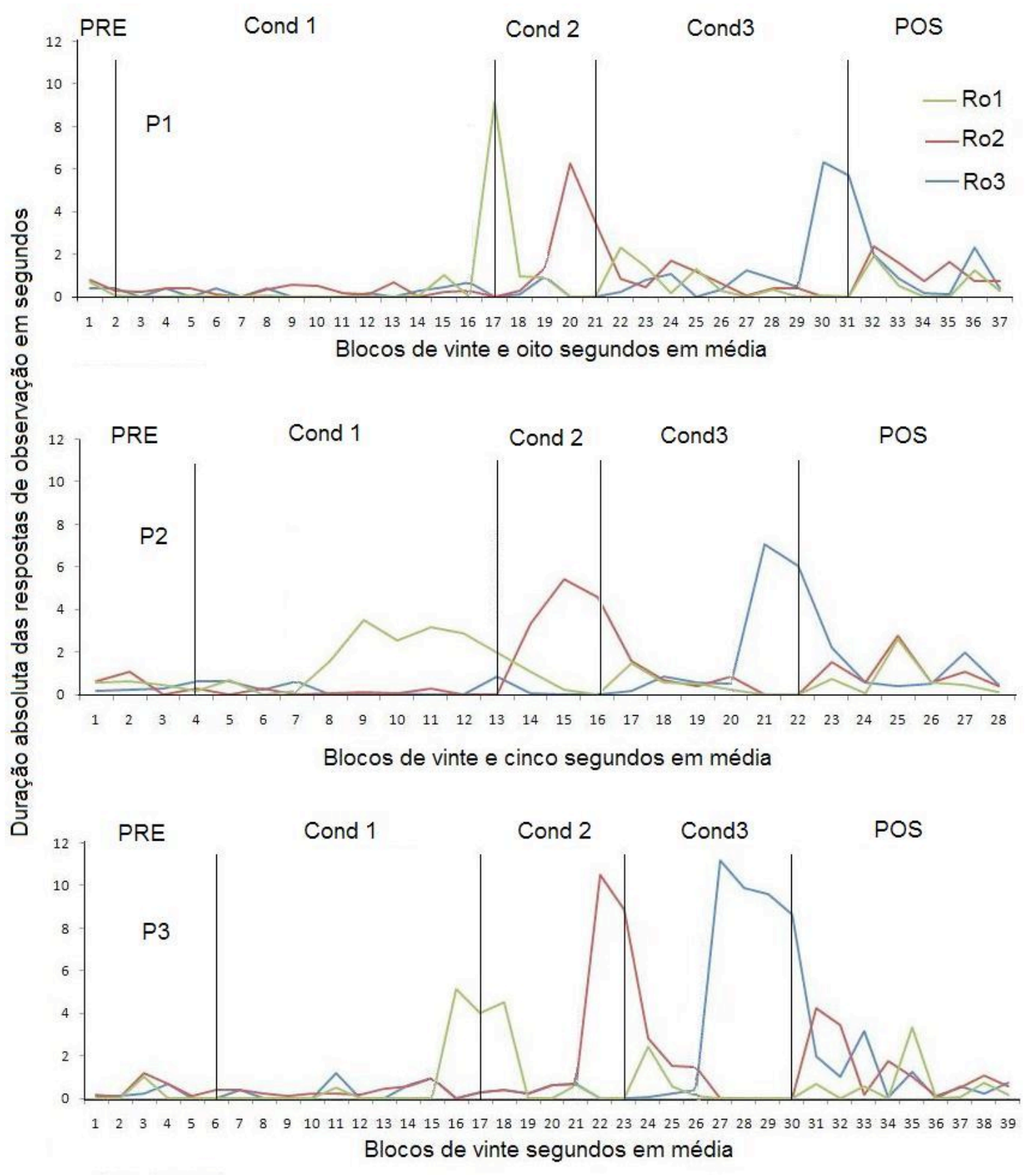

Figura 11. Distribuição da duração das respostas de observação por blocos de tempo do três participantes ao longo das fases e condições experimentais. 
- S1, a cor vermelha indica a de $\mathrm{Ro}^{2}-\mathrm{S} 2$ e a cor azul indica a de $\mathrm{Ro}^{3}-\mathrm{S} 3$.

Não foi possível, segundo dados apresentados por esta figura, definir com precisão a relação entre uma seqüência ininterrupta de respostas que produziam som leve e o momento em que a duração das respostas de observação aumentou, configurando assim, o que estamos chamando de "durante a discriminação". Esta impossibilidade se deu por alguns motivos. Pelo fato de o participante acertar duas ou três tentativas de um bloco (ao acaso), porém apenas encontrar a falha na terceira ou quarta tentativa e emitir todas as respostas seguintes corretamente. Mas, sobretudo, pelo fato de o exato momento do começo da seqüência não poder ser exemplificado com exatidão em um bloco de $20 \mathrm{~s}, 25 \mathrm{~s}$ e 28 s. Por conta destas questões, não haverá uma linha tracejada marcando os momentos "antes da discriminação" e "durante a discriminação". Porém, pela análise dos dados e dos tempos, é possível afirmar com segurança que o bloco 17 do Participante 1, os blocos 8, 9,10, 11, 12 e 13, para o Participante 2, e os blocos 16 e 17 para o Participante 3, estão inseridos no tempo que, nas figuras anteriores, se convencionou chamar de "durante a discriminação".

Na Fase PRE, todos os participantes apresentam a duração das três respostas de observação variando entre 0 e 1,03 s. Este padrão na duração se mantém, para todos os participantes, no início da Condição 1.

Na Condição 1, para todos os participantes, a duração da Ro ${ }^{1}$ aumenta a partir de um determinado bloco da condição, indicando a seleção desta resposta. Para o Participante 1, no Bloco 17, a duração da resposta de observação $\left(\operatorname{Ro}^{1}\right)$ aumenta para 9,14 s. Para este participante, observa-se apenas um aumento, pois a duração aumentou apenas em um e último bloco.

Para o Participante 2, a duração da $\mathrm{Ro}^{1}$, a partir do Bloco 8, aumenta para 1,59 s e mantém distintos valores nos blocos subseqüentes. 
Para o Participante 3, a duração da $\operatorname{Ro}^{1}$, a partir do Bloco 16, aumenta para 5,17 s e apresenta, então, uma leve queda para 4,04 s.

Na Condição 2, como já pôde ser observado na Figura 10, houve uma queda da Ro $^{1}$ para todos os participantes. No final da Condição, a duração da Ro ${ }^{2}$ apresenta um aumento.

No começo da Condição 3, foi possível observar que há um aumento na duração da $\operatorname{Ro}^{1}$ para todos os participantes. Para o Participante 1 , a duração da $\operatorname{Ro}^{1}$ passa de $\underline{0 \mathrm{~s}}$, na condição anterior, para $\underline{2,3 \mathrm{~s}}$ no primeiro bloco. Para o Participante 2 , a duração passa de $\underline{0}$ $\underline{\mathrm{s}}$, na condição anterior, para $\underline{1,44 \mathrm{~s}}$ no primeiro bloco. Para o Participante 3 , a duração passa de $\underline{0 \mathrm{~s}}$, na condição anterior, para $\underline{2,43 \mathrm{~s}}$ no primeiro bloco.

No final da Condição 3, há um aumento na duração da $\mathrm{Ro}^{3}$, o que coincidiu com o estabelecimento de um responder discriminado.

No final da Condição 3, a duração da $\mathrm{Ro}^{1}$, para todos os participantes já se encontra em 0 (zero). Porém, no início da Fase POS, a duração da Ro ${ }^{1}$ volta a aumentar. Para o Participante 1, a duração passa de $\underline{0 \mathrm{~s}}$, na Condição anterior, para $\underline{1,93 \mathrm{~s}}$ no primeiro bloco e, então, 0,51 s, 0s , 0 s, 1,22 s e 0,31 s nos blocos consecutivos. Para o Participante 2, a duração passa de $\underline{0 \mathrm{~s}}$, na condição anterior, para $0,73 \mathrm{~s}$ no primeiro bloco e, então, 0,07 s, $2,57 \mathrm{~s}, 0,57 \mathrm{~s}, 0,44 \mathrm{~s}$ e $0,1 \mathrm{~s}$ nos blocos consecutivos. Para o Participante 3 , a duração passa $\underline{0 \mathrm{~s}}$, na Condição anterior, para $0,7 \mathrm{~s}, 0 \mathrm{~s}, 0,57 \mathrm{~s}, 0 \mathrm{~s}, \underline{3,38 \mathrm{~s}}, 0,07 \mathrm{~s}$ nos blocos consecutivos.

Outro aumento na duração que pôde ser observado foi o da $\operatorname{Ro}^{2}$. Para o Participante 1 , a duração passa de $\underline{0 \mathrm{~s}}$, na condição anterior para $\underline{2,39 \mathrm{~s}}$ no primeiro bloco. Para o Participante 2, a duração passa de $\underline{0 \mathrm{~s}}$, na condição anterior, para $\underline{1,53 \mathrm{~s}}$ no primeiro bloco. Para o Participante 3, a duração passa de $\underline{0 \mathrm{~s}}$, na condição anterior, para $\underline{4,23 \mathrm{~s}}$.

Para uma discussão posterior sobre a extinção da $\mathrm{Ro}^{1}$ e da $\mathrm{Ro}^{2}$, os dados a seguir 
são importantes.

A média da duração de $\mathrm{Ro}^{1}$, na Fase PRE foi de $\underline{0,36 \mathrm{~s}}, \underline{0,45 \mathrm{~s}}$ e $\underline{0,2 \mathrm{~s}}$ para os Participantes 1, 2 e 3, respectivamente. O maior valor da duração de $\operatorname{Ro}^{1}$ na Fase PRE foi de 0,69 s, 0, 58 s, 1,03 s para os Participantes 1, 2 e 3, respectivamente

A média da duração da $\operatorname{Ro}^{1}$ nos últimos dois blocos da Condição 2 foi de $0,0 \mathrm{~s}$, $0,12 \mathrm{~s}, 0,0 \mathrm{~s}$ para os Participantes 1,2 e 3, respectivamente. E o maior valor da duração de Ro $^{1}$ nos últimos dois blocos da Condição 2 foi de $0,0 \mathrm{~s}, 0,24 \mathrm{~s}$ e $0,0 \mathrm{~s}$ para os Participantes 1,2 e 3 , respectivamente.

A média da duração de $\operatorname{Ro}^{2}$ na Fase PRE foi de $\underline{0,35 \mathrm{~s}}, \underline{0,24 \mathrm{~s}}$ e $\underline{0,36 \mathrm{~s}}$ para os três participantes, respectivamente. O maior valor apresentado da duração de $\mathrm{Ro}^{2}$ foi de $0,77 \mathrm{~s}$, $1,09 \mathrm{~s}, 1,2 \mathrm{~s}$.

A média da duração de $\mathrm{Ro}^{2}$ dos últimos dois blocos da Condição 3 foi $0,0 \mathrm{~s}, 0,0 \mathrm{~s}$ e 0,0 s para os participantes 1,2 e 3 . O maior valor apresentado da duração de $\operatorname{Ro}^{2}$ nos últimos dois blocos da Condição 3 foi de $0,0 \mathrm{~s}$ para todos os participantes.

Apesar da descrição exaustiva dos valores apresentados sobre a duração de $\operatorname{Ro}^{1} \mathrm{e}$ $\mathrm{Ro}^{2}$, os valores sublinhados e sua localização nos diferentes blocos serão de grande importante para uma discussão posterior. Um padrão observado a partir destes valores é que a duração de $\mathrm{Ro}^{1}$ apresenta valores mais altos no primeiro bloco da Condição 3 do que no primeiro bloco da Fase POS. Outro padrão observado é que na Fase POS, no primeiro bloco, a duração de $\mathrm{Ro}^{2}$ apresenta valores mais altos do que a de $\mathrm{Ro}^{1}$.

A partir do fato, apresentado na Figura 11, de haver ocorrências da duração de Ro $^{1}$ na Condição 3 e de $\operatorname{Ro}^{1} \operatorname{Ro}^{2}$ na Fase POS, procurou-se identificar, por meio de um fluxo contínuo, os 50 primeiros eventos comportamentais emitidos pelos Participantes nesta fase.

A Figura 12 apresenta a ocorrência de olhar para S1, S2, S3 e para outras regiões 
(incluindo, outras partes das imagens e fora da imagem) dos três participantes. Uma ocorrência foi definida, como em Schroeder e Holland (1968), como a intrusão da reflexão da córnea em uma determinada área. Deste modo, não é levada em consideração, nesta figura, a duração destas ocorrências. Foram registrados, apenas, os lugares para onde o participante foi acomodando seus movimentos oculares em um contínuo de eventos.

No que se refere a S1, S2 e S3, um dado comum a todos os Participantes é que há, primeiramente, ocorrências de olhar para S3 nas diferentes imagens, que na condição anterior era a propriedade discriminativa e, logo em seguida, ocorrências de olhar para o S1. Os Participantes 1 e 2 apresentam 4 ocorrências de olhar para a mão, enquanto o Participante 2 apresenta 3 ocorrências. Todos os participantes registram ocorrências de olhar, primeiramente, para S1. 

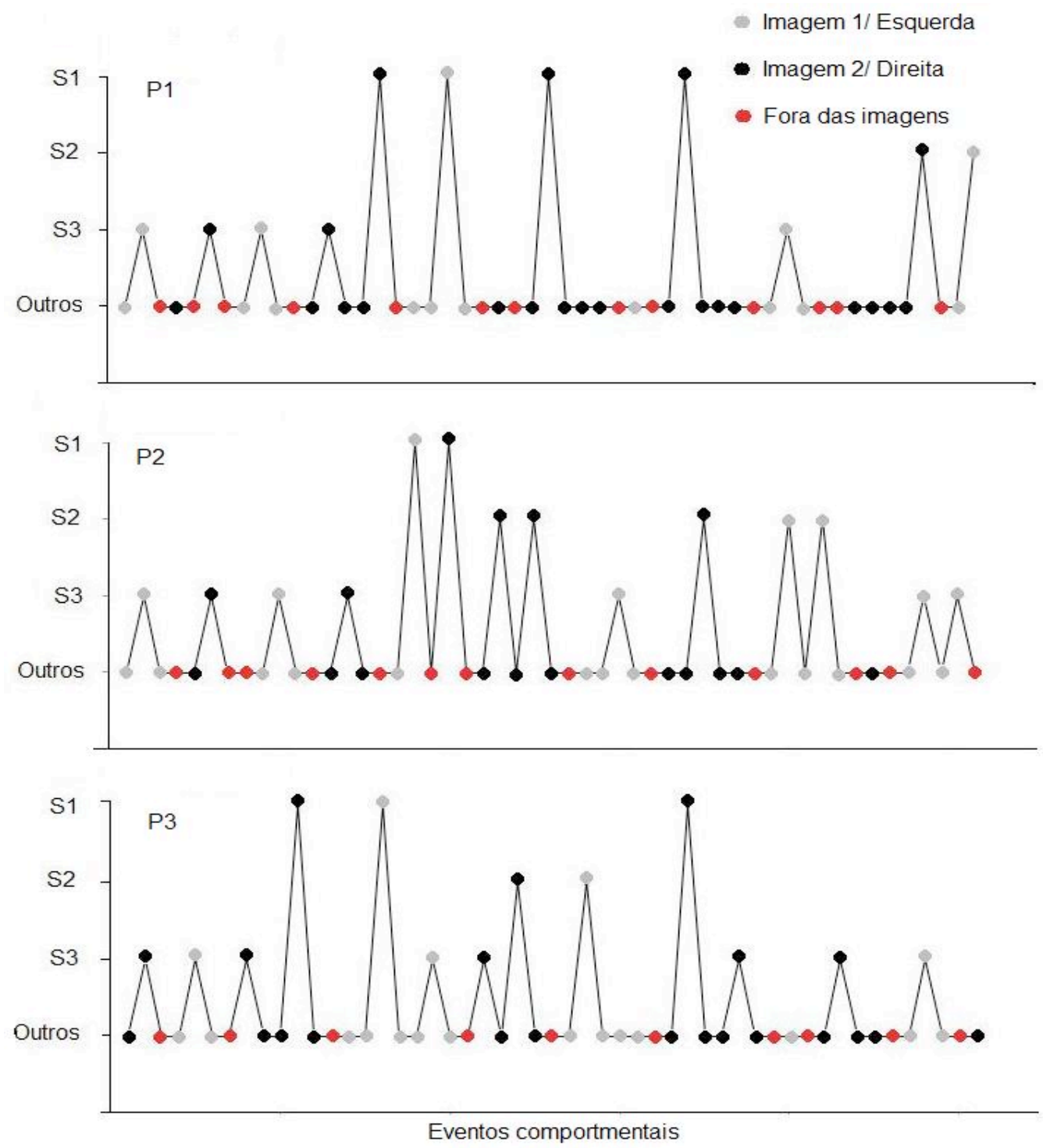

Figura 12. Ocorrência de olhar para S1, S2, S3 e para outras regiões (incluindo, outras partes das imagens e fora da imagem) dos três Participantes. Como a seqüência dos eventos comportamentais apresentada ocorreram em uma única tentativa, os pontos cinzas indicam que a ocorrência de olhar para um dos lugares apresentados no eixo y se encontra na Imagem 1/esquerda, os pontos pretos, na imagem 2/direita e os pontos vermelhos, fora das imagens. 


\section{DISCUSSÃO}

Como chamam a atenção Skinner (1938, 1953), Dinsmoor (1985), Schroeder (1969a, 1969b, 1997), as características físicas dos estímulos, como eles são apresentados (simultânea ou sucessivamente), introduzidos (Schroeder, 1997) ou, mesmo, como no caso deste experimento, modificados de lugar imediatamente após critério de acerto, podem determinar o desempenho do participante em tarefas de discriminação simples.

A análise da resposta de observação, apresentada, em relevo neste trabalho, por meio do movimento dos olhos, pode fornecer indícios de variáveis e relações de controle envolvidas no estabelecimento da discriminação simples. Isto será analisado a partir do procedimento elaborado para a presente pesquisa.

Com o intuito de produzir uma transferência no controle de estímulos, ou o estabelecimento de novas discriminações, as três condições experimentais foram manipuladas de modo a apresentar duas imagens que compunham um conjunto complexo de características 'estáticas' (Dinsmoor, 1985) e propriedades discriminativas em três diferentes lugares nesse conjunto. Segundo Millenson (1967), "quando manipulamos ou mudamos aspectos limitados do meio e os correlacionamos com o comportamento, estamos manipulando essas unidades" (p. 186).

\section{Respostas manuais, aprendizado e discriminação}

Os resultados apresentados na Figura 6, sobre a freqüência acumulada de respostas manuais, atestam o estabelecimento da discriminação de diferentes formas para os três participantes e levantam, agora, algumas questões. 
Primeiramente, é possível afirmar que, a partir das instruções, do desempenho discriminado apresentado pelos participantes ao longo das três condições e da disposição imediata à resposta do 'som leve', este adquiriu a função de reforçador.

No desempenho apresentado pelos participantes ao longo das condições experimentais, é possível notar um aprendizado cumulativo, ou segundo Harlow (1949), um learning set, ou ainda, segundo Catânia (1998), uma transferência positiva. Estes termos, juntos aos resultados aqui relatados, dizem respeito ao fato de a aprendizagem, em sucessivas discriminações, apresentar as seguintes peculiaridades: a) uma redução no número de emissão de respostas incorretas (erros), ou, no caso desse experimento, de respostas ao acaso e b) uma redução no tempo em que o organismo cumpre critérios exigidos, ou no tempo em que o participante, no caso desse experimento, encontra a falha. Estes itens ( $\mathrm{a}$ e b) demonstram, então, o efeito de um aprendizado inicial em desempenhos subseqüentes, em situações que conservem relações similares (Catânia, 1998; Harlow, 1949).

Sobre o item a). Antes da discriminação, na Condição 1, o Participante 1 emite 180 respostas; na Condição 2, emite 7 respostas; e na Condição 3, emite 14 respostas. O Participante 2, na Condição 1, emite 8 respostas; na Condição 2, emite apenas 2 respostas; e na Condição 3, emite 7 respostas. O Participante 3, na Condição 1, emite 20 respostas; na Condição 2, não emite respostas; e na Condição 3, emite 1 resposta.

Sobre o item b). Antes da discriminação, o participante 1, na Condição 1 leva 387 s; na Condição 2 leva 56,36 s; e na seguinte, 229 s. O Participante 2, na Condição 1 leva 88,59 s; na seguinte, 7,14 s; e na próxima, 108 s. O Participante 3, na Condição 1 leva 185 s; na seguinte, 84 s; e na próxima, 57 s.

Segundo Keller e Schoenfeld (1950/1973), “o tempo necessário para se estabelecer uma discriminação dependerá do treino prévio” (pp. 135-136). Porém, o tempo 
que o participante levou para encontrar a falha e, assim, cumprir o critério estabelecido, pode estar mais relacionado às características físicas dos estímulos e à dificuldade de encontrar a falha.

Deste modo, entre as peculiaridades apresentadas, o item b) parece melhor demonstrar o efeito de um aprendizado inicial, no caso, a primeira emissão de um responder consistente (seqüência ininterrupta de respostas corretas) na Condição 1, durante a discriminação, no desempenho subseqüente. Em termos de redução no número de respostas, o participante, ao entrar na Condição 2, antes da discriminação, em que as propriedades discriminativas foram deslocadas, já se comporta diferentemente, e assim nas condições e fase seguintes. O participante, mesmo na ausência das propriedades discriminativas programadas (falhas), reconhece ${ }^{3}$ a situação por estar diante de relações similares. O número de respostas, durante a discriminação, variou a depender do momento que o participante encontrou a falha e deu iniciou a uma seqüência ininterrupta de respostas.

Uma possibilidade para equacionar o desempenho dos participantes seria elaborar uma análise estatística, envolvendo as variáveis tempo e número de respostas dos participantes ao longo das fases.

De outro modo, dados sobre o tempo que o participante levou para encerrar uma fase ou uma condição e sobre o tempo das latências médias (tempo entre a apresentação das imagens e a resposta de clicar) das respostas ao longo das fases podem auxiliar na compreensão dos desempenhos dos participantes após a Condição 2.

Sobre o tempo de duração das fases, os resultados dos Participantes 1 e 3, apresentados na Figura 6, chamaram atenção pela diferença apresentada na Fase PRE e POS. O Participante 1 emite 10 respostas em apenas 50,59 s na Fase PRE e leva 178 s para

${ }^{3}$ O termo reconhece, aqui, está sendo usado no interior da noção de conhecer em Skinner (1974/1993). Conhecer é comportamento, um modo de relação diferenciado e mais eficaz do organismo como um todo e o ambiente com o qual ele interage, em contingências de reforço. 
emitir 10 respostas na Fase POS. O Participante 3 leva 120 s para emitir 10 respostas na Fase PRE e nem sequer emite a resposta de clicar na Fase POS.

Sobre a latência das respostas, os dados dos Participantes 1 e 3 são representativos. Segundo Millenson (1967) e Keller e Schoenfeld (1950/1973), a latência das respostas, também chamada de tempo de reação discriminativo, é produto de um treino de reforçamento diferencial e do estabelecimento do controle pelos estímulos antecedentes. Michael (2000), afirma que variação na latência das respostas operantes define, entre outras coisas (freqüência, resistência à extinção etc), o estímulo discriminativo. $\mathrm{O}$ Participante 1, durante toda a Condição 1, antes da discriminação, emitiu 180 respostas com uma latência média de $1,43 \mathrm{~s}$; na Condição 2, antes da discriminação, emitiu 7 respostas com uma latência média de $7,1 \mathrm{~s}$; na Condição 3 , antes da discriminação, emitiu 14 respostas com latência média de 18,23 s; e na Fase POS, emitiu 10 respostas com uma latência média de 25,4 s.

Tendo em vista que a conseqüência era a mesma e estava disposta, enquanto resultado de respostas aos estímulos, aleatoriamente, o que teria controlado esta diferença (aumento) na latência das respostas dos participantes, ou mesmo, a ausência de resposta, como no caso do Participante 3 na Fase POS?

Segundo Terrace (1966) o controle de estímulo se refere à determinação da probabilidade das respostas pelo valor do estímulo antecedente. Se há discriminação, então, há controle de estímulos. O estímulo discriminativo, para este autor, indica ao organismo se uma conseqüência reforçadora seguirá ou não a emissão da resposta. Segundo Michael, (2000), o modo correto de se referir ao controle de estímulos e ao estímulo discriminativo é dizer que uma condição de estímulo torna-se um $\mathrm{S}^{\mathrm{d}}$ para uma resposta por conta de sua relação com o reforço. De qualquer modo, o condicionamento das respostas e o valor dos estímulos são conferidos, primeiramente, pela disposição de 
conseqüências reforçadoras.

A discriminação é definida, de modo geral, pela produção de um responder diferenciado do organismo a estímulos antecedentes específicos (Catânia, 1998; Fester, 1978; Fester, Culbertson \& Perrot, 1968/1977; Keller \& Schoenfeld, 1950/1973; Millenson, 1967; Reynolds, 1968; Skinner, 1938, 1953) e como ressalta Sério, Andery, Micheletto e Gioia (2005b),

o estabelecimento de controle de estímulos não precisa ficar restrito a um responder diferencial caracterizado pela ocorrência/não ocorrência da resposta, de acordo com o estímulo presente. Podemos colocar a freqüência e o padrão de resposta sob controle de estímulos, de forma que uma mesma resposta ocorrerá com freqüência e distribuição diferentes, dependendo do estímulo presente (Sério et al., 2005b, p. 30).

De determinada maneira, os participantes aprenderam a responder apenas em ocasiões específicas, ou seja, na presença de estímulos discriminativos. Outro aprendizado, que será mais bem discutido posteriormente, é o de procurar a falha, ou mais especificamente, procurar a diferença. À primeira vista, e que apenas precisa ficar claro neste momento, é o fato de que a resposta de procurar a diferença e de clicar nas imagens não eram, necessariamente, concorrentes, o que apóia o learning set ser admitido por meio do item $b$.

Segundo Millenson (1967), "em geral, os organismos emitem respostas seletivamente, de acordo com o estado de seus ambientes presentes, passados" (p.186). Segundo Keller e Schoenfeld (1950/1973), “um estímulo pode ser definido provisoriamente como uma parte, ou a modificação em uma parte, do meio" (p. 17) e ainda, segundo Catânia (1999, p. 22), esta parte do meio pode estar restrita a aspectos físicos e específicos, ou a propriedades funcionais ou, ainda, a relações, como por 
exemplo, maior, menor, igual, diferente etc.

De acordo com o que foi demonstrada na história experimental dos participantes, a probabilidade da emissão da resposta (clicar com o mouse) diminui (ausência de resposta, aumento na latência etc) na presença da relação "igualdade", ou seja, na Fase POS, em que duas imagens foram apresentadas idênticas e nas Condições 2 e 3, antes da discriminação; e a probabilidade aumenta na presença da relação "diferença" (entre alguma propriedade das imagens), ou seja, nas Condições 1,2 e 3, durante a discriminação. Isto pode ser claramente observado por meio do desempenho do Participante 3. Dessa maneira, é possível afirmar que a relação "diferença" adquiriu a função de S+ e a relação "igualdade" adquiriu a função de S- para a resposta de clicar? Segundo Millenson (1967), o “estímulo é uma unidade arbitrária" (p. 186), assim, além de poder ser analisado de diferentes modos, pode ter extrapolado as funções programadas pelo experimentador, pois se de fato a “igualdade" e a "diferença" adquiriram funções daquela natureza, a situação experimental pode ter colocado o participante, também, em contato com uma discriminação sucessiva, pois ambas ("igualdade" e "diferença") foram apresentadas deste modo.

Esta unidade arbitrária (o estímulo, a “igualdade", a “diferença”) será mais bem analisada junto à análise da discriminação simultânea, em que os estímulos (suas funções) são apresentados simultaneamente e à análise da resposta de observação. Porém, antes de discutirmos a resposta de observação em uma discriminação simples simultânea, pode ser interessante levantarmos, primeiro, algumas considerações sobre a distribuição da duração do olhar dos participantes.

Distribuição do olhar: uma introdução para a discussão sobre resposta de observação

Algumas características, ainda gerais, do movimento e fixação dos olhos podem ser observadas na Figura 7. O primeiro padrão observado e descrito foi o de olhar mais 
para o Dom Quixote, de modo intermediário para o Sancho, e menos para o Sol, na Fase PRE, nas condições, antes da discriminação e na Fase POS.

Levando em consideração os resultados e os desempenhos dos participantes, o padrão, estabelecido desde a Fase PRE e na Condição 1, antes da discriminação, pode ter se mantido nas condições seguintes, antes da discriminação, e na Fase POS por ter sido um padrão reforçado pelo encontro da Falha. Segundo Skinner (1953):

O comportamento de procurar enxergar no escuro ou em um espesso nevoeiro é um exemplo de olhar com orientação para um campo visual inteiro. O comportamento de examinar o campo - ou responder a cada parte do campo de acordo com algum padrão exploratório - é o comportamento que é mais freqüentemente reforçado pela descoberta de objetos importantes; por conseqüência, torna-se mais provável. Podemos observar que o comportamento com o qual a criança procura um brinquedo perdido é especificamente condicionado. Se certos modos de procurar são reforçados pela descoberta de objetos mais freqüentemente do que outros, emergem como comportamentos típicos (p. 136).

Os padrões, observados na Fase PRE, nas Condições, antes da discriminação e na Fase POS, podem ser analisados, segundo estes argumentos de Skinner, como topografias do comportamento de procurar, tendo como conseqüência reforçadora a descoberta da falha. Algumas questões, então, se colocam. A primeira questão é se o aprendizado deste comportamento inibiu a emissão da resposta de clicar com o mouse sobre uma das imagens, levando em consideração que não eram concorrentes? Se sim, de que modo e por quê? E, ainda, qual análise e definição devem ser impostas ao comportamento de olhar para as falhas após sua descoberta? 
Mudanças nos padrões, estabelecidos e mantidos pela descoberta da falha, foram observada nas condições, durante a discriminação (Figura 7). Neste momento, todos os participantes diminuem a duração de olhar para as partes cujas propriedades são irrelevantes para a discriminação. O Participante 2 apenas estabelece este padrão a partir da Condição 2.

Tendo em vista a configuração dos estímulos, olhar para o Dom Quixote e só para o da esquerda, na Condição 1 (Participantes 1 e 3) e na Condição 2 (todos os participantes), durante a discriminação, pode ter registrado ocorrências pela alta probabilidade de o participante passar pelo Dom Quixote da esquerda para fixar as partes relevantes e correspondentes de cada condição. Mas isto não pode ser afirmado com segurança, pois mesmo em outras fases e nas condições, antes da discriminação, o Dom Quixote da esquerda é sempre olhado por mais tempo. E como o Sancho Pança da direita, assim como o Sol da direita, são olhados por mais tempo do que os da esquerda, é possível afirmar que as partes mais centrais são olhadas por mais tempo.

Na Figura 7, na Condição 3, quando o Participante 2 não olhou para nenhuma outra parte da imagem, mas apenas para o Dom Quixote, pensou-se na possibilidade futura de espelhar as imagens. Desse modo, teríamos dois Sanchos centrais, e o movimento dos olhos do participante (do cursor que indica o olhar) não precisaria passar por nenhuma outra parte para olhá-los. Do mesmo modo, teríamos dois sóis centrais e o cursor, também, não precisaria passar por nenhuma outra parte para olhá-los. O Dom Quixote ficaria nos extremos, mas como apresentou o Participante 2, o cursor poderia entrar na região do Dom Quixote sem passar por nenhuma outra parte. Esta configuração poderia auxiliar na discussão sobre mudanças nos padrões de olhar durante a discriminação, analisando o papel da localização e a queda na duração do olhar para as partes irrelevantes. 
As mudanças nos padrões de olhar, já apontadas, podem ser observadas, também, na Figura 8. A partir da duração do olhar (padrão) na Fase PRE, foi possível observar a razão da distribuição do olhar nas condições, durante a discriminação e na Fase POS. O padrão observado na Figura 7, e já discutido, produziu efeito inverso na Figura 18, ou seja, os pontos mais altos na Figura 7 (Fase PRE) se apresentaram, com exceção do Participante 2, mais baixos na Figura 8. Na Figura 8, o ponto que indica o Sol na Condição 1, durante a discriminação, apresenta uma razão de distribuição elevada pelo fato de que era o menos olhado proporcionalmente na Fase PRE (Figura 7). Do mesmo modo, o Dom Quixote apresentou, na Condição 3 da Figura 8, as razões mais baixas.

Esta série de resultados corrobora, em parte, os dados obtidos por Schroeder (1970, 1969a, 1969b) em que o participante deixa de olhar para estímulos redundantes, porém a medida de análise de Schroeder, no conjunto de seus experimentos, foi a freqüência e além do mais, a configuração em que os estímulos eram apresentados era bem distinta do presente experimento. Os resultados, até então relatados e discutidos, corroboram, de modo mais estreito, os argumentos de Dinsmoor (1985), dando suporte empírico, sobretudo, aos argumentos de que a resposta de observação cumpre a função de aumentar, em termos de duração, o contato com estímulos ou propriedades dos estímulos relevantes para a discriminação e diminuir o contato com aqueles que são irrelevantes, nesse caso, as semelhanças. Apesar de a presente pesquisa privilegiar a duração como medida de análise, pode haver contribuições importantes para o estudo do movimento dos olhos, enquanto resposta de observação, na relação entre medidas de duração e freqüência. Pesquisas futuras poderiam seguir nesta direção. Segundo Dinsmoor (1995), “o aumento do controle de estímulo que ocorre durante o treino de discriminação pode ser atribuído a uma maior freqüência e a um tempo mais longo de observação dos estímulos relevantes" (p. 253). 
Resposta de observação, extinção e ressurgência

A resposta de observação é, primeiramente, definida (Wyckoff, 1952, 1969) como aquela que expõe o organismo a estímulos discriminativos para outra resposta, chamada por Wyckoff (1952) de resposta efetiva (effective response).

A partir dos experimentos de Wyckoff (1969) e de Schroeder e Holland (1968a), a definição de resposta de observação encontra algumas divergências. Porém, de um modo geral, o que há de comum nestes experimentos é que a resposta de observação, tratada em Wyckoff, por meio da resposta de pisar em um pedal e em Schroeder e Holland, por meio da resposta de apertar um botão, produziria os estímulos. Discute-se uma sutil diferença entre produzir o estímulo por meio das respostas apontadas e o fato de o organismo entrar efetivamente em contato com esses estímulos, como argumentado por Dinsmoor (1985) ao discutir o papel da resposta de observação no estabelecimento do controle de estímulos. Dinsmoor (1983) já chamava atenção para o fato de que os organismos poderiam observar (entrar em contato) diferencialmente os estímulos em procedimentos que utilizassem respostas artificiais de observação, assim, os organismos poderiam estar, por exemplo, em esquema misto (e não multi, como programado) caso o contato não ocorresse (Dinsmoor, 1983). Estudos que analisam as diferenças entre respostas de observação manuais e oculares (cf. Tomanari, Balsamo, Fowler, Farren \& Dube, 2007), o conjunto de pesquisa que vem sendo realizado especificamente com respostas de observação oculares (cf. Dube, Lombard, Farren, Flusser, Balsamo \& Fowler, 1999; Dube, Lombard, Farren, Flusser, Balsamo, Fowler \& Tomanari, 2003; Dube, Balsamo, Fowler, Dickson, Lombard \& Tomanari, 2006; Magnusson , 2002; Tomanari \& Pergher, 2003), envolvendo topografias de controle de estímulo (cf. Perez, 2008) ou discriminação simples sucessiva e/ou simultânea (Pergher, 2008; Silva, 2008), podem contribuir tanto para os estudos dos 
movimentos dos olhos e sua aplicação como medida auxiliar de controle de estímulos, como para equacionar as relações entre produção e contato.

A partir da definição de Wyckoff (1952) do conceito de resposta de observação, em que o termo "discriminativo", atribuído aos estímulos produzidos para outra resposta, é imperativo, não faz sentido manter uma distinção entre produção e contato, ambos devem compor a resposta de observação. A resposta de observação, como no experimento de Kaplan e Schoenfeld (1966), pode não dizer respeito apenas a uma resposta discreta, mas a uma seqüência de respostas até a produção do estímulo discriminativo, no caso, a palavrasolução. Também não faria sentido falar em resposta de observação, se alguém apertasse um botão e o "estímulo" fosse produzido na impossibilidade do contato. No caso deste experimento, as respostas sob controle do arranjamento ambiental programado foram o movimento e fixação dos olhos e o contato, compreendido pelos resultados. Ambos, junto à definição dos estímulos, definem a resposta de observação e seu uso na presente discussão dos dados.

A partir do conjunto de novas divisões das partes da imagem (Figura 5), houve, na presente pesquisa, a definição dos estímulos S1, S2 e S3 (condição de estímulo). O que, na apresentação dos resultados, está sendo chamado de estímulo, por exemplo, S1 - lugar da falha no Sol, adquire função de S+ quando, de fato, apresenta a falha e S- quando não a apresenta. Do mesmo modo, S2 foi definido como o pescoço (lugar em que o pescoço era apresentado) e S3, como a mão (lugar em que a mão era apresentada), adquirindo as funções de S+ e S- na apresentação ou não da falha. As imagens que conservavam estas características eram a ocasião para o responder (clicar) produzir som leve e som forte, respectivamente. A definição destes estímulos tem como base a noção de estímulo discriminativo em Michael (2000). Segundo Michael, no treino discriminativo, uma condição de estímulo adquire a função de $\mathrm{S}+$, quando correlacionada ao reforço e de S-, 
quando correlacionada à extinção. Deste modo, S1, S2 e S3, que na configuração das imagens, são definidas por lugares específicos, são compreendidas como condições e adquirem funções diferenciadas quando, segundo Dinsmoor (1995), são selecionadas dentre um conjunto de outros estímulos pela correlação com o reforço.

A partir da definição dos estímulos, S1, S2 e S3, respectivos das Condições 1, 2 e 3, definiram-se as respostas de observação $\mathrm{Ro}^{1}, \mathrm{Ro}^{2}$ e $\mathrm{Ro}^{3}$. Ro ${ }^{1}-\mathrm{S} 1$, na Condição 1 ; Ro ${ }^{2}-$ S2, na Condição 2; e Ro ${ }^{3}-\mathrm{S} 3$, na Condição 3.

Wyckoff $(1952,1969)$ foi o primeiro autor a demonstrar que a proporção do tempo gasto pela resposta de observação está relacionada com variações no controle de estímulos, no estabelecimento da discriminação. Segundo Dinsmoor (1985), a relação entre o comportamento e suas conseqüências na presença de pelo menos um par alternativo de estímulos depende do tempo de contato do organismo com os estímulos. Deste modo, a presente pesquisa utilizou a duração como uma medida auxiliar para a análise da resposta de observação no estabelecimento de uma discriminação simultânea, ou seja, a Ro ${ }^{1}$, a Ro ${ }^{2}$ e a $\mathrm{Ro}^{3}$ podem ser lidas como a duração de olhar para S1, S2 e S3, respectivamente.

Wyckoff (1952, 1969) argumenta, ao discutir seus dados, que a exposição a estímulos discriminativos teria um efeito reforçador sobre a duração da resposta de observação (Wyckoff, 1952, p. 435). Com base nos dados obtidos no experimento de 1969, Wyckoff argumenta que a duração total da resposta de observação aumenta sob condições de reforçamento diferencial e diminui em condições de reforçamento não-diferencial. Estes dados são confirmados pela Figura 11, em que durante o treino de reforçamento diferencial, a duração da resposta de observação $\left(\operatorname{Ro}^{1}, \mathrm{Ro}^{2}\right.$ ou $\left.\mathrm{Ro}^{3}\right)$ aumenta e em outras ocasiões a duração diminui. Apesar de Wyckoff ter medido apenas a duração total, ele levanta a hipótese de que o valor reforçador adquirido pelo $\mathrm{S}+$ serviu para fortalecer ou manter a resposta de observação durante o treino de reforçamento diferencial. 
Essa interpretação foi demonstrada empiricamente por Dinsmoor, Browne, Lawrence \& Wasserman, (1971, citado em Dinsmoor, 1983). Nesse experimento, os autores realizaram uma replicação sistemática da condição de treino em reforçamento diferencial para o Grupo II (exceto o subgrupo II-b) do estudo de Wyckoff (1969). Dinsmoor et al. (1971) registraram separadamente a duração da resposta de observação na produção de S+ e de S- durante o estabelecimento da discriminação.

A partir da definição dos estímulos e respostas, e da replicação de Dinsmoor et al. (1971) do procedimento aplicado ao Grupo II de Wyckoff (1969), procurou-se observar se havia diferenças na duração de observação para S+ e S-, em cada condição experimental (Figura 9).

Os resultados apresentados na Figura 9 atestam o estabelecimento de um padrão sistemático de observação para S+e S-. Todos os participantes observam por mais tempo o S+ do que o S-. Estes dados são semelhante aos dados obtidos por Dinsmoor et al. (1971). Como resultado, Dinsmoor et al. demonstraram que a duração das respostas de observação quando o S+ era produzido foi maior do que a duração da resposta de observação que produzia o S-. Essa assimetria na duração das respostas de observação foi definida como observação seletiva (Dinsmoor et al., 1971; Dinsmoor, 1983, 1985). Dinsmoor (1983, p. 700) afirma que, em Dinsmoor et at. (1971), a cor verde serviu como um estímulo discriminativo para manter o pedal pressionado até uma nova mudança nas cores e a cor vermelha serviu como estímulo discriminativo para deixar imediatamente de pressionar o pedal. Segundo Dinsmoor (1983, 1995), no momento em que o estímulo, dentre outros, é selecionado pela correlação com o estímulo reforçador disposto à resposta efetiva (no caso desse experimento, à resposta manual), este estímulo adquire a função de reforçador condicionado. 
Segundo Keller e Schoenfeld (1950/1973), "um reforço condicionado deve, pois, satisfazer o seguinte critério: ter, através do condicionamento, adquirido o poder de condicionar" (p. 248) e ainda, afirmam que para adquirirem a função de reforçador condicionado, os estímulos devem, necessariamente, ter servido como estímulos discriminativos para outras respostas. Estas afirmações sobre reforço condicionado têm grande importância para apontar as possíveis funções de um estímulo e, sobretudo, para o estudo da resposta de observação (Dinsmoor, Flint, Smith \& Viemeister, 1969). A resposta de observação é definida, também, pelo índice de discriminação da resposta efetiva, ou seja, na medida em que os estímulos vão adquirindo as funções de S+ e S- no controle de um responder efetivo diferenciado por meio de sua observação (Dinsmoor, 1983, 1985, 1995; Hirota, 1972; Wyckoff, 1952, 1969), e como visto, assimétrica e seletiva (Dinsmoor, 1983, 1985). Segundo Wyckoff, “a exposição a estímulos discriminativos terá um efeito reforçador sobre uma resposta de observação, o que se estende ao fato de que o sujeito aprendeu a responder diferentemente aos estímulos discriminativos produzidos pela resposta de observação" (Wyckoff, 1952, p. 237). Deste modo, o estímulo assume duas funções, de reforçador condicionado para a resposta de observação e discriminativo para a resposta efetiva (Dinsmoor, 1983, 1985, Pessôa, 2008).

Assim, pela correlação da falha no Sol, no pescoço e na mão com o reforçador (som leve) para as respostas manuais, as falhas adquiriram a função de reforçador condicionado e as respostas de observação correspondentes se mantiveram por mais tempo.

Uma das funções desempenhada pelo reforçador condicionado, além de controlar a resposta, é impor a esta resposta certa resistência à extinção (Keller e Schoenfeld, 1950/1973). Deste modo, a presente pesquisa tentou observar a extinção das respostas de observação na passagem de uma condição para outra. Para isto o procedimento manipulou a apresentação dos estímulos como se segue. 
Todos os participantes, ao atingirem os critérios da Condição 1 em que a única diferença entre as imagens apresentadas se encontrava na falha do Sol de uma delas, passaram para a Condição 2. Na Condição 2, aos Participantes 1 e 2, foram apresentadas as imagens, ambas com a falha no Sol. Para o Participante 3, a apresentação foi inversa, duas imagens sem falhas no Sol. E para todos os participantes a falha, na Condição 2, estava no pescoço do burrico do Sancho Pança. A partir da mesma lógica, para os Participantes 1 e 2, na mudança da Condição 2 para a Condição 3, foram apresentados dois pescoços fechados e para o Participante 3, dois pescoços abertos (com a falha).

Como tanto o lugar da falha no Sol, na condição 2, como no pescoço, na Condição 3, ambos abertos ou fechados, eram idênticos, não poderiam manter ou adquirir, nestas condições, diferenciadas funções ( $\mathrm{S}+$ ou $\mathrm{S}-$ ). Levando em consideração que a resposta de observação tem como conseqüência a produção de estímulos discriminativos e a definição de extinção pressupõe a quebra da relação entre a resposta e a conseqüência (Keller e Schoenfeld, 1950/1973; Skinner 1938), entende-se a Condição 2, como um procedimento de extinção da Ro ${ }^{1}$ e a Condição 3 como extinção da Ro ${ }^{2}$. Com isso, tentou-se observar se houve algum efeito em apresentar, na fase seguinte à discriminação, dois $\mathrm{S}+$ ou dois $\mathrm{S}-$ (da condição anterior), mesmo que não fossem mais funcionalmente relevantes para a nova discriminação. O principal efeito esperado era uma resistência diferenciada à extinção. Por exemplo, para os Participantes 1 e 2, esperava-se que demonstrassem uma maior resistência da $\operatorname{Ro}^{1}$ na Condição 2 e menor da $\operatorname{Ro}^{2}$ na Condição 3 e de modo inverso para o participante 3. Não se observaram diferenças ou padrões entre os participantes.

Um motivo pode ser encontrado a partir da definição de reforçador condicionado e em sua aplicação no procedimento em questão. O procedimento controlou algumas variáveis importantes para o estabelecimento e demonstração da observação seletiva e sua explicação por meio da teoria do reforço condicionado, como por exemplo, independência 
relativa (e não concorrência) entre a resposta de observação (o movimento dos olhos) e a resposta de clicar e, também, o tempo de disponibilidade do S+ e S- (cf. Dinsmoor, 1983). Segundo a teoria, a resposta sob controle do reforço condicionado apresentará maior resistência à extinção (Keller \& Schoenfeld, 1950/1973). Nesse caso, uma especificidade, por exemplo, da $\operatorname{Ro}^{1}$ (olhar especificamente para o lugar da falha do Sol, com a falha) apresentaria uma maior resistência à extinção em comparação com a outra especificidade da $\operatorname{Ro}^{1}$ (olhar para o lugar da falha no Sol, mas sem a falha) na condição (Condição 2) de extinção. Diante da igualdade no lugar da falha, na Condição 2, não seria possível ter um registro das diferenças entre essas especificidades (topografias). Além disso, se, de fato, o participante aprendeu a responder diferentemente diante da relação "igualdade" e "diferença", como apontado, é possível levantar a hipótese de que a "diferença" tenha assumido a função de $\mathrm{S}+$, e com isso, a de reforçador condicionado. Deste modo, mesmo apresentando, na Condição 2, dois sóis abertos ( $\mathrm{S}+$, na Condição 1) para os participantes 1 e 2 e dois sóis fechados (S-) para o Participante 3, o estímulo com função de reforçador condicionado, a "diferença", foi retirada para todos os participantes igualmente, tendo efeito na paridade (com respeito às diferenças) dos desempenhos apresentados por cada participante na Figura 10. Assim, parafraseando Dinsmoor (1983, p. 700), a relação "diferença" serviu como um estímulo discriminativo para manter os movimentos e fixações dos olhos sobre os estímulos (S1, S2, S3) e a relação "igualdade", serviu como estímulo discriminativo para deixar de olhá-los, no caso deste experimento, serviu, como já foi afirmado, de discriminativo para procurar a falha, já que esta resposta teve outras fontes de reforço nestas ocasiões, como por exemplo, a descoberta da falha.

Poder-se-ia, no futuro, elaborar um procedimento para a análise específica da extinção das duas diferentes topografias da resposta de observação, olhar para o lugar da falha, com e sem a falha. Uma possibilidade seria manter a diferença funcionalmente 
relevante na condição anterior, mas irrelevante para a atual. Deste modo, haveria duas diferenças nas imagens, uma irrelevante (a manutenção da falha no Sol, por exemplo) e uma nova diferença relevante para a discriminação na condição atual. A extinção das respostas de observação, assim, poderia ser tornada mais lenta e gradual e com isso, poderia ser possível observar tanto diferenças no processo de extinção das respostas e de suas topografias, como uma transferência gradual no controle de estímulo.

Falar em procedimento de extinção pressupõe uma supressão na relação entre a resposta e uma conseqüência reforçadora (Keller \& Schoenfeld, 1950/1973; Skinner, 1938, 1953). Outro ponto importante é o fato de que a resposta que foi condicionada precisa ocorrer durante o procedimento para que se possa falar em supressão (Skinner, 1953). Porém, a extinção não pressupõe que a resposta, ou no caso, a duração da resposta, chegará a zero, mas tenderá a ser emitida com duração semelhante àquela apresentada no nível operante, ou seja, na Fase PRE (Linha de Base). Como apontado na Figura 10, a condição 2, enquanto procedimento de extinção da $\operatorname{Ro}^{1}$ produziu uma diminuição na duração desta resposta para todos os participantes. A Condição 3 produziu o mesmo efeito sobre a $\mathrm{Ro}^{2}$. A última fase (Fase POS) produziu este efeito sobre a Ro ${ }^{3}$ (Figura 11).

Outros eventos podem ser observados durante a aplicação do procedimento de extinção, como por exemplo, o reaparecimento de outras respostas que eram emitidas durante o nível operante (Barba, 1997; Catânia, 1998/1999), ou o aparecimento de novas respostas, variação (Antonitis, 1951). Em uma comparação entre a Figura 7 e Figuras 10 e 11, pode-se notar que no momento em que há a extinção (queda na duração da resposta) da $\mathrm{Ro}^{1}, \mathrm{Ro}^{2}$ ou $\mathrm{Ro}^{3}$ (Figuras 10 e 11), o padrão apresentado na Fase PRE, com algumas diferenças, foi reapresentado nas condições que lhes foram subseqüentes (Figura 7). Podese observar também o aparecimento de respostas emocionais (Keller \& Schoenfeld, 1950/1973; Skinner, 1938, 1953). Na Figura 10, os Participantes 2 e 3, na mudança da 
Condição 1 para a Condição 2, apresentam um aumento na duração da Ro ${ }^{1}$. Este aumento, por meio de uma análise mais refinada, poderia ser identificado como ocorrências daquelas respostas emocionais.

Outro evento, que pesquisas em Análise do Comportamento têm identificado durante o procedimento de extinção, é o (re)aparecimento de respostas anteriormente reforçadas (condicionadas) (cf. Cleland, Foster \& Temple, 2000; Cleland, Guerin, Foster \& Temple, 2001; Epstein, 1983, 1985; Lieving \& Lattal, 2003; Murayama, Villas-Bôas, Napolitano \& Tomanari, 2004; Villas-Bôas, 2006; Villas-Bôas, Murayama \&Tomanari, 2005)

No experimento de Epstein (1983), foi utilizada uma caixa de condicionamento operante com duas chaves, uma esquerda e outra direita. Seis pombos foram treinados a bicar em uma das chaves (R1), metade na esquerda e metade na direita, em esquema VI 1 min. Após a apresentação de um responder estável (bicar), todos os sujeitos passaram pelo procedimento de extinção de $30 \mathrm{~min}$. (Ext1) Definido arbitrariamente pelo autor, os sujeitos passaram por números distintos de sessões neste procedimento: 1, 2, 5, 6, 11 e 12 . Quando nenhuma resposta era emitida por um período de 10 minutos, uma resposta alternativa, como mover a cabeça, girar etc. (R2) era, então, reforçada por apenas 20 vezes. No procedimento de extinção (Ext2), ou seja, no final dos 20 reforços, Epstein observou o aumento da freqüência de bicar em uma das chaves, aquela treinada para os diferentes sujeitos. Deste modo, Epstein argumenta que a condição de extinção da R2 é determinante para o (re)aparecimento da R1. Em suas palavras, "quando em determinada condição, um comportamento recentemente reforçado não é mais reforçado, comportamentos que foram anteriormente reforçados, sob circunstâncias similares, tendem a recorrer" (p. 391, sublinhado acrescentado). A este fenômeno, Epstein chamou de ressurgência induzida por extinção (extinction-induced resurgence). 
Epstein (1983) se preocupou em diferenciar a ressurgência, a emissão de um comportamento reforçado anteriormente, de outros comportamentos emitidos durante a extinção. Por esta preocupação, Epstein deixou disponível duas chaves. Epstein observou que os sujeitos bicaram apenas na chave na qual foram treinados (R1). O autor observou, ainda, que aqueles sujeitos que passaram por mais sessões de extinção (Ext1) apresentaram menor freqüência da R1 na extinção da R2, atribuindo deste modo, um valor determinante para a extinção da resposta (R1) que posteriormente (re)aparecerá. Segundo Lieving e Lattal (2003), em um artigo que discute os determinantes da ressurgência a partir de uma análise experimental, “o comportamento operante é função conjunta de contingências passadas e presentes" (p. 217). Sobre as variáveis envolvidas em contingências passadas (R1, por exemplo), Epstein chama atenção para o esquema a que foram submetidos os sujeitos, para a magnitude dos estímulos reforçadores, para o tempo no qual foram reforçados e quando foram. Sobre contingências presentes, Epstein é enfático em afirmar que a extinção de uma resposta recentemente reforçada é uma contingência determinante para o (re)aparecimento, de diferentes modos, das respostas que foram anteriormente reforçadas por diferentes magnitudes, em diferentes esquemas em um tempo passado longínquo ou recente.

$\mathrm{Na}$ Figura 11, pode-se observar que todos os participantes apresentam um aumento na duração da Ro ${ }^{1}$, já no primeiro bloco da Condição 3. Na última fase, observouse, de diferentes modos, o aumento da duração da Ro ${ }^{1}$ e da $\operatorname{Ro}^{2}$ para cada participante.

A primeira questão que se levanta sobre os dados é se de fato os participantes apresentaram extinção da $\mathrm{Ro}^{1}$ e da Ro2, na Condição 2 (para Ro ${ }^{1}$ ) e na Condição 3 (para $\mathrm{Ro}^{2}$ ). Para isto, foi preciso observar comparativamente os valores apresentados na Fase PRE e os valores apresentados nos respectivos procedimentos de extinção. Como pôde ser observado nos resultados, a variação da duração da $\operatorname{Ro}^{1}$ e da $\operatorname{Ro}^{2}$ na Fase PRE ficou entre 0 
e 1,3 s, permanecendo deste modo na Condição 1, antes da discriminação. Porém a variação da duração das $\operatorname{Ro}^{1}$ e $\mathrm{Ro}^{2}$ no procedimento de extinção ultrapassaria em muito esses valores. Outra possibilidade seria a média da duração em nível operante (Fase PRE) e nas condições de extinção. Apesar de os valores, na condição de extinção, indicarem uma tendência de queda da duração das respostas, eles trazem os valores dos primeiros blocos da condição em que a duração da respostas pode refletir uma resistência ao procedimento de extinção. De qualquer modo, os valores apresentado atestam a emissão das respostas (ocorrência de diferentes durações) no procedimento de extinção. Qual seria, então, nossa medida? Optou-se por calcular a média dos dois últimos blocos de tempo da condição de extinção e junto a isso, apresentar o maior valor destes dois blocos. Todos esses valores precisariam ser menores ou iguais que a média apresentada em nível operante e não ultrapassar o maior valor apresentado, também, em nível operante. Os resultados apresentados cumprem as exigências desses critérios, atestando, deste modo a extinção da Ro $^{1}$. A mesma análise foi aplicada na Condição 3 para a extinção da duração de Ro $^{2}$, atestando sua extinção.

A partir dos critérios apresentados: estabelecimento da Ro ${ }^{1}$ (Condição 1), extinção da $\operatorname{Ro}^{1}$, estabelecimento da $\operatorname{Ro}^{2}$ (Condição 2), extinção da $\operatorname{Ro}^{2}$ (Condição 3), discute-se o reaparecimento da $\mathrm{Ro}^{1}$, na Condição 3, e da $\mathrm{Ro}^{2}$, na Fase POS e seu comprometimento com o fenômeno da ressurgência. A duração da Ro ${ }^{1}$, já no primeiro bloco da Condição 3 foi de 2,3 s, 1,44 s e 2,43 s para os Participantes 1, 2 e 3, respectivamente. A partir do que foi apresentado, identificam-se estas durações como o reaparecimento daquelas respostas $\left(\operatorname{Ro}^{1} e^{2} o^{2}\right)$ e sua explicação deve ser elaborada a partir do que Epstein (1983) chamou de ressurgência comportamental, ou ressurgência induzida por extinção.

Na Fase POS, foi possível, novamente, observar um aumento na duração de Ro ${ }^{1}$. Segundo Lieving e Lattal (2003), “a ressurgência é um efeito da história de reforçamento 
recente" (p. 230). Deste modo, no primeiro bloco da Fase POS, Pôde-se observar que a duração de $\mathrm{Ro}^{2}$ foi maior do que de $\mathrm{Ro}^{1}$ para todos os participantes. Este fato pode estar atrelado ao fato de a $\mathrm{Ro}^{2}$ ter sido estabelecida e extinta temporalmente mais próxima da Fase POS, demonstrando assim, um efeito da "recência" (recency) do treino de $\mathrm{Ro}^{2}$ (Lieving \& Lattal, 2003) sobre a duração mais elevada de $\mathrm{Ro}^{2}$ sobre Ro ${ }^{1}$. O único controle imposto pelo presente procedimento foi a seqüência temporal do treino de $\mathrm{Ro}^{1} \mathrm{e} \mathrm{Ro}^{2}$. Os Participantes 2 e 3 apresentam duração mais elevadas de Rol apenas no terceiro e quinto bloco da Fase POS, respectivamente. Estes dados mostram uma ressurgência de modo regressivo ${ }^{4}$ na Fase POS, ou seja, houve, primeiro, a ressurgência de $\mathrm{Ro}^{2}$, a última estabelecida e extinta e posteriormente de $\mathrm{Ro}^{1}$. Porém um dado curioso é apresentado na Figura 12. Apesar de a ressurgência das respostas, para os Participantes 2 e 3, terem sido regressivas e a duração de $\mathrm{Ro}^{2}$, no primeiro bloco da Fase POS, ter sido mais alta do que a duração de $\mathrm{Ro}^{1}$ para todos os participantes, a primeira resposta emitida após da $\mathrm{Ro}^{3}$ foi a Ro $^{1}$. Será que a partir de uma análise molecular, poderíamos, então, afirmar que a ressurgência foi progressiva? Várias questões, a partir do presente procedimento, não podem ser concluídas. Um fato positivo deste procedimento e da resposta analisada (movimento dos olhos) foi que criou as condições necessárias para o aparecimento da ressurgência e sua análise. O custo da resposta, as características físicas dos estímulos, as condições experimentais (estabelecimento de novas discriminações), a Fase POS, e ainda, outros fatores podem ter contribuído para este aparecimento. Pesquisas futuras, que tenham como objeto de estudo a ressurgência, podem manipular diversas variáveis, como por exemplo, as indicadas por Epstein (1983), para um estudo mais refinado sobre os determinantes e processos envolvidos.

\footnotetext{
4 A ressurgência, como chamada por Epstein (1983), foi primeiramente estudada e analisada a partir dos estudos teóricos de Freud (1920) sobre a regressão. Os procedimentos versavam no condicionamento de R1, seguido pelo condicionamento de R2. Após o condicionamento, era apresentada uma situação aversiva, não necessariamente, relacionada a uma das duas respostas, então se observava a re-emissão das respostas.
} 


\section{CONSIDERAÇÕES FINAIS}

O procedimento utilizado para a presente pesquisa foi eficaz em estabelecer e replicar um responder discriminado em três condições experimentais. Analisou-se a distribuição do movimento dos olhos ao longo de toda a sessão experimental. Sobre a resposta de observação, pôde-se observar e analisar o estabelecimento desta resposta em um treino de reforçamento diferencial e compará-lo com a definição de Wyckoff (1952, 1969), apesar das diferenças entre um procedimento de discriminação simples sucessiva (utilizado por Wyckoff, 1969) e simultânea. Analisou-se ainda, a observação seletiva (Dinsmoor 1983, 1985), o papel do reforço condicionado e a extinção das respostas de observação. Vários estudos foram propostos. Parece, agora, ser de grande importância elaborar, a partir das mesmas características das imagens, um procedimento de discriminação simples sucessiva e, além de analisar as questões, aqui analisadas em um procedimento de discriminação simples simultânea, realizar uma comparação entre os diferentes procedimentos, a distribuição dos movimentos dos olhos e o papel da resposta de observação.

Algumas questões ficaram, ainda, em aberto. Tendo em vista o conceito de estímulo, de que modo a imagem, suas partes, suas propriedades discriminativas (S1, S2 e S3) assumiram funções diferenciadas para o participante ao longo de toda a tarefa? A área de topografia de controle de estímulo e sua coerência poderiam contribuir para essa questão? Uma análise mais refinada da resposta de observação, por meio dos movimentos dos olhos, poderia auxiliar nesta análise?

Sobre a ressurgência, uma característica deste estudo que parece diferenciá-lo de outros está na relação entre a ressurgência e o controle de estímulos. Um primeiro estudo que tentou demonstrar ressurgência e controle de estímulos foi o de Wilson e Hayes (1996), 
porém, como apontam alguns autores (cf. Villas-Bôas, 2006), o papel da extinção não pôde ser claramente observado. Porém, apesar de não discutido nos dados de Epstein (1983), não já haveria controle de estímulos? Controle por posição, uma vez que os sujeitos voltaram a bicar apenas na chave da esquerda ou da direita? Seria possível colocar em cima de cada chave luzes diferenciadas e após o treino e a extinção, mudar a posição das chaves e ainda assim observarmos a ressurgência na chave treinada? Os dados do presente experimento indicam que $\operatorname{sim}$.

Outra diferença é o fato de esta pesquisa lidar, não com a resposta que produz o reforçador na chave principal, no caso, clicar sobre a imagem (resposta efetiva), mas com a resposta de observação, que por sua vez, produz os estímulos discriminativos para a resposta efetiva. Qual efeito teria a manipulação da magnitude dos estímulos reforçadores (dispostos para a resposta efetiva) sobre a ressurgência (e a ordem da ressurgência) da resposta de observação? Pelo baixo custo da resposta, quantas respostas poderiam ser estabelecidas e extintas? Será que em uma seqüência longa de respostas, observaríamos os dados apresentados na Figura 12, ou seja, a emissão primeira da Ro ${ }^{1}$ (mesmo na extinção de $\mathrm{Ro}^{12}$ ). E, sobretudo, de que modo observaríamos a ressurgência das respostas de observação se caso mantivéssemos as diferenças (como sugerido acima), ou seja, mantivéssemos a diferença funcionalmente relevante na condição anterior, mas irrelevante para uma condição atual? Estudos posteriores podem seguir nesta direção. 


\section{REFERÊNCIAS}

Antonitis, J.J. (1951). Response variability in the white rat during conditioning, extinction, and reconditioning. Journal of Experimental Psychology, 42, 273-281.

Barba, L. S. (1997). Variabilidade comportamental aprendida. Dissertação de Mestrado não publicada, Instituto de Psicologia, Universidade de São Paulo, São Paulo, Brasil.

Becker, W. (1991). Saccads. In: R. H. S. Carpenter (Ed.), Eye movements. New York: The McMillan Press Ltd.

Catania, C. A. (1973). The concept of the operant in the analysis of behavior. Behaviorism, $8,103-116$.

Catania, C. A. (1999). Aprendizagem: comportamento, linguagem e cognição. (4a . ed.). Porto Alegre, RS: ArtMed. Publicado originalmente em 1998.

Cleland, B. S., Foster, T.M., Temple, W. (2000). Resurgence: the role of extinction. Behavioural Processes, 52, 117-129.

Cleland, B.S., Guerin, B., Foster, T.M., Temple, W. (2001). On Terms: ressurgence. The Behavior Analyst, 24, 255-260.

Dinsmoor, J. A. (1983). Observing and conditioned reinforcement. The Behavioral and Brain Sciences, 6, 693-728.

Dinsmoor, J. A. (1985). The role of observing and attention in establishing stimulus control. Journal of the Experimental Analysis of Behavior, 43, 365-381.

Dinsmoor, J. A., Flint, G. A., Smith, R. F., \& Viemeister, N. F. (1969). Differential reinforcing effects of stimuli associated with the presence or absence of a schedule of punishment. In D. P. Hendry (Ed.). Conditioned Reinforcement, (pp. 357-384). Homewood, IL: The Dorsey Press. 
Dinsmoor, J. A., Browne, M. P., Lawrence, C. E. \& Wasserman, E. A. (1971). A new analysis of Wyckoff's observing response. Proceedings of the $79^{\text {th }}$ Annual Convention of the American Psychological Association, 6, 679-680 (resumo).

Dube, W. V. \& Hiris, J. (1999). Match to Sample Program (Version 11.6.7) [computer software]. Walthan, MA: E. K. Shriver Center of Mental Retardation.

Dube, W. V., Balsamo, L. M., Fowler, T. R., Dickson, C. A., Lombard, K. M., \& Tomanari, G. Y. (2006). Observing behavior topography in delayed matching to multiple samples. The Psychological Record, 56, 233-244.

Dube, W. V., Lombard, K. M., Farren, K. M., Flusser, D. S., Balsamo, L. M., \& Fowler, T. R. (1999). Eye tracking assessment of stimulus overselectivity in individuals with mental retardation. Experimental Analysis of Human Behavior bulletin, 17, 8-14.

Dube, W. V.; Lombard, K. M.; Farren, K. M.; Flusser, D. S.; Balsamo, L. M., Fowler, T. R., \& Tomanari, G. Y. (2003). Stimulus overselectivity and observing behavior in individuals with mental retardation. Em: Soraci \& Soraci (Eds.), Visual information processing (pp 109-123). London: Proeger.

Epstein, R. (1983). Resurgence of previously reinforced behavior during extinction. Behaviour Analysis Letters, 3, 391-397.

Epstein, R. (1985). Extinction-induced resurgence: preliminary investigations and possible applications. The Psychological Record, 35, 143-153.

Freud, S. (1920). A general intruduction to psychoanalysis. New York: Boni \& Liveright.

Kaplan, I. \& Schoenfeld, W. N. (1966). Oculomotor paterns during the solution of visually displayed anagrams. Journal of Experimental Psychology, 72, 3, 447-351.

Keller, F.S. \& Schoenfeld, W.N. (1973). Principios de psicologia - um texto sistemático na ciência do comportamento. São Paulo: EPU. Publicado originalmente em 1950. 
Lattal, K. A. (1995). Contingency and behavior analysis. The Behavior Analyst, 18, 209224.

Holland, J. G. (1958). Human vigilance, Science, 128, 61-63.

Mackworth, N. \& Thomas, E (1962). Head-mounted eye-marker camera. Journal of Optical Society of America, 52, 713-716.

Magnusson, A. (2002). Topography of eye movements under select and reject control. Dissertação de mestrado não publicada. Boston: Northeastern University.

Millenson, J. R. (1967). Principles of behavior analysis. NY: MacMillan Company.

Murayama, V.K., Villas-Bôas, A., Napolitano, L.R., Tomanari, G.Y. (2004). Ressurgência: uma revisão conceitual baseada em parâmetros experimentalmente identificados. Comunicação oral apresentada no XIII Encontro da ABPMC/ABA em agosto de 2004. Campinas, São Paulo, Brasil.

Perez, W. F. (2008). Movimentos dos olhos e topografias de controle de estímulo em treinos de discriminação condicional e testes de equivalência. Dissertação de Mestrado não publicada, Instituto de Psicologia, Universidade de São Paulo, São Paulo, Brasil.

Pessôa, C.; Huziwara, E.; Perez, W. F.; Endemann, P, \& Tomanari, G. Y. (2008). Eye movements in a four-choice simultaneous discrimination with bi-dimensional and three-dimensional stimuli. $34^{\text {th }}$ Association for Behavior Analysis Convention. Chicago, Illinois.

Pessôa, C. V. B. B., \& Sério, T. M. A. P. (2006). Análise do comportamento de observação. Revista Brasileira de Análise do Comportamento, 2(2), 143-153.

Rees, H. J. \& Israel, H. E. (1935). An investigation of the establishment and operation of mental set. Psyhol. Monogr. 46, 210. 
Repp, A. C., Deitz, D. E. D., Boles, S. M., Deitz, S. M., \& Repp, C. F. (1976). Differences among common methods for calculating interobserver agreement. Journal of Applied Behavior Analysis, 9, 109-113

Reynolds, G. S. (1968). A primer of operant conditioning. Illinois: Scott, Foresman and Company.

Schroeder, S. R. (1969a). Effects of cue factors on selective eye movements and choices during successive discriminations. Perceptual and Motor Skills, 29, 991-998.

Schroeder, S. R. (1969b). Fixation and choice selectivity during discrimination transfer. Psychonomic Science, 17(6), 324-325.

Schroeder, S. R. (1970). Selective eye movements to simultaneously presented stimuli during discrimination. Perception \& Psychophysics, 7(2), 121-124.

Schroeder, S. R. (1997). Selective eye fixations during transfer of discriminative stimulus control. Em D. M. Baer e E. M. Pinkston (Eds.), Environment and Behavior (pp 97110). Boulder, CO: Westview.

Schroeder, S. R. \& Holland, J, G. (1968a). Operant control of eye movements. Journal of Applied Behavior Analysis, 1, 161-166.

Schroeder, S. R. \& Holland, J, G. (1968b). Operant control of eye movements during human vigilance. Science, 161, 292-293.

Schroeder, S. R. \& Holland, J, G. (1969). Reinforcement of eye movements with concurrent schedules. Journal of the Experimental Analysis of Behavior, 12, 897-903.

Schwartz, S. H. (2004). Visual Perception - a clinical orientation. New York: McGraw Hill.

Sério, T. M. A. P., Andery, A. M., Gioia, P. S. \& Micheletto, N. (2005a). Os conceitos de discriminação e generalização. In: Controle de estímulo e comportamento: Uma (nova) introdução. São Paulo: EDUC. 
Sério, T. M. A. P., Andery, A. M., Micheletto, N. \& Gioia, P. S. (2005b). Discriminação e generalização: Algumas extensões. In: Controle de estímulo e comportamento: Uma (nova) introdução. São Paulo: EDUC.

Silva, M. J. M. (2008). Rastreamento do olhar ao longo de discriminações visuais simples sucessivas e simultâneas. Dissertação de Mestrado não publicada, Instituto de Psicologia, Universidade de São Paulo, São Paulo, Brasil.

Skinner, B. F. (1938). The behavior of organisms: Na experimental analysis. New York: Appleton-Century-Crofts.

Skinner, B. F. (1953). Science and human behavior. NY: The Free Press

Skinner, B. F. (1950). Are theories of learning necessary? Psychological Review, 57, 193216.

Skinner, B. F. (1957). Verbal behavior. NY: Applenton-Century-Crofts.

Tomanari, G. Y. (2008). Resposta de observação: As principais questões na area analisadas a partir de três experimentos com pombos. Tese de Livre-docência: São Paulo. Universidade de São Paulo.

Tomanari, G. Y. \& Pergher, N. K. (2003). Observing behavior and eye movements in a Wyckoff observing response procedure. Annual Meeting of the Association for Behavior Analysis. São Francisco.

Tomanari, G. Y., Balsamo, L. M., Fowler, T. R., Farren, K. M., \& Dube, W. V. (2007). Manual and ocular observing behavior in human subjects. European Journal of Behavior Analysis, 8, 29-40.

Tourinho, E. Z. (2003). A produção de conhecimento em psicologia: A análise do comportamento. Psicologia Ciência e Profissão, 23, 30-41. 
Villas-Bôas, A. A. (2006). Efeitos do procedimento de extinção sobre o responder em ratos: seqüências de respostas como operante. Dissertação de Mestrado não publicada, Instituto de Psicologia, Universidade de São Paulo, São Paulo, Brasil.

Villas-Bôas, A., Murayama, V.K., Tomanari, G.Y. (2005). Ressurgência: conceitos e métodos que podem (ou não) contribuir para a Análise do Comportamento. In: Guilhardi,H.J. e Aguirre, N.C. (orgs.) Sobre Comportamento e Cognição:Expondo a Variabilidade, 15, 18-28. Santo André: ESETec.

Wyckoff, L. B. (1952). The role of observing responses in discrimination learning: Part I. Psychological Review, 59, 431-442.

Wyckoff, L. B. (1969). The role of observing responses in discrimination learning: Part II. Em: D. P. Hendry (Org.) Conditioned Reinforcement (pp 237-259). Homewood, Illinois: The Dorsey Press.

Wilson, K. G., \& Hayes, S. C. (1996). Resurgence of derived stimulus relations. Journal of the Experimental Analysis of Behavior, 66, 267-281. 
ANEXOS 
Anexo 1

Termo de Consentimento Livre e Esclarecido 


\section{Termo de Consentimento Livre e Esclarecido}

Os mecanismos envolvidos na observação são essenciais para uma aprendizagem eficaz. A pesquisa a ser desenvolvida tem como objetivo investigar alguns desses mecanismos através de uma tarefa simples de ensino de relações entre imagens.

Tais atividades poderão durar de 20 a 40 minutos e deverão ser feitas preferencialmente durante um mesmo dia. Caso seja a sua vontade, as atividades também poderão ser divididas em dois dias de coleta.

Você foi convidado para participar deste estudo, por isso, sua participação não é obrigatória e sua recusa não trará nenhum prejuízo em sua relação com o pesquisador ou com a instituição. Além disso, a qualquer momento durante a realização do procedimento, você poderá desistir de participar e retirar o seu consentimento. O pesquisador também tem a obrigação de lhe esclarecer toda e qualquer dúvida.

Todas as informações que você fornecer durante a pesquisa serão mantidas em sigilo, conservando o seu anonimato. Após a conclusão do estudo, você poderá ter acesso aos resultados com o pesquisador responsável.

Você receberá uma cópia deste termo onde consta o e-mail do pesquisador, podendo tirar suas dúvidas sobre o projeto e sua participação, agora ou a qualquer momento.

$\mathrm{Eu}$

aceito participar dessa pesquisa, consentindo na divulgação e publicação dos dados, nos termos apresentados acima.

Declaro que entendi os objetivos, riscos e benefícios de minha participação na pesquisa e concordo em participar.

São Paulo,

Assinatura do participante:

Assinatura do pesquisador:

Peter Endemann (peterendemann@hotmail.com)

Assinatura do orientador responsável:

Prof. Dr. Gerson Yukio Tomanari 
Anexo 2

Distribuição do movimento dos olhos (Figura 7) 
Tabela 3. Porcentagens do Participante 1 da distribuição da duração do olhar para as partes ao longo dos oito momentos em que a sessão experimental foi dividida. A Fase PRE; a Fase Experimental: Condição 1, antes e durante a discriminação; a Condição 2, antes e durante a discriminação; a Condição 3, antes e durante a discriminação; e a Fase POS. Parte 1 = Sol; Parte = Sancho Pança; e Parte 3 = Dom Quixote. A distribuição proporcional está dividida pela posição das partes.

\begin{tabular}{|c|c|c|c|}
\hline Fase/condição & Partes & Posição 1 & ção 2 \\
\hline \multirow{3}{*}{ PRE } & 1 & 1,897608223 & 3,261514133 \\
\hline & 2 & 4,131251235 & 17,98774461 \\
\hline & 3 & 33,05000988 & 14,44949595 \\
\hline & 1 & 0,516328902 & 1,12817865 \\
\hline Antes da & 2 & 0,782238286 & 17,67910159 \\
\hline discriminação & 3 & 24,62114367 & 6,645152962 \\
\hline
\end{tabular}

COND 1

\begin{tabular}{rrrr}
\hline & & & \\
durante a & 2 & 19,91957934 & 23,81688834 \\
discriminação & 3 & 8,75347974 & 0,618620476 \\
& & & 0 \\
\hline
\end{tabular}

$\begin{array}{rlll} & 1 & 3,317955997 & 13,04116395 \\ \text { Antes da } & 2 & 8,090844571 & 11,78140525 \\ \text { discriminação } & 3 & 25,01774308 & 19,23349894\end{array}$

COND 2

$\begin{array}{rrrr}\text { durante a } & 1 & 0 & 0 \\ \text { discriminação } & 2 & 19,31187569 & 22,75249723 \\ & 3 & 8,361080281 & 0 \\ \text { Antes da } & 1 & 1,547785141 & 5,009591908 \\ \text { discriminação } & 2 & 3,753923962 & 11,79804674 \\ & 3 & 30,26682944 & 26,4169864\end{array}$

COND 3

\begin{tabular}{rrrr}
\hline & 1 & 0 & 3,198420533 \\
durante a & 2 & 0 & 0 \\
discriminação & 3 & 28,96347483 & 22,46791708 \\
& & & \\
\hline & 1 & 0,780811145 & 5,813953488 \\
POS & 2 & 11,06055499 & 13,01539153 \\
& 3 & 28,83945624 & 24,50848219
\end{tabular}


Tabela 4. Porcentagens do Participante 2 da distribuição da duração do olhar para as partes ao longo dos oito momentos em que a sessão experimental foi dividida. A Fase PRE; a Fase Experimental: Condição 1, antes e durante a discriminação; a Condição 2, antes e durante a discriminação; a Condição 3, antes e durante a discriminação; e a Fase POS. Parte 1 = Sol; Parte = Sancho Pança; e Parte 3 = Dom Quixote. A distribuição proporcional está dividida pela posição das partes.

\begin{tabular}{|c|c|c|c|}
\hline Fase/condição & Partes & Posição 1 & ção 2 \\
\hline \multirow{3}{*}{ PRE } & 1 & 1,610713963 & 4,379694145 \\
\hline & 2 & 5,737037372 & 13,59153018 \\
\hline & 3 & 34,45842005 & 24,35978644 \\
\hline & 1 & 1,148379761 & 3,706651507 \\
\hline Antes da & 2 & 6,469584991 & 9,01648664 \\
\hline discriminação & 3 & 33,2347925 & 29,06196703 \\
\hline
\end{tabular}

COND 1

\begin{tabular}{rrrr}
\hline & & & \\
durante a & 2 & 0,969353516 & 12,8625755 \\
discriminação & 3 & 4,898963537 & 10,00671091 \\
& & 26,03087018 & 13,02661994 \\
Antes da & 1 & 0 & 15,96638655 \\
discriminação & 2 & 15,54621849 & 20,16806723 \\
& 3 & 14,28571429 & 17,64705882
\end{tabular}

COND 2

$\begin{array}{rrrr} & 1 & 0 & 2,788400255 \\ \text { durante a } & 2 & 17,08094328 & 16,01338432 \\ \text { discriminação } & 3 & 8,333333333 & 0,430210325\end{array}$

\begin{tabular}{|c|c|c|c|c|}
\hline & & 1 & 5,000919287 & 5,000919287 \\
\hline & Antes da & 2 & 5,000919287 & 9,781209781 \\
\hline & discriminação & 3 & 28,7552859 & 27,04541276 \\
\hline \multicolumn{5}{|l|}{ COND 3} \\
\hline & & 1 & 0 & 0 \\
\hline & durante a & 2 & 0 & 0 \\
\hline & discriminação & 3 & 26,93932412 & 21,29416283 \\
\hline & & 1 & 2,095375723 & 2,74566474 \\
\hline & POS & 2 & 9,089595376 & 14,04624277 \\
\hline & & 3 & 30,98988439 & 26,04768786 \\
\hline
\end{tabular}


Tabela 5. Porcentagens do Participante 3 da distribuição da duração do olhar para as partes ao longo dos oito momentos em que a sessão experimental foi dividida. A Fase PRE; a Fase Experimental: Condição 1, antes e durante a discriminação; a Condição 2, antes e durante a discriminação; a Condição 3, antes e durante a discriminação; e a Fase POS. Parte 1 = Sol; Parte = Sancho Pança; e Parte 3 = Dom Quixote. A distribuição proporcional está dividida pela posição das partes.

\begin{tabular}{|c|c|c|c|c|}
\hline \multicolumn{2}{|c|}{ Fase/condição } & Partes & Posição 1 & Posição 2 \\
\hline & \multirow{3}{*}{ PRE } & 1 & 1,995344197 & 2,028599933 \\
\hline & & 2 & 4,015630196 & 16,05420685 \\
\hline & & 3 & 34,27835052 & 20,19454606 \\
\hline \multirow{6}{*}{ COND 1} & & 1 & 0,553912342 & 1,166980371 \\
\hline & Antes da & 2 & 1,328314063 & 13,15407368 \\
\hline & discriminação & 3 & 35,53105674 & 28,13659586 \\
\hline & & 1 & 16,89638783 & 21,81558935 \\
\hline & durante a & 2 & 0 & 5,727186312 \\
\hline & discriminação & 3 & 12,69011407 & 0 \\
\hline \multirow{6}{*}{ COND 2} & & 1 & 6,528681254 & 10,33707865 \\
\hline & Antes da & 2 & 5,996451804 & 11,30691898 \\
\hline & discriminação & 3 & 22,42460083 & 17,20875222 \\
\hline & & 1 & 0 & 0 \\
\hline & durante a & 2 & 25,93491986 & 30,93734823 \\
\hline & discriminação & 3 & 5,998057309 & 0 \\
\hline \multirow{7}{*}{ COND 3} & & 1 & 2,226474169 & 4,174639068 \\
\hline & Antes da & 2 & 14,1763785 & 15,5331362 \\
\hline & discriminação & 3 & 25,18698904 & 18,54235519 \\
\hline & & & & \\
\hline & & 1 & 0 & 0 \\
\hline & durante a & 2 & 0 & 7,35563703 \\
\hline & discriminação & 3 & 28,37992667 & 23,72823098 \\
\hline & & 1 & 2,128710154 & 5,354693584 \\
\hline & POS & 2 & 5,025511602 & 18,8950458 \\
\hline & & 3 & 26,11510396 & 22,97690243 \\
\hline
\end{tabular}


Anexo 3

Duração da observação para $S+e S$ - (Figura 9) 
Tabela 6. Distribuição proporcional da duração de observação para o S+ e para o S- ao longo das condições experimentais para os três participantes.

\begin{tabular}{|c|c|c|c|c|c|c|}
\hline \multirow[b]{2}{*}{ Participantes } & \multicolumn{2}{|c|}{$\begin{array}{l}\text { COND1 } \\
\text { L. falha no Sol }\end{array}$} & \multicolumn{2}{|c|}{$\begin{array}{l}\text { COND2 } \\
\text { pescoço }\end{array}$} & \multicolumn{2}{|c|}{$\begin{array}{c}\text { COND3 } \\
\text { mão }\end{array}$} \\
\hline & $\mathrm{S}+$ & S- & S+ & S- & S+ & S- \\
\hline P1 & 17 & 9,8 & 19,3 & 7,1 & 13,6 & 10 \\
\hline P2 & 8,5 & 2,58 & 15,4 & 5,8 & 17,2 & 7,8 \\
\hline P3 & 14,5 & 7,3 & 35,5 & 11,7 & 27,1 & 17,9 \\
\hline
\end{tabular}


Anexo 4

História das respostas de observação(Figura 11) 
Tabela 7. Duração absoluta das respostas de observação do Participante 1 por blocos de 28 s em média ao longo da Fase PRE, da Fase Experimental: Condição 1; a Condição 2; a Condição 3; e da Fase POS. 1. falha no $\mathrm{Sol}=\mathrm{S} 1-\mathrm{Ro}^{1}$; pescoço $=\mathrm{S} 2-\mathrm{Ro}^{2}$; mão $=\mathrm{S} 3-$ $\mathrm{Ro}^{3}$.

\begin{tabular}{|c|c|c|c|c|}
\hline FASE & blocos & I. falha no Sol & pescoço & mão \\
\hline \multirow[b]{2}{*}{ PRE } & 1 & 0,69 & 0,77 & 0,4 \\
\hline & 2 & 0,04 & 0,27 & 0,37 \\
\hline \multirow{15}{*}{ COND 1} & 3 & 0 & 0,24 & 0 \\
\hline & 4 & 0 & 0,4 & 0,4 \\
\hline & 5 & 0,04 & 0,37 & 0 \\
\hline & 6 & 0 & 0,13 & 0,37 \\
\hline & 7 & 0 & 0 & 0 \\
\hline & 8 & 0,03 & 0,33 & 0,39 \\
\hline & 9 & 0 & 0,54 & 0 \\
\hline & 10 & 0 & 0,5 & 0 \\
\hline & 11 & 0 & 0,19 & 0 \\
\hline & 12 & 0 & 0,1 & 0,17 \\
\hline & 13 & 0 & 0,66 & 0 \\
\hline & 14 & 0,07 & 0 & 0,26 \\
\hline & 15 & 1,02 & 0,24 & 0,47 \\
\hline & 16 & 0 & 0,29 & 0,67 \\
\hline & 17 & 9,14 & 0 & 0 \\
\hline \multirow{4}{*}{ COND 2} & 18 & 0,96 & 0,3 & 0,14 \\
\hline & 19 & 0,88 & 1,35 & 0,94 \\
\hline & 20 & 0 & 6,25 & 0 \\
\hline & 21 & 0 & 3,51 & 0 \\
\hline \multirow{10}{*}{ COND 3} & 22 & 2,3 & 0,84 & 0,2 \\
\hline & 23 & 1,41 & 0,44 & 0,8 \\
\hline & 24 & 0,17 & 1,68 & 1,1 \\
\hline & 25 & 1,28 & 1,17 & 0 \\
\hline & 26 & 0,27 & 0,6 & 0,33 \\
\hline & 27 & 0 & 0,07 & 1,27 \\
\hline & 28 & 0,33 & 0,37 & 0,83 \\
\hline & 29 & 0 & 0,37 & 0,48 \\
\hline & 30 & 0,03 & 0 & 6,33 \\
\hline & 31 & 0 & 0 & 5,69 \\
\hline \multirow{6}{*}{ POS } & 32 & 1,93 & 2,39 & 1,96 \\
\hline & 33 & 0,51 & 1,57 & 0,87 \\
\hline & 34 & 0 & 0,74 & 0,17 \\
\hline & 35 & 0 & 1,63 & 0,1 \\
\hline & 36 & 1,22 & 0,74 & 2,32 \\
\hline & 37 & 0,31 & 0,74 & 0,38 \\
\hline
\end{tabular}


Tabela 8. Duração absoluta das respostas de observação do Participante 2 por blocos de 25 s em média ao longo da Fase PRE, da Fase Experimental: Condição 1; a Condição 2; a Condição 3; e da Fase POS. 1. falha no $\mathrm{Sol}=\mathrm{S} 1-\mathrm{Ro}^{1}$; pescoço $=\mathrm{S} 2-\mathrm{Ro}^{2}$; mão $=\mathrm{S} 3-$ $\mathrm{Ro}^{3}$.

\begin{tabular}{|c|c|c|c|c|}
\hline FASE & blocos & I. falha no Sol & pescoço & mão \\
\hline \multirow{4}{*}{ PRE } & 1 & 0,58 & 0,62 & 0,15 \\
\hline & 2 & 0,6 & 1,09 & 0,23 \\
\hline & 3 & 0,46 & 0 & 0,27 \\
\hline & 4 & 0,19 & 0,3 & 0,63 \\
\hline \multirow{9}{*}{ COND 1} & 5 & 0,68 & 0 & 0,6 \\
\hline & 6 & 0 & 0,27 & 0,23 \\
\hline & 7 & 0,19 & 0 & 0,61 \\
\hline & 8 & 1,59 & 0,07 & 0 \\
\hline & 9 & 3,48 & 0,11 & 0,03 \\
\hline & 10 & 2,52 & 0,03 & 0,03 \\
\hline & 11 & 3,16 & 0,3 & 0 \\
\hline & 12 & 2,88 & 0 & 0 \\
\hline & 13 & 1,97 & 0 & 0,83 \\
\hline \multirow{3}{*}{ COND 2} & 14 & 1,06 & 3,34 & 0,07 \\
\hline & 15 & 0,24 & 5,45 & 0 \\
\hline & 16 & 0 & 4,58 & 0 \\
\hline \multirow{6}{*}{ COND 3} & 17 & 1,44 & 1,6 & 0,16 \\
\hline & 18 & 0,57 & 0,67 & 0,87 \\
\hline & 19 & 0,49 & 0,37 & 0,59 \\
\hline & 20 & 0,23 & 0,87 & 0,5 \\
\hline & 21 & 0 & 0 & 7,06 \\
\hline & 22 & 0 & 0 & 6,04 \\
\hline \multirow{6}{*}{ POS } & 23 & 0,73 & 1,53 & 2,18 \\
\hline & 24 & 0,07 & 0,57 & 0,54 \\
\hline & 25 & 2,57 & 2,79 & 0,39 \\
\hline & 26 & 0,57 & 0,55 & 0,51 \\
\hline & 27 & 0,44 & 1,06 & 1,98 \\
\hline & 28 & 0,1 & 0,39 & 0,44 \\
\hline
\end{tabular}


Tabela 9. Duração absoluta das respostas de observação do Participante 3 por blocos de 20 s em média ao longo da Fase PRE, da Fase Experimental: Condição 1; a Condição 2; a Condição 3; e da Fase POS. 1. falha no Sol $=\mathrm{S} 1-\mathrm{Ro}^{1}$; pescoço $=\mathrm{S} 2-\mathrm{Ro}^{2}$; mão $=\mathrm{S} 3-$ $\mathrm{Ro}^{3}$.

\begin{tabular}{|c|c|c|c|c|}
\hline FASE & blocos & I. falha no Sol & pescoço & mão \\
\hline \multirow{6}{*}{ PRE } & 1 & 0 & 0,17 & 0,13 \\
\hline & 2 & 0 & 0,07 & 0,12 \\
\hline & 3 & 1,03 & 1,2 & 0,24 \\
\hline & 4 & 0 & 0,67 & 0,67 \\
\hline & 5 & 0 & 0,14 & 0 \\
\hline & 6 & 0 & 0,37 & 0 \\
\hline \multirow{11}{*}{ COND 1} & 7 & 0 & 0,42 & 0,42 \\
\hline & 8 & 0 & 0,24 & 0 \\
\hline & 9 & 0 & 0,13 & 0 \\
\hline & 10 & 0 & 0,2 & 0 \\
\hline & 11 & 0,51 & 0,2 & 1,2 \\
\hline & 12 & 0 & 0,16 & 0 \\
\hline & 13 & 0 & 0,44 & 0 \\
\hline & 14 & 0 & 0,59 & 0,63 \\
\hline & 15 & 0 & 0,98 & 0,98 \\
\hline & 16 & 5,17 & 0 & 0 \\
\hline & 17 & 4,04 & 0,27 & 0,27 \\
\hline \multirow{6}{*}{ COND 2} & 18 & 4,56 & 0,41 & 0,41 \\
\hline & 19 & 0 & 0,2 & 0,2 \\
\hline & 20 & 0 & 0,61 & 0,61 \\
\hline & 21 & 0,6 & 0,69 & 0,69 \\
\hline & 22 & 0 & 10,54 & 0 \\
\hline & 23 & 0 & 8,91 & 0 \\
\hline \multirow{7}{*}{ COND 3} & 24 & 2,43 & 2,83 & 0,06 \\
\hline & 25 & 0,54 & 1,55 & 0,2 \\
\hline & 26 & 0,1 & 1,47 & 0,37 \\
\hline & 27 & 0 & 0 & 11,19 \\
\hline & 28 & 0 & 0 & 9,9 \\
\hline & 29 & 0 & 0 & 9,58 \\
\hline & 30 & 0 & 0 & 8,67 \\
\hline \multirow{9}{*}{ POS } & 31 & 0,7 & 4,23 & 1,97 \\
\hline & 32 & 0 & 3,44 & 1 \\
\hline & 33 & 0,57 & 0,15 & 3,17 \\
\hline & 34 & 0 & 1,76 & 0,06 \\
\hline & 35 & 3,38 & 1,03 & 1,23 \\
\hline & 36 & 0 & 0,14 & 0 \\
\hline & 37 & 0,07 & 0,5 & 0,56 \\
\hline & 38 & 0,76 & 1,1 & 0,24 \\
\hline & 39 & ก 16 & 058 & $\cap 75$ \\
\hline
\end{tabular}

